\title{
Apollo 13 Guidance, Navigation, and Control Challenges
}

\author{
John L. Goodman* \\ United Space Alliance, LLC, Houston, TX, 77058
}

\begin{abstract}
Combustion and rupture of a liquid oxygen tank during the Apollo 13 mission provides lessons and insights for future spacecraft designers and operations personnel who may never, during their careers, have participated in saving a vehicle and crew during a spacecraft emergency. Guidance, Navigation, and Control (GNC) challenges were the reestablishment of attitude control after the oxygen tank incident, re-establishment of a free return trajectory, resolution of a ground tracking conflict between the LM and the Saturn V S-IVB stage, Inertial Measurement Unit (IMU) alignments, maneuvering to burn attitudes, attitude control during burns, and performing manual GNC tasks with most vehicle systems powered down. Debris illuminated by the Sun and gaseous venting from the Service Module (SM) complicated crew attempts to identify stars and prevented execution of nominal IMU alignment procedures. Sightings on the Sun, Moon, and Earth were used instead. Near continuous communications with Mission Control enabled the crew to quickly perform time critical procedures. Overcoming these challenges required the modification of existing contingency procedures.
\end{abstract}

\section{Introduction}

$\mathrm{T}$ he Apollo 13 lunar mission was aborted after a short circuit in a Service Module (SM) oxygen tank caused combustion and tank rupture, resulting in extensive damage to SM systems and the loss of both SM oxygen tanks. This incident changed the mission objective from a lunar landing to crew survival and expeditious return to Earth. ${ }^{1-10}$ The loss of SM oxygen and power, as well as possible damage to the SM Service Propulsion System (SPS) prevented the use of Command Service Module (CSM) systems for crew survival and trajectory corrections required for return to Earth (Figure 1). Lunar Module (LM) life support, power, and thermal control systems were required to keep the crew alive. In addition, the LM Guidance, Navigation, and Control (GNC) and

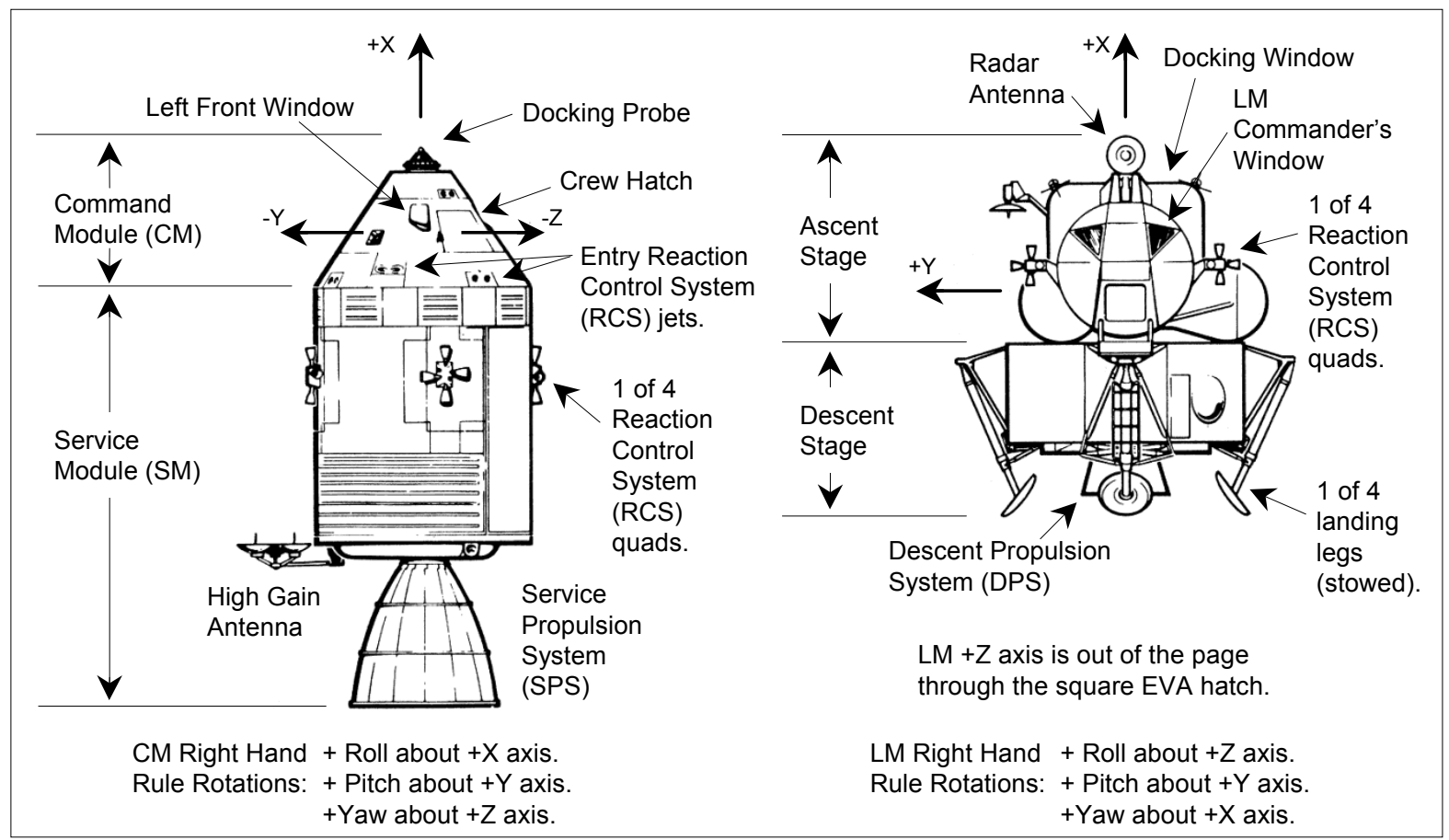

Figure 1. Apollo Command Service Module (CSM) (left) and Lunar Module (LM) (right).

\footnotetext{
* Senior Navigation and Rendezvous Specialist. Mail Code USH-806A, 600 Gemini Ave. Member AIAA.
} 
propulsion systems were used to perform trajectory adjustments and attitude maneuvers to control spacecraft thermal conditions. The limited power and LM GNC software functionality required the use of previously developed or new contingency procedures that were labor intensive. The ability of the crew and ground personnel to create, verify, and implement new contingency procedures and work-arounds in limited time was crucial to the safe return of the crew. One example was the adaption of square CSM lithium hydroxide $(\mathrm{LiOH})$ canisters for use in the LM (the LM used round LiOH canisters) to remove carbon dioxide from the cockpit (Figure 2).

After a mission abort was declared, four trajectory adjustment maneuvers were performed. The first placed the vehicle on a trajectory that would ensure return to Earth with appropriate trajectory conditions at Entry Interface (EI), that is, the arrival of the vehicle at an altitude 400,000 feet above an oblate earth, a point at which the

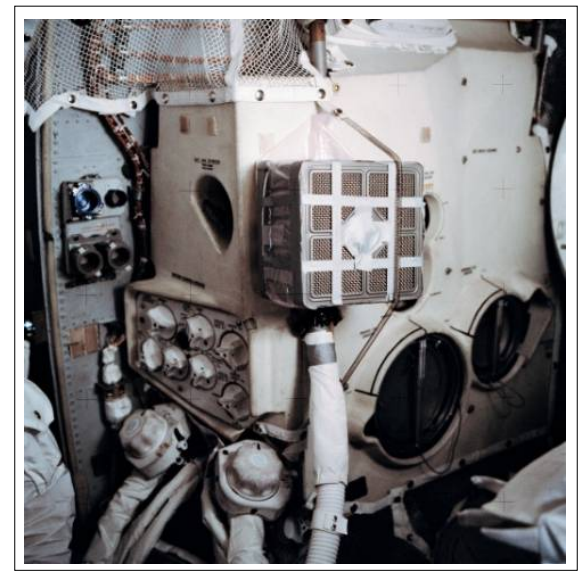

Figure 2. LiOH canister adapter in the LM. vehicle enters the sensible atmosphere. The second shortened the remaining flight time and moved the splashdown point from the Indian Ocean to the mid Pacific, the normal landing area for Apollo lunar missions. The third and fourth maneuvers were small trajectory adjustments to meet required EI conditions.

This paper contains an overview of the Apollo 13 nominal mission plan followed by a chronological description of GNC performance and mission activities. Topics include a summary of the mission before the oxygen tank incident, GNC performance from the incident though LM activation, re-establishment of the free return to Earth trajectory, ground-based orbit determination, shortening the return trajectory, mid-course correction maneuvers, separation of the SM and LM, Mission Control preparation for entry and landing, entry and landing performance, and finally observations on GNC challenges. Mission events are discussed in terms of Ground Elapsed Time, or GET. The GET clock started at the integral second before lift-off, also called range zero. Range zero for the Apollo 13 mission was at 19:13:00 Greenwich Mean Time on Saturday, April 11, 1970.

Table 1 lists key events during the mission. Figure 3 illustrates the planned and as-flown timeline of key crew activities. Appendices A and B provide descriptions of the LM and CSM GNC capability. Appendix C lists acronyms used in the paper.

\section{Apollo 13 Nominal Mission Plans}

This section provides a summary of the nominal mission plan for Apollo 13. ${ }^{11}$ Topics include an overview of the mission and objectives, trans-lunar trajectory design, the post Trans-Lunar Injection (TLI) S-IVB trajectory, nominal crew activities, lunar orbit insertion, lunar orbit and lunar surface activities, mid-course corrections, and re-entry. Figure 4 is an illustration of the nominal mission trajectory.

\section{A. Mission Overview}

The April 1970 flight of Apollo 13 (Apollo mission H-2) was to be the third lunar landing of the Apollo Program. The objective was exploration of the Fra Mauro uplands. Apollo missions 11 and 12 had landed in "sea" or mare areas, the Sea of Tranquility and the Ocean of Storms. ${ }^{13,14}$

The primary crew was James A. Lovell (commander), Thomas K. Mattingly (Command Module or CM pilot), and Fred W. Haise (LM pilot). The backup crew was John W. Young (commander), John L. Swigert (CM pilot), and Charles M. Duke (LM pilot). Support crew members were Vance D. Brand, Jack R. Lousma, and William R. Pogue. ${ }^{13}$ Mission Control Flight Directors were Eugene F. Kranz (White Team), Glynn S. Lunney (Black Team), Gerald D. Griffin (Gold team), and Milton L. Windler (Maroon Team). ${ }^{15}$

The CSM and LM were named so that Mission Control could unambiguously communicate with crew members in each spacecraft. CSM-109 was named Odyssey, while LM-7 was named Aquarius.

\section{B. Ascent and Low Earth Orbit}

The nominal launch of Saturn V AS-508 was to occur on Saturday, April 11, 1970, at 2:13 pm Eastern Standard Time (EST) from Launch Complex 39A. The nominal mission plan included one and a half revolutions in low earth orbit. Crew activities in low earth orbit included checkout of S-IVB and CSM systems. 
Table 1 Apollo 13 Key Events

\begin{tabular}{|c|c|c|c|c|c|c|}
\hline Event & $\begin{array}{l}\text { Ground } \\
\text { Elapsed } \\
\text { Time }\end{array}$ & $\begin{array}{l}\text { DV } \\
\text { TGO }\end{array}$ & $\begin{array}{l}\text { Attitude } \\
\text { Control for } \\
\text { Maneuver to } \\
\text { Burn Attitude }\end{array}$ & $\begin{array}{l}\text { Attitude } \\
\text { Control } \\
\text { for Burn }\end{array}$ & $\begin{array}{l}\text { Translational } \\
\text { Propulsion }\end{array}$ & Comments \\
\hline TLI & $2: 35: 46$ & $\begin{array}{l}10,437.1 \mathrm{ft} / \mathrm{sec} \\
350.7 \mathrm{sec}\end{array}$ & S-IVB & S-IVB & S-IVB & $\begin{array}{l}\text { Place vehicle on trans- } \\
\text { lunar free return } \\
\text { trajectory. }\end{array}$ \\
\hline MCC-1 & $\begin{array}{l}\text { Planned for } \\
11: 41: 23\end{array}$ & & & & & Not performed. \\
\hline MCC-2 & $30: 40: 50$ & $\begin{array}{l}23.1 \mathrm{ft} / \mathrm{sec} \\
3.37 \mathrm{sec}\end{array}$ & CSM RCS & $\begin{array}{l}\text { CSM } \\
\text { PGNCS }\end{array}$ & CSM SPS & $\begin{array}{l}\text { Place vehicle on hybrid } \\
\text { trajectory. }\end{array}$ \\
\hline MCC-3 & $\begin{array}{l}\text { Planned for } \\
55: 26: 02\end{array}$ & & & & & Not performed. \\
\hline $\begin{array}{l}\text { Oxygen Tank } \\
\text { Incident }\end{array}$ & $55: 54: 53$ & $0.5 \mathrm{ft} / \mathrm{sec}$ & & & & \\
\hline $\begin{array}{l}\text { DPS-1 } \\
(\mathrm{MCC}-4)\end{array}$ & $\begin{array}{l}61: 29: 43.5 \text { to } \\
61: 30: 17.7\end{array}$ & $\begin{array}{l}37.8 \mathrm{ft} / \mathrm{sec} \\
34.2 \mathrm{sec}\end{array}$ & $\begin{array}{l}\text { LM RCS } \\
\text { LM AGS for } \\
\text { piloting cues. }\end{array}$ & $\begin{array}{l}\text { LM PGNS } \\
\text { AUTO }\end{array}$ & LM DPS & $\begin{array}{l}\text { Place vehicle on free- } \\
\text { return trajectory for } \\
\text { Indian Ocean landing. } \\
\text { AGS powered for } \\
\text { monitoring and backup } \\
\text { control. }\end{array}$ \\
\hline $\begin{array}{l}\text { DPS-2 } \\
(\mathrm{PC}+2)\end{array}$ & $\begin{array}{l}79: 27: 39.0 \text { to } \\
79: 32: 02.8 \\
(\mathrm{PC}+2 \text { hours })\end{array}$ & $\begin{array}{l}860.5 \mathrm{ft} / \mathrm{sec} \\
263.8 \mathrm{sec}\end{array}$ & $\begin{array}{l}\text { LM RCS } \\
\text { LM PGNS for } \\
\text { piloting cues. } \\
\text { LM AGS cross } \\
\text { check of PGNS. }\end{array}$ & $\begin{array}{l}\text { LM PGNS } \\
\text { AUTO } \\
\text { LM AGS } \\
\text { cross check } \\
\text { of PGNS. }\end{array}$ & LM DPS & $\begin{array}{l}\text { Shorten return time } \\
\text { and move landing } \\
\text { point to the Pacific. }\end{array}$ \\
\hline MCC-5 & $\begin{array}{l}105: 18: 28.0 \text { to } \\
105: 18: 42.0\end{array}$ & $\begin{array}{l}7.8 \mathrm{ft} / \mathrm{sec} \\
14.0 \mathrm{sec}\end{array}$ & $\begin{array}{l}\text { LM RCS } \\
\text { Earth AGS align. } \\
\text { AGS piloting cues. }\end{array}$ & $\begin{array}{l}\text { LM AGS for } \\
\text { FDAI } \\
\text { piloting } \\
\text { cues. }\end{array}$ & LM DPS & $\begin{array}{l}\text { Steepen EI flight path } \\
\text { angle to }-6.52 \mathrm{deg} \text {. }\end{array}$ \\
\hline MCC-7 & $\begin{array}{l}137: 39: 51.5 \text { to } \\
137: 40: 13.0 \\
\text { (EI-5 hours) }\end{array}$ & $\begin{array}{l}3.0 \mathrm{ft} / \mathrm{sec} \\
21.5 \mathrm{sec}\end{array}$ & $\begin{array}{l}\text { LM RCS } \\
\text { Earth AGS align. } \\
\text { AGS piloting cues. } \\
\text { PGNS for } \\
\text { cross check. }\end{array}$ & $\begin{array}{l}\text { LM AGS for } \\
\text { FDAI } \\
\text { piloting } \\
\text { cues. }\end{array}$ & LM RCS & $\begin{array}{l}\text { Steepen EI flight path } \\
\text { angle to }-6.49 \mathrm{deg} \text {. }\end{array}$ \\
\hline SM Sep & 138:01:48 & $0.5 \mathrm{ft} / \mathrm{sec}$ & & & LM RCS & $\begin{array}{l}\text { Followed by SM } \\
\text { photos. }\end{array}$ \\
\hline $\begin{array}{l}\text { Undocking } \\
\text { from LM }\end{array}$ & 141:30:00 & $\begin{array}{l}1.88 \mathrm{ft} / \mathrm{sec} \text { CM A } \\
0.65 \mathrm{ft} / \mathrm{sec} \mathrm{LM}\end{array}$ & & & $\begin{array}{l}\text { Docking tunnel } \\
\text { air pressure. }\end{array}$ & \\
\hline EI & $142: 40: 46$ & & & & & $\begin{array}{l}\text { Arrival at } 400,000 \text { foot } \\
\text { altitude. }\end{array}$ \\
\hline Splashdown & $142: 54: 41$ & & & & & $\begin{array}{l}3.5 \mathrm{~nm} \text { from } \\
\text { USS Iwo Jima }\end{array}$ \\
\hline
\end{tabular}

A LM and CM separation was achieved by leaving the docking tunnel pressurized. Neither the LM nor CM RCS systems were used.

AGS - LM Abort Guidance System, CM - Command Module, CSM - Command Service Module, DPS - Descent Propulsion System, DV Delta Velocity, EI - Entry Interface, FDAI - Flight Director Attitude Indicator, LM - Lunar Module, MCC - Mid-Course Correction, PC Pericynthion, PGNCS - CSM Primary Guidance, Navigation, and Control System, PGNS - LM Primary Guidance and Navigation Section, RCS - Reaction Control System, Sep - Separation, SM - Service Module, SPS - CSM Service Propulsion System, TGO - Time to Go, TLI Trans Lunar Injection, USS - United States Ship 


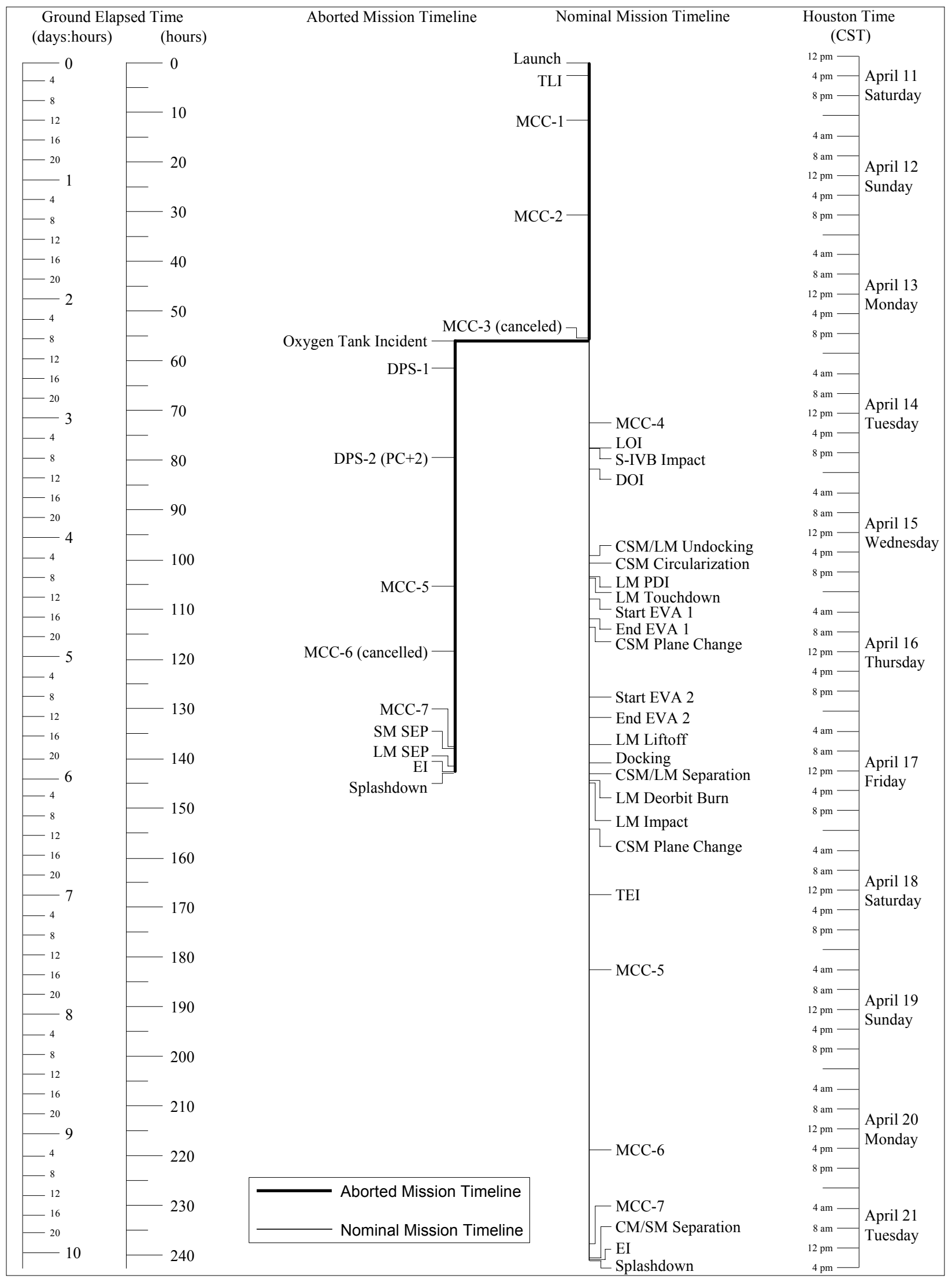

Figure 3. Apollo 13 Aborted Mission and Nominal Mission Timelines 


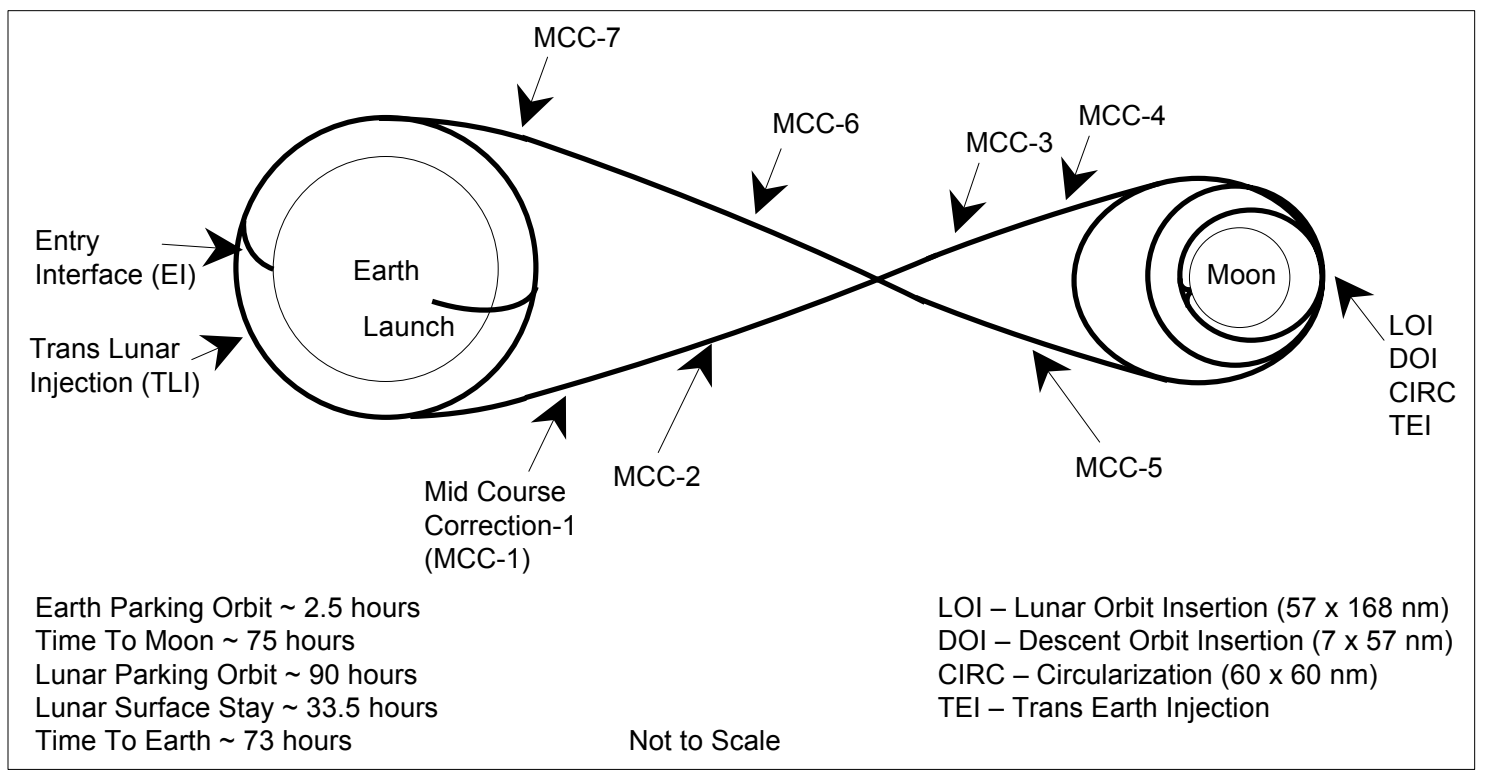

Figure 4. Nominal Apollo 13 mission profile. ${ }^{12}$

\section{Apollo 13 Trans-Lunar Trajectory Design}

Apollo missions 8, 10, and 11 flew free return trans-lunar trajectories. The S-IVB TLI burn was targeted to place the vehicle on a translunar trajectory that would arrive at the moon with a $60 \mathrm{~nm}$ closest approach (pericynthion, or PC) altitude. However, the TLI burn and resulting trajectory was also designed to return the spacecraft to the nominal Earth re-entry corridor if the Lunar Orbit Insertion (LOI) maneuver was not performed. In the event of a SM SPS failure and normally expected trajectory dispersions, the SM Reaction Control System (RCS) could perform any Mid-Course Corrections (MCC) that were required to ensure acceptable Entry EI conditions (flight path angle and velocity magnitude at an altitude of 400,000 feet) for re-entry. ${ }^{16}$

Apollo 12 introduced a new cis-lunar trajectory technique, the hybrid free return. This technique was also flown by Apollo 13 (Figure 5). ${ }^{\dagger}$ The hybrid mission plan lowered the delta velocity requirements for LOI, increased payload mass, and increased LM hover time before landing through LOI propellant savings. More flexibility in landing site selection and larger launch windows with the required lunar landing site lighting were obtained.

The S-IVB TLI maneuver was designed to place the vehicle on a free-return trajectory as was done for Apollo missions 8, 10, and 11. On Apollo 13, this trajectory had a PC of $210 \mathrm{~nm}$. The later MCC-2 maneuver would place the vehicle on a non-free return trajectory with a PC of $59 \mathrm{~nm}$. This trajectory had an Earth perigee of approximately $2,500 \mathrm{~nm}$, a value that would not result in atmospheric capture of the spacecraft and a safe re-entry. In the event of a mission contingency requiring return to Earth before LOI, a SM RCS burn could re-establish a circumlunar return trajectory with the appropriate vacuum perigee and EI conditions. Once the spacecraft was in or near the lunar sphere of influence, the SPS or the LM Descent Propulsion System (DPS) was required to re-establish circumlunar return due to the size of the burn. Departure from the free return trajectory at MCC-2 required the availability of the LM DPS as a backup to the CSM SPS.

Two further MCC burns were scheduled to ensure that the trajectory conditions at the LOI point were acceptable. MCC-3 was scheduled for LOI-22 hours and MCC-4 at LOI-5 hours. If the MCC delta-velocity computed based on MSFN tracking data was small, a MCC burn may not be performed.

A systems performance problem could require the crew to abort the mission and return to Earth. Normally such burns would be computed by Mission Control. In case an extended loss of communications occurred, Mission

\footnotetext{
$\uparrow$ Apollo 14 also flew a hybrid free return. Apollo missions 15, 16, and 17 (the J missions) flew a modified free return. TLI targeted the vehicle for the LOI pericynthion. If the vehicle needed to return without entering lunar orbit, a burn could be executed at pericynthion to establish a return trajectory with appropriate EI conditions. The modified free return required one less maneuver than the hybrid, was easier to plan for, required less propellant, provided more flexibility in landing site selection, and enabled the $\mathrm{J}$ series LM to carry more payload, such as the Lunar Rover.
} 


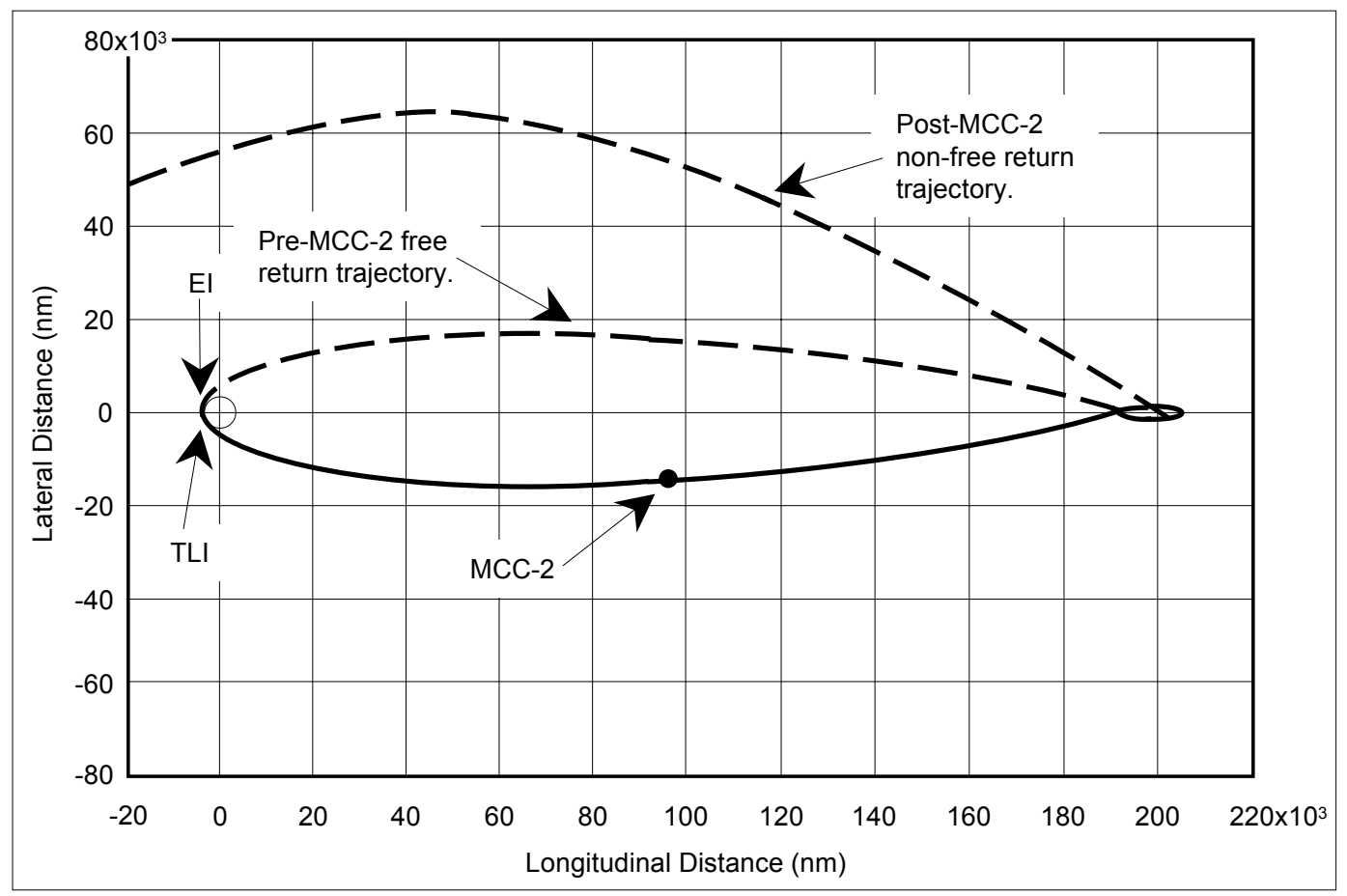

Figure 5. Example of free return (pre MCC-2 burn) and hybrid (post MCC-2 burn) trajectories. ${ }^{12}$

The Apollo 13 non-free return Earth perigee was much smaller than the above at $2500 \mathbf{~ n m}$.

Control had supplied Apollo crews with burn data for abort burns at 25, 35, and 60 hours GET, as well as for LOI-5 hours and PC +2 hours. A back-up source of return to Earth abort burn data, when outside the lunar sphere of influence, was the Command Module Computer (CMC). If a direct return to Earth was required (no lunar fly-by) the LM would be jettisoned before the burn. Abort burns could also make use of the LM DPS and could involve a lunar fly-by. Once the spacecraft entered the lunar sphere of gravitational influence a lunar fly-by provided a faster return to Earth than a direct return that did not include a lunar fly-by.

\section{Post TLI S-IVB Trajectory}

During Apollo missions 8, 10, 11, and 12 the S-IVB stage was placed in heliocentric orbit using residual liquid oxygen dumped though the $\mathrm{J}-2$ engine for propulsion and a subsequent lunar gravity assist. However, for Apollo 13 the S-IVB would be targeted for a lunar impact at a specified range from the Apollo 12 seismometer in an attempt to reproduce seismic phenomena observed during the Apollo $12 \mathrm{LM}$ ascent stage impact (Figure 6). The S-IVB would be tracked by the MSFN until impact. Orbit determination data obtained using MSFN tracking would be used to target two mid-course corrections after the liquid oxygen dump, if they were required. Impact was planned to occur approximately 20 minutes after the CSM/LM entered lunar orbit.

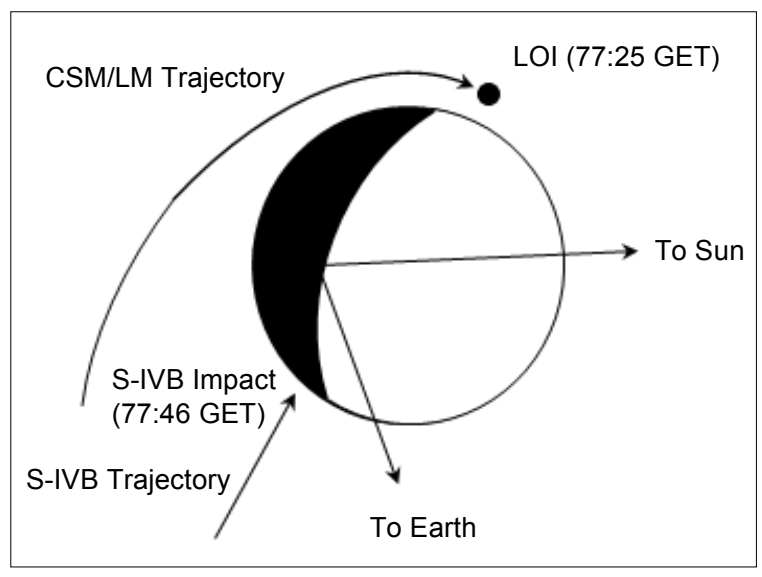

Figure 6. Planned Apollo 13 LOI burn and lunar S-IVB impact. ${ }^{11}$

\section{E. Nominal Crew Activities En Route to the Moon}

After TLI the CSM nominally provides all GNC and propulsion functions during this phase of the mission. Crew activities include MCC burns to adjust the trajectory, Inertial Measurement Unit (IMU) alignments, horizon altitude and sextant trunnion bias determinations for back-up cis-lunar navigation, LM checkout, systems maintenance, fuel cell purges, waste water dumps, Earth photography, and public affairs events. 
Passive Thermal Control (PTC) rotation of the spacecraft, a roll about the longitudinal axis, is performed to control the thermal conditions of spacecraft systems and structure. Three revolutions are performed per hour. PTC rotation occurs during crew sleep periods and when other attitudes are not required.

\section{F. Lunar Orbit and Lunar Surface Activities}

Another departure from the Apollo 11 and Apollo 12 mission design was the combining of the second lunar orbit insertion burn (called LOI-2 on missions 11 and 12) with the Descent Orbit Insertion (DOI) burn. On Apollo 11 and 12 the LOI-1 burn placed the spacecraft in a $60 \times 169 \mathrm{~nm}$ orbit. Two revolutions later the LOI-2 maneuver placed the vehicle in a $54 \times 66 \mathrm{~nm}$ orbit that would shift due to lunar gravity to a $60 \mathrm{~nm}$ altitude circular orbit at the time of LM rendezvous with the CSM. The DOI burn, which occurred half revolution before landing, placed the LM in a $8 \times 60 \mathrm{~nm}$ altitude orbit from which powered descent to the surface could take place.

On Apollo 13 LOI was to place the spacecraft in an initial $57 \times 168 \mathrm{~nm}$ altitude orbit. Two revolutions later DOI would place the spacecraft in a $7 \times 57 \mathrm{~nm}$ orbit that would shift over 12 revolutions, due to the gravitational field, to a $8.3 \times 58.9 \mathrm{~nm}$ orbit by the time of Powered Descent Initiation (PDI). Apollo 13 was to perform DOI using the SM SPS rather than the LM DPS, as had been done on previous missions. The combined LOI-2/DOI maneuver would conserve enough propellant to provide an additional 15 seconds of LM hover time for landing.

The mission plan included a LM lunar surface stay of 33.5 hours, with landing occurring at 9:55 pm EST on Wednesday, April 15. Lovell and Haise were to conduct two Extra Vehicular Activities (EVA), each of four hours duration. Among many exploration activities was the deployment of a second Apollo Lunar Surface Experiment Package (ALSEP). The first ALSEP was left on the lunar surface by the crew of Apollo 12 in November of 1969.

While the LM was on the lunar surface the CM pilot was to perform science activities from lunar orbit. This included detailed photography of potential landing sites for future Apollo missions. Photography of Comet Bennett was also to be performed. The CSM Very High Frequency (VHF) communications system was also to be used in a lunar VHF bistatic radar experiment, jointly with an Earth-based antenna.

Lunar liftoff of Aquarius was planned to occur at 7:22 am EST on Friday, April 17. The rendezvous was to be the same type of coelliptic profile flown on the previous Apollo missions.

After crew and lunar sample transfer to the CSM, the CSM and the LM ascent stage were to separate. Like Apollo 12, the LM ascent stage was to perform a deorbit burn targeted by Mission Control for lunar impact. For Apollo 13 the targeted impact point was near the Apollo 13 landing site. This was to provide data for the Apollo 13 and Apollo 12 seismometers. The Apollo 10 LM ascent stage was placed in a heliocentric orbit by burning the ascent stage propulsion system to propellant depletion. The Apollo $11 \mathrm{LM}$ ascent stage was left in lunar orbit and eventually impacted the lunar surface due to gravitational perturbations.

The Trans-Earth Injection (TEI) maneuver was planned to occur after the CSM had been in lunar orbit for approximately 90 hours. For the nominal mission plan the CSM was to leave lunar orbit at 1:42 pm EST on Saturday, April 18, 1970.

\section{G. Mid-Course Corrections and Entry}

Three MCC burns were scheduled to ensure the appropriate trajectory conditions at EI. MCC-5 was scheduled for TEI+15 hours, MCC-6 for EI-22 hours, and MCC-7 for EI-3 hours. The burns were spaced to permit adequate MSFN tracking for ground navigation and for other factors. On Apollo missions it was normal for MCC burns to be skipped if the computed delta-velocity was small.

Nominal velocity magnitude at EI was 36,129 feet/second with a flight path angle of -6.5 degrees. Range from EI to the landing site for a nominal entry trajectory was $1,250 \mathrm{~nm}$. For a Saturday, April 11, launch and nominal mission timeline, splashdown was scheduled to occur at 3:17 pm EST, Tuesday, April 21, in the Pacific about 180 $\mathrm{nm}$ south of Christmas Island. The amphibious assault ship USS Iwo Jima was the primary recovery ship.

\section{Mission Summary Before the Oxygen Tank Incident}

This section provides an overview of the actual crew and GNC activities and performance from pre-launch through the oxygen tank incident. Topics include the pre-launch crew change, launch and orbit insertion, low Earth orbit, TLI and the transposition and docking maneuver, IMU alignments and cis-lunar navigation, mid-course correction burns, and PTC attitude maneuvers. GNC performance before the incident was nearly nominal, and the crew was ahead of the nominal flight plan up until the incident. Figure 7 illustrates key events on a reconstruction of the Apollo 13 trajectory. ${ }^{17}$ 


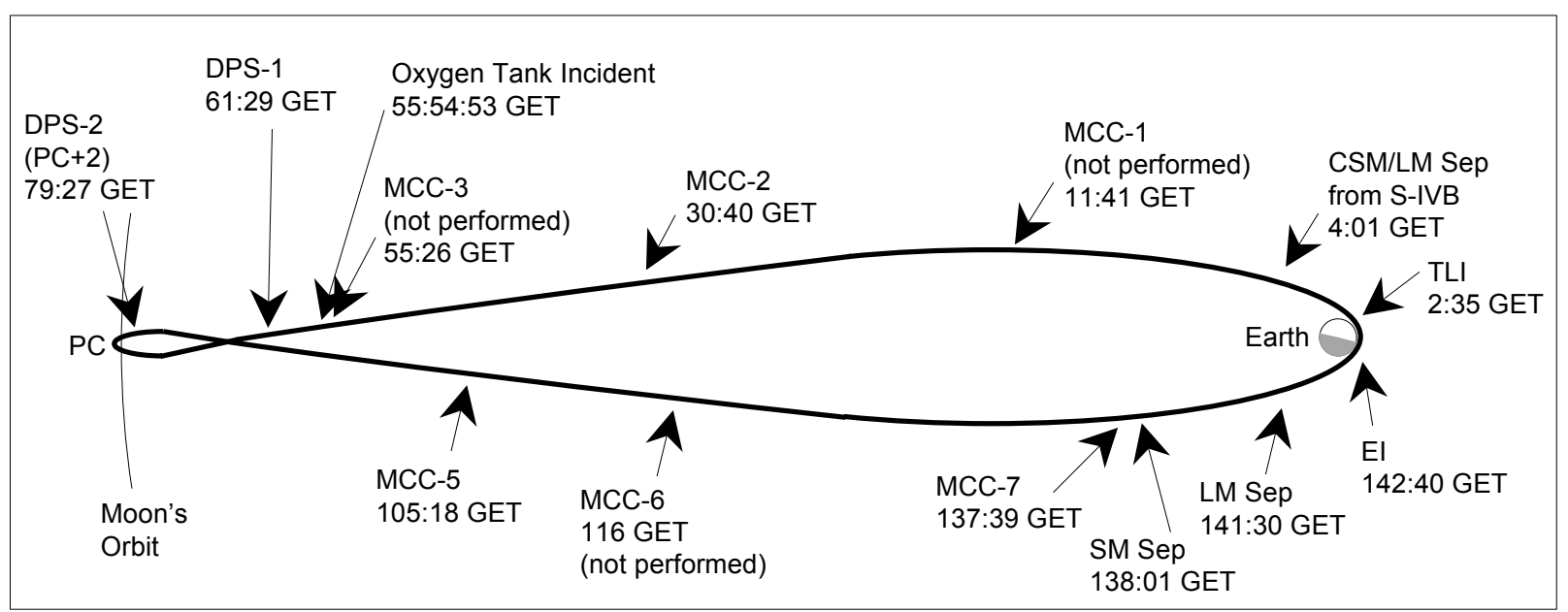

Figure 7. As-flown Apollo 13 trajectory and key events. ${ }^{17}$

\section{A. Crew Change}

Five days before the launch, on Monday, April 6, the flight surgeon recommended that Swigert replace Mattingly due to the possibility that Mattingly had contracted Rubella. Swigert flew simulated contingency cases with Lovell and Haise in a CSM simulator on Thursday, April 9. Swigert's replacement of Mattingly was agreed to by NASA management and the crew on the afternoon of Friday, April $10 .{ }^{13}$

\section{B. Launch and Orbit Insertion}

Lift-off occurred as planned on Saturday, April 11, 1970, at 2:13 pm EST. The Saturn V S-II (second) stage Center Engine Cut-Off (CECO) occurred 132.36 seconds early, due to high amplitude low frequency oscillations in the engine and supporting structure. The Iterative Guidance Mode (IGM) adjusted for the early shutdown during the remaining part of the second stage and during third stage. ${ }^{18}$ The remaining four S-II outboard engines fired 34.53 seconds longer than the pre-mission prediction in response to the early CECO. There were no flight control problems and subsequent S-II performance was nominal. Under-speed at S-II Out-board Engine Cut-Off (OECO) was $223 \mathrm{feet} / \mathrm{second}$.

The third stage (S-IVB) burned 9.3 seconds longer than predicted. The targeted parking orbit was $100 \mathrm{~nm}$ circular, but the actual orbit was $98 \times 100.2 \mathrm{~nm}$ with a $1.9 \mathrm{foot} / \mathrm{second}$ under-speed and a heading angle of 1.2 degrees greater than the nominal value. Orbit insertion time was 44 seconds later than planned. ${ }^{15,19,20}$

The early S-II CECO reduced the delta-velocity margin for the first TLI opportunity to about 295 feet/second, about half the normal margin for TLI. However, delta-velocity margin was deemed acceptable and the crew was given a go for the first TLI opportunity by Mission Control.

\section{Low Earth Orbit}

Spacecraft systems checks were performed while in the parking orbit in preparation for TLI. The Orbital Rate Display - Earth and Lunar (ORDEAL) unit was unstowed and installed. The sextant optics cover was jettisoned while the optics were driven to point at the first star to be sighted. The CM IMU platform alignment was successfully performed using the stars Spica and Antares. The Crewman Optical Alignment Sight (COAS) was unstowed and installed, and the horizon check was successful (Figure 8). $.1,22$

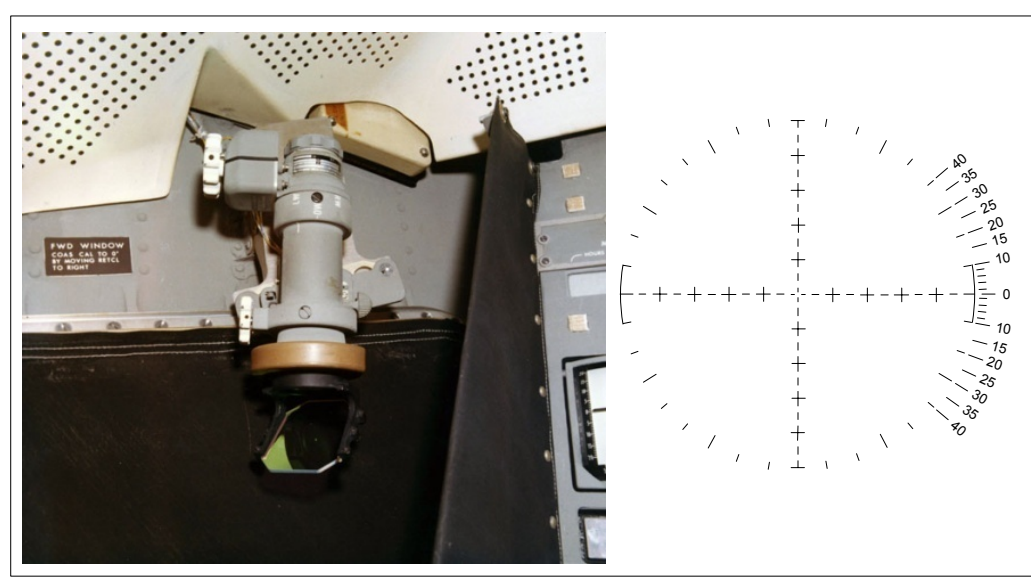

Figure 8. Crewman Optical Alignment Sight (COAS) in the Lunar Module (LM) commander's window (left). A similar COAS was installed in the Command Module (CM) left front window. The LM COAS pattern is depicted at right. The CM COAS pattern was similar, but not the same. 


\section{TLI and the Transposition and Docking Maneuver}

The IGM guided TLI burn was nominal. After TLI the S-IVB maneuvered the stack to the transposition and docking attitude. Once this attitude was achieved the S-IVB maintained an inertial attitude hold. Maximum spacecraft separation during the CSM Transposition and Docking maneuver was about 80 feet, with a CSM pitch rate during the maneuver of about 1.5 degrees/second. The CM pilot reported that sunlight on the LM docking target washed out the COAS. The COAS was therefore set at maximum brightness, making it difficult for the CM pilot to see the LM docking target. Just before docking the CSM shadowed the LM docking target and target visibility was improved. Closing rate at docking was about 0.2 feet/second. The docking and spring ejection of the LM/CSM from the S-IVB was nominal. ${ }^{21,23}$

\section{E. IMU Alignments and Cis-Lunar Optical Navigation}

Five CM IMU alignments were successfully performed using the sextant in the CM. Star pairs for each alignment were 1) Rasalhague and Enif, 2) Dnoces and Akaid, 3) Arcturus and Vega, 4) Menkent and Alphecca, and 5) Denebola and Alphecca. ${ }^{23}$

Two periods of sextant sightings were taken by the crew to estimate the Earth horizon bias and the sextant trunnion bias. This data would have been used in the event an extended loss of communications with Mission Control forced the crew to perform on-board cis-lunar navigation to facilitate an autonomous return to Earth. The bias determination was successful. ${ }^{22}$

\section{F. Mid-Course Correction Burns}

Three MCC burns were scheduled to occur before the oxygen tank incident (Table 1). MCC-1, planned for execution at 11:41 GET, was canceled 3.5 hours after TLI due to nominal trajectory performance. MCC-2, at 30:40 GET, a $23.1 \mathrm{foot} / \mathrm{second}$ nearly retrograde burn, placed the spacecraft on the non-free return trajectory. The CSM SPS was used for MCC-2. The planned altitude of pericynthion was $60.22 \mathrm{~nm}$, and a value of $60 \mathrm{~nm}$ was achieved by the burn. The crew had secured the $\mathrm{CM}$ docking hatch and the docking probe and drogue in a $\mathrm{CM}$ crew couch using lap belt and shoulder harness restraints. This prevented hardware movement during maneuvers.

MCC-3, scheduled for 55:26 GET, was canceled about 14 hours after MCC-2, as the MCC-4 maneuver was predicted to be only 4 feet/second. Post TLI trajectory, up to the incident, was excellent. ${ }^{15,24}$

Tropical storm Helen in the Pacific drove adjustment of the landing areas for 25, 35, and 60 hour GET abort opportunities to the east of the mid-Pacific recovery line.

\section{G. Passive Thermal Control Attitude Maneuver}

The first PTC roll was initiated about seven and a half hours into the mission. Some difficulty was encountered in establishing the first PTC due to an error in the crew checklist and flight plan. The PTC was later correctly initiated. Four periods of PTC rotation were conducted before the incident.

\section{H. S-IVB Trajectory}

After the spring ejection of the CSM/LM stack, the S-IVB successfully performed an evasive maneuver using the Auxiliary Propulsion System (APS) to reduce the risk of a collision with the CSM/LM. Targeting the S-IVB for lunar impact near the Apollo 12 seismometer was accomplished through the use of a liquid hydrogen propulsive dump, a liquid oxygen vent, and an APS burn (Figure 6). These activities were successfully performed. Subsequent tracking indicated that the S-IVB would impact in the target area on the lunar surface and no further APS burns were performed. S-IVB telemetry and attitude control was lost at 19:34 GET. At the time of the telemetry loss some unplanned delta-velocity was imparted to the S-IVB that actually improved the predicted impact point. MSFN S-Band tracking of the S-IVB continued until lunar impact at 77:56:40 GET. ${ }^{20}$

\section{GNC Performance From the Oxygen Tank Incident Through Completion of LM Activation}

During the period immediately following the incident the Apollo 13 crew and Mission Control conducted several time critical activities. These included assessing CSM systems to determine which ones were viable and which ones were compromised, establishing and maintaining effective attitude control, activating the LM, and aligning the LM IMU platform to support future GNC activities necessary for crew return to Earth. 


\section{A. Cause of the Oxygen Tank Incident}

The post-flight investigation determined that a failure of the SM oxygen tank \#2 thermostatic switches damaged Teflon insulation located near fan motor wires. During the oxygen tank stirring (a nominal procedure) the fan motor wiring short circuited, causing combustion in the oxygen tank. The release of oxygen under high pressure from the tank blew the panel covering SM bay four off of the vehicle, caused a leak in the oxygen tank \#1 system, damaged the high gain antenna, and caused other damage to the SM (Figure 1). The loss of oxygen from both tanks and the loss of power generated by the fuel cells that use oxygen prompted Mission Control to declare a mission abort. ${ }^{25}$

\section{B. GNC Impact of the Oxygen Tank Combustion}

The integrating accelerometers in the CM IMU indicated that a velocity increment of approximately 0.5 feet/second was imparted to the spacecraft at a time between 55:54:53 and 55:54:55 GET. Doppler tracking data from the MSFN measured an incremental velocity component of 0.26 feet/second, along a line-of-sight from the Earth to the spacecraft at approximately 55:54:55 GET.

For about one hour and 45 minutes after the incident the crew and Mission Control focused on resolving the CSM electrical problems, re-establishing attitude control using the CSM GNC system and RCS, and attempting to halt the loss of oxygen from the SM. Oxygen venting into space was observed by the crew. The oxygen quickly disappeared, but a large amount of small particle debris surrounded the spacecraft. Crew control of attitude using the SM RCS jets was initially successful, but eventually the spacecraft began to drift in attitude, SM RCS propellant consumption increased, and omni communications antenna switching occurred. The crew reported that venting induced negative rates in pitch and roll. Changes were made to the SM RCS configuration in an attempt to reduce propellant consumption. Avoiding CM IMU platform gimbal lock while maintaining a stable attitude was a challenge. In the first 39 minutes after the incident approximately $70 \mathrm{lbs}$ of SM RCS propellant was used for attitude control. Approximately 45 minutes after the incident, vehicle attitude had stabilized and venting had apparently stopped..$^{15}$

\section{LM Activation}

Efforts to save the remaining oxygen tank failed and by 57:35 GET the crew had entered the LM to begin activating LM systems required for crew survival such as power, life support, communications, and GNC. The crew used the LM activation checklist to power-up systems considered to have the highest priority. Mission Control personnel facilitated the activation of LM systems at a pace faster than could have been achieved if the crew used the activation checklist without ground assistance. The LM activation checklist was not normally performed until the spacecraft was in lunar orbit.

Fortunately, communications was maintained during this period and high bit rate telemetry was obtained through the 210 foot MSFN antenna at Goldstone, CA. ${ }^{15}$ Later the establishment of MSFN communications with the LM was complicated by the use of the same frequency by the S-IVB S-Band transponder and the LM S-Band system. This issue was eventually resolved (see Section VI, Ground Based Orbit Determination, for a description of this problem).

The CM Primary Guidance, Navigation, and Control System (PGNCS) was left powered as long as possible while other CM systems were shut down. A controlled CM power-down was completed by 58:40 GET. The CM switches were placed in a known configuration to facilitate future procedure development by the crew and Mission Control personnel.

During this time there was a period ( 2.5 minutes) when the spacecraft was not under active attitude control. Attitude control was re-established as soon as the condition was recognized. ${ }^{1,15}$ Concerns about LM water consumption for LM Primary Navigation and Guidance System (PGNS) cooling led flight controllers to examine use of the Abort Guidance Section (AGS) to maintain an attitude reference while keeping the PGNS powered down until it was required.

\section{LM Platform Alignment}

During LM activation IMU platform alignment was a top priority so that the LM could be used to perform burns to place the spacecraft on a return to Earth trajectory. Aligning the LM platform before the CM platform alignment was lost, due to the CM power-down, was a challenge. LM PGNS activation was nominal.

A CM to LM docked alignment was performed. The CM pilot provided CM IMU gimbal angles to the commander for the docked LM alignment. The procedure required some pencil and paper calculations and the 
commander asked Mission Control to do the math to ensure accuracy. The crew reported that debris surrounding the spacecraft made it impossible to recognize constellations needed to perform a CM IMU or LM IMU optical alignment using star sightings.

\section{Re-Establishment of the Return to Earth Trajectory}

After the incident, it became apparent that the lunar landing could not be accomplished due to the loss of oxygen in the SM and that the spacecraft trajectory must be altered for a return to Earth. At the time of the incident, the spacecraft was on a non-free return trajectory with an Earth perigee of approximately $2500 \mathrm{~nm}$ that precluded a re-entry and splashdown. Lunar pericynthion was $62 \mathrm{~nm}$. Once the LM was activated and CM powerdown was complete, Mission Control and supporting personnel focused attention on developing a return to Earth trajectory plan.

\section{A. Maneuver Targeting}

Targeting and orbit determination for trajectory maneuvers performed in transit to and from the Moon were normally performed by Mission Control. In the event of an extended communications outage, the crew could perform an autonomous return using the CMC Return to Earth Targeting Program and the Cis-Lunar Mid-Course Navigation Program. However, due to the loss of SM power these backup navigation and targeting functions were unavailable. Fortunately, adequate communications between the spacecraft and Earth were maintained for most of the mission. As with a nominal Apollo lunar mission, Mission Control computed all Apollo 13 cis-lunar trajectory burns and performed all precision orbit determination using tracking data from the MSFN.

\section{B. Direct Return to Earth}

Soon after the incident Mission Control personnel examined direct return to Earth aborts that did not include a lunar fly-by. These burns had to be performed with the SM SPS before $\sim 61$ hours GET, when the spacecraft entered the lunar sphere of gravitational influence. Landings in both the Pacific and Atlantic could be made.

A direct return to Earth (no lunar fly-by) with a landing at 118 hours GET could only be accomplished by jettisoning the LM and performing a 6,079 foot/second SM SPS burn (Table 2). Abort maneuver data for this burn was already on-board the spacecraft as a part of normal mission procedures. However, this option was unacceptable due to possible damage to the SPS and the necessity of using LM systems and consumables (power, water, oxygen, etc.) for crew survival. ${ }^{15}$

\section{Options for DPS-1}

Return to Earth planning assumed use of the LM DPS and RCS, a lunar fly-by, and that the SM SPS would only be used as a last resort. Table 2 lists the direct return and $\mathrm{PC}+2$ burn options examined at this point in the mission. ${ }^{15}$ Several options (not in Table 2) for the DPS-1 burn were debated. DPS-1 was designed to re-establish the free return trajectory to Earth. During this period of high activity by ground personnel some confusion existed over the DPS-1 requirements, such as minimum delta-velocity, fastest return time, water or land landing.

A decision was made to execute a maneuver expeditiously to place the spacecraft back on a free return trajectory. The LM PGNS was powered and the current IMU alignment was of sufficient accuracy to support DPS1. If the burn was delayed there was a concern that the PGNS alignment could degrade. The transfer time could then be shortened with a later burn at pericynthion $+2(\mathrm{PC}+2)$ hours $($ Table 2$)$ to ensure that landing occurred while the LM had sufficient oxygen, water, power, and RCS propellant.

The DPS-1 option with the lowest delta-velocity was a $17 \mathrm{foot} / \mathrm{second}$ burn that would result in a land landing in Madagascar, if no subsequent maneuvers were performed. This option was dismissed. ${ }^{24}$ A larger burn (37.8 feet/second) could be executed to achieve an Indian Ocean landing at approximately 152 hours GET. Another option was to wait until PC+2 at about 79:30 hours GET (after the lunar fly-by) to place the spacecraft on a return trajectory (Table 2).

It was decided to target DPS-1 for an Indian Ocean landing south of Mauritius at 152 hours GET. Advantages of this option included: 1) A water landing if no subsequent burns could be performed, and 2) A reduction in flight time by several hours. LM consumables would be evaluated in an attempt to keep the LM PGNS and AGS powered until after the PC+2 burn. DPS- 1 would result in a pericynthion altitude of $135 \mathrm{~nm} .{ }^{24}$ However, the landing area for a backup entry piloting technique in the event of both PGNCS and Entry Monitoring System 
Table 2 Abort Options Considered Before DPS-1 Burn Execution ${ }^{15}$

\begin{tabular}{|c|c|c|c|c|c|c|c|}
\hline Scenario & $\begin{array}{l}\text { TIG } \\
\text { (GET) }\end{array}$ & DV & $\begin{array}{l}\text { Splashdown } \\
\text { Ocean }\end{array}$ & $\begin{array}{l}\text { Splashdown } \\
\text { Location }\end{array}$ & $\begin{array}{l}\text { GET of } \\
\text { Splashdown }\end{array}$ & Weather & Recovery Ships \\
\hline \multirow{3}{*}{$\begin{array}{l}\text { Direct } \\
\text { Return } \\
\text { Burn }\end{array}$} & $60: 00$ & $6079 \mathrm{ft} / \mathrm{sec}$ & Mid Pacific & 21:05 S latitude & $118: 12$ & Good & USS Iwo Jima \\
\hline & & & & $153 \mathrm{~W}$ longitude & & & \\
\hline & $60: 00$ & $10,395 \mathrm{ft} / \mathrm{sec}$ & Mid Pacific & $\begin{array}{l}\text { 26:13 S latitude } \\
165 \mathrm{~W} \text { longitude }\end{array}$ & $94: 15$ & Good & USS Iwo Jima \\
\hline \multirow{3}{*}{$\begin{array}{l}\mathrm{PC}+2 \text { burn, no } \\
\text { previous DPS-1 } \\
\text { burn to } \\
\text { re-establish } \\
\text { free return. }\end{array}$} & $79: 30$ & $670 \mathrm{ft} / \mathrm{sec}$ & Mid Pacific & $\begin{array}{l}\text { 11:35 S latitude } \\
165 \mathrm{~W} \text { longitude }\end{array}$ & $142: 47$ & Good & USS Iwo Jima \\
\hline & $79: 30$ & $4657 \mathrm{ft} / \mathrm{sec}$ & Mid Pacific & $\begin{array}{l}\text { 28:26 S latitude } \\
165 \mathrm{~W} \text { longitude }\end{array}$ & 118:07 & Good & USS Iwo Jima \\
\hline & $79: 30$ & $1798 \mathrm{ft} / \mathrm{sec}$ & Atlantic & $\begin{array}{l}\text { 22:48 S latitude } \\
25 \mathrm{~W} \text { longitude }\end{array}$ & $133: 15$ & Very Good & $\begin{array}{l}\text { Some Ships } \\
\text { Available }\end{array}$ \\
\hline \multirow{4}{*}{$\begin{array}{l}\mathrm{PC}+2 \text { burn with } \\
\text { DPS-1 burn to } \\
\text { reestablish } \\
\text { free return. }\end{array}$} & $79: 30$ & $854 \mathrm{ft} / \mathrm{sec}$ & Mid Pacific & 21:38 S latitude & $142: 47$ & Good & USS Iwo Jima \\
\hline & $79: 30$ & $4836 \mathrm{ft} / \mathrm{sec}$ & Mid Pacific & $\begin{array}{l}\text { 12:24 S latitude } \\
165 \mathrm{~W} \text { longitude }\end{array}$ & 118:12 & Good & USS Iwo Jima \\
\hline & $79: 30$ & $1997 \mathrm{ft} / \mathrm{sec}$ & Atlantic & $\begin{array}{l}23: 21 \mathrm{~S} \text { latitude } \\
25 \mathrm{~W} \text { longitude }\end{array}$ & $133: 15$ & Very Good & $\begin{array}{l}\text { Some Ships } \\
\text { Available }\end{array}$ \\
\hline & $79: 30$ & $1452 \mathrm{ft} / \mathrm{sec}$ & $\begin{array}{l}\text { Eastern } \\
\text { Pacific }\end{array}$ & $\begin{array}{l}\text { 22:16 S latitude } \\
86: 40 \mathrm{~W} \text { longitude }\end{array}$ & $137: 27$ & OK & None \\
\hline
\end{tabular}

DV - Delta Velocity, GET - Ground Elapsed Time, PC - Pericynthion, TIG - Time of Ignition, USS - United States Ship

(EMS) failures (a constant $4 \mathrm{~g}$ roll to the right entry, see the EMS entry in Appendix B) during entry contained an island. If the $\mathrm{PC}+2$ burn was not executed and the failures occurred the crew would have flown a constant $4 \mathrm{~g}$ roll to the left entry. ${ }^{15}$

\section{SM Jettison Option}

At this point there was also discussion of jettisoning the SM since all the oxygen had vented into space. A faster return (landing at $\sim 118$ to 119 hours GET) could be achieved by jettisoning the SM before the PC+2 maneuver (Table 3). Before DPS-1 the LM DPS total delta-velocity available was 1,994 feet/second with the SM attached and 4,830 feet/second if the SM was jettisoned. However, speeding up the return would require most of the LM DPS propellant. Analysis was performed to determine if a DPS burn could be performed after a SM jettison with the $\mathrm{CM}$ attached to the LM (a LM/CM configuration). Computer simulations indicated there were no

Table 3 PC+2 Burn Options Considered After DPS-1 ${ }^{15}$

\begin{tabular}{llllll}
\hline \hline $\begin{array}{l}\text { TIG } \\
(\text { GET })\end{array}$ & DV & Ocean & $\begin{array}{l}\text { GET of } \\
\text { Splashdown }\end{array}$ & $\begin{array}{l}\text { MCC-5 DV at 105 GET for } \\
\text { 1 Degree PC+2 Attitude Error }\end{array}$ & $\begin{array}{l}\text { SM Jettison } \\
\text { Before PC+2 }\end{array}$ \\
\hline $78: 30$ & $4728 \mathrm{ft} / \mathrm{sec}$ & Mid Pacific & 118 & $\sim 87 \mathrm{ft} / \mathrm{sec}$ & Yes \\
$\mathrm{PC}+1$ & & & & \\
$79: 30$ & $845 \mathrm{ft} / \mathrm{sec}$ & Mid Pacific & 142 & $\sim 22 \mathrm{ft} / \mathrm{sec}$ & No \\
$\mathrm{PC}+2$ & & & & & \\
$79: 30$ & $1997 \mathrm{ft} / \mathrm{sec}$ & Atlantic & 133 & $\sim 50 \mathrm{ft} / \mathrm{sec}$ & No \\
$\mathrm{PC}+2$ & & & & & \\
\hline \hline
\end{tabular}

DV - Delta Velocity, GET - Ground Elapsed Time, PC - Pericynthion, TIG - Time of Ignition 
problems with a DPS maneuver for a LM/CM configuration. DPS gimbal trim angles were computed for the $\mathrm{LM} / \mathrm{CM}$ configuration.

However, it was decided to keep the SM attached to the CM until just before entry for the following four reasons: 1) The SM SPS and SM RCS could still be fired using the CM entry batteries, 2) Digital Auto-Pilot (DAP) problems (flight control) may exist without the SM attached, 3) The LM had sufficient lifetime ( 140 hours) to support a return, and 4) Heat shield exposure to low temperatures for a long period and internal CM thermal problems could arise if the SM were jettisoned too early.

\section{E. DPS-1 Execution}

DPS-1 was performed with the LM DPS and the LM PGNS. A DPS firing with the LM docked to the CSM was first performed in low Earth orbit during the Apollo 9 mission (March 1969) to test the DPS backup capability for the SPS. ${ }^{26}$ For the maneuver to burn attitude the crew used Flight Director Attitude Indicator (FDAI) error needles driven by the AGS as cues (Figure 9). The Thrust/Translation Controller Assembly (TTCA, Figure 10) was used for roll and pitch control, and the Attitude Controller Assembly (ACA, Figure 11) for yaw. The ACA was normally used for manual attitude control during LM only flight. However, use of the TTCA for pitch and roll control was required since it provided more pitch and roll control authority than the ACA when the LM RCS was used to control the docked CSM/LM spacecraft with a fully loaded SM. Once the attitude error needles were nulled, PGNS attitude control (Figure 12) was placed in the automatic mode. Figure 13 shows the location of this hardware in the LM.

Before the DPS- 1 burn a 10 second ullage burn was performed with the LM RCS. Manual crew throttling of the DPS engine was performed. Thrust levels were 5 seconds at $12.6 \%$ thrust followed by 27 seconds at $40 \%$ thrust. DPS-1 at $\sim 61: 30$ GET was successful and the crew reported that attitude excursions during the burn were minimal. ${ }^{21}$

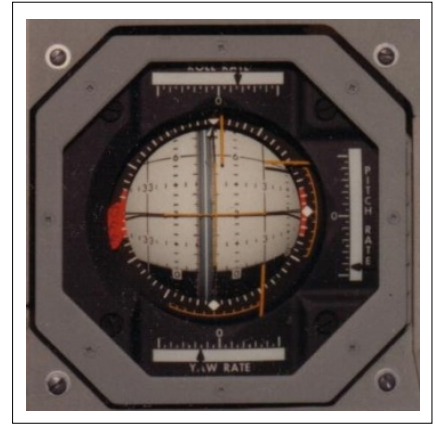

Figure 9. Lunar Module Flight Director Attitude Indicator (FDAI).

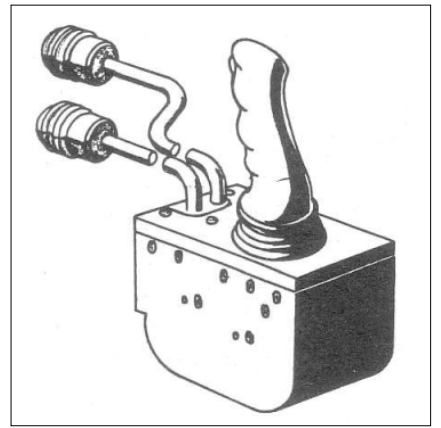

Figure 11. Lunar Module Attitude Controller Assembly (ACA).

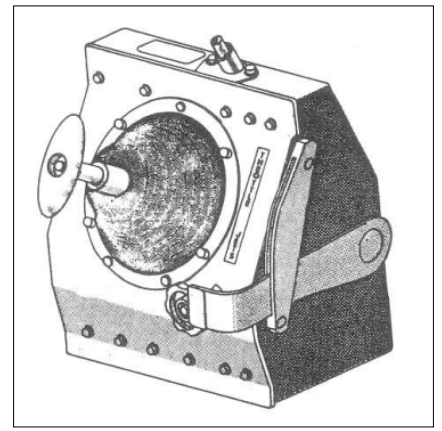

Figure 10. Lunar Module Thrust/Translation Controller Assembly (TTCA).

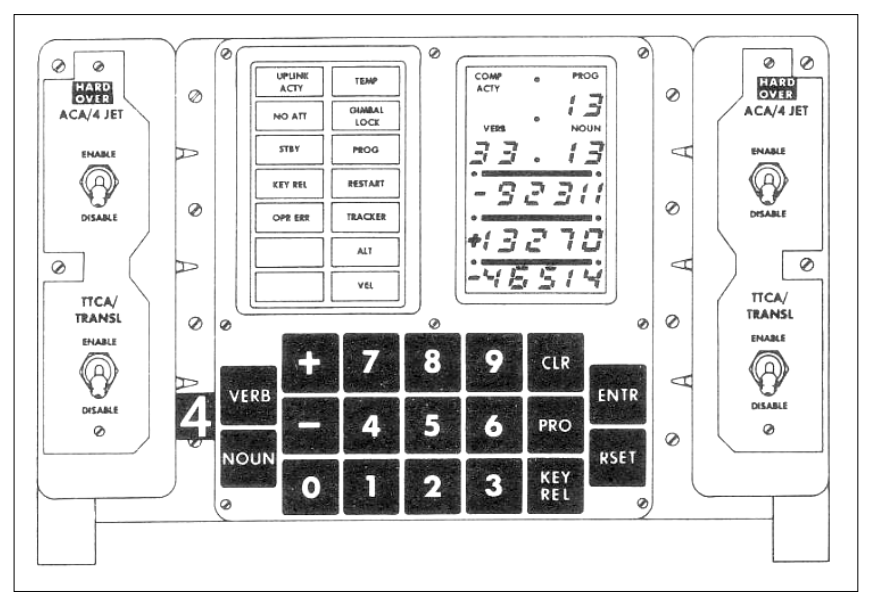

Figure 12. Lunar Module Display and Keyboard (DSKY). 


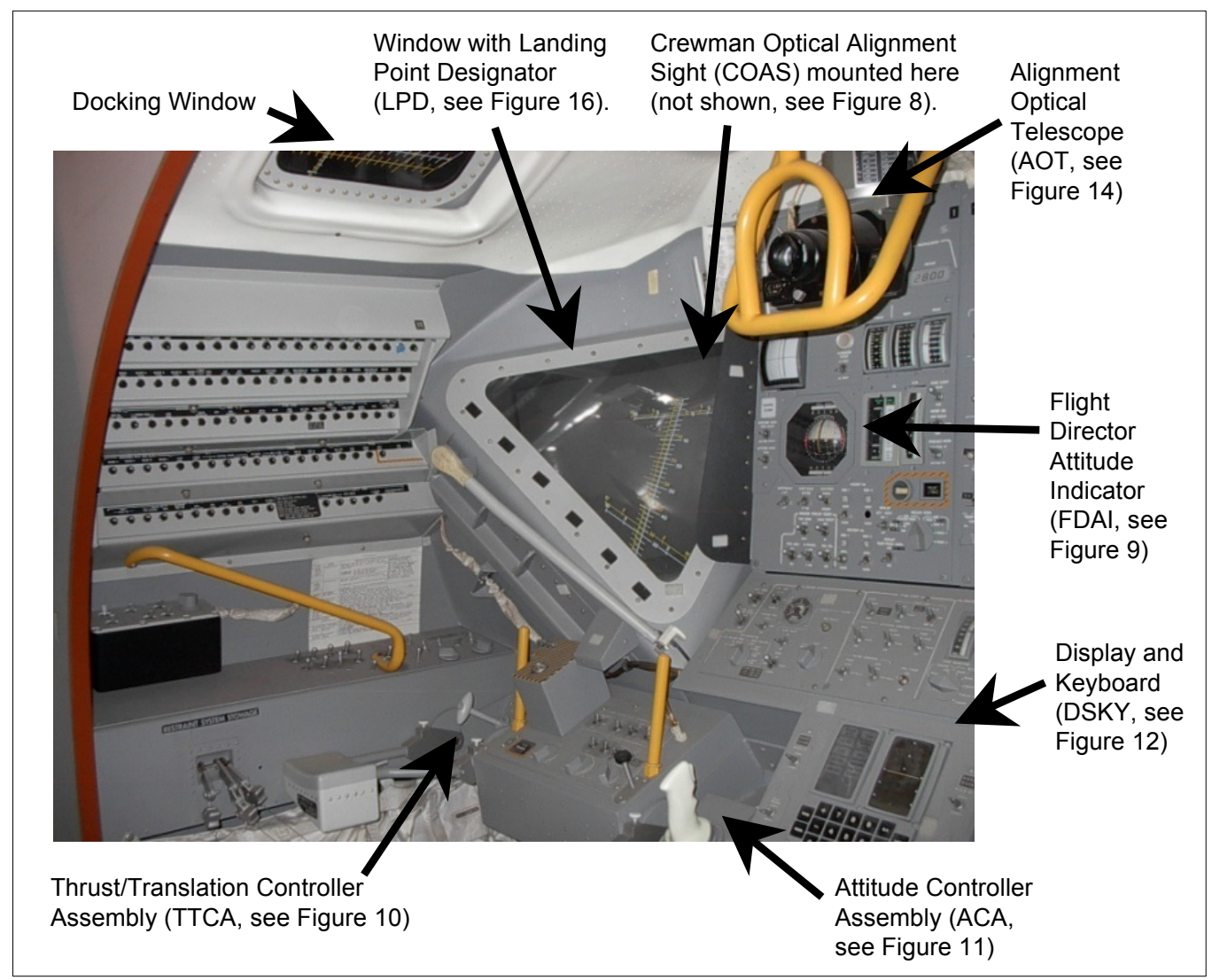

Figure 13. Lunar Module commander's station. The pilot's station (to the right, not shown) was also equipped with a TTCA, ACA, and FDAI.

After DPS-1 was successfully performed the LM was partially powered down to conserve power and water. The PGNS remained on to support the PTC rotation and to provide a platform reference for the PC +2 burn.

An attempt was made to manually place the stack in a PTC rotation. The FDAI units were powered off after DPS-1 and the crew monitored attitude using IMU gimbal angles shown on the LM PGNS computer display for piloting cues (Figure 12). The crew found this procedure and avoiding gimbal lock to be challenging as it had not been practiced in training.

By 63:50 GET difficulty in initiating the PTC rotation led to a different PTC procedure. The spacecraft was manually maneuvered 90 degrees in yaw (LM body frame) once an hour. Since the spacecraft yaw axis was not aligned with the IMU platform yaw axis, a pitch or roll command from the TTCA could cause a change in both of the corresponding digital gimbal angle displays. This complicated attempts to avoid gimbal lock of the middle gimbal. Vehicle attitude was changed to more closely align the platform and body yaw axes. This made the piloting task easier. ${ }^{21,23}$ Later the crew placed tape on the top and side of each FDAI and wrote notes on the tape correlating TTCA deflections with desired spacecraft pitch and roll rotations. ${ }^{21}$

Propellant use with the 1.4 degree attitude error deadband was too high at $\sim 1 \%$ per hour. A new attitude error deadband value of 5 degrees was determined using ground simulations. All LM $+X$ jets (downward firing) were disabled since the LM plume deflectors were nullifying the effective $+\mathrm{X}$ RCS thrust and increasing propellant consumption.

\section{F. Recovery Preparations}

By 58:26 GET, Mission Control recovery operations personnel had been tasked to evaluate four landing points for possible use on the mid-Pacific, Atlantic, eastern Pacific, and Indian Ocean recovery lines. Landing times for these points were 142, 133, 137, and 152 hours GET. Weather personnel evaluated weather forecasts for the potential landing points, and the U.S. Department of Defense identified which naval and merchant ships in those areas might be available to assist with crew and spacecraft recovery. Offers of assistance and use of aircraft, airfields, and ships were received from many foreign governments. 
In the event of an Indian Ocean landing (targeted by the DPS-1 burn), the destroyer USS Bordelon would perform the recovery. The Bordelon was in Port Louis, Mauritius. A U.S. Air Force C-141 Starlifter was placed on standby to fly a recovery crane and a NASA advisor to Mauritius, if needed. Three other U.S. destroyers were also available in the Indian Ocean. The aircraft carrier USS America, scheduled to cruise to Rio de Janerio, left Puerto Rico early to cover a possible Atlantic landing. ${ }^{15}$

By 66:14 GET, three landing points in the mid-Pacific were under consideration. The USS Iwo Jima was positioned to be within range of all three points.

\section{Ground Based Orbit Determination}

The power-down of the CSM required the power-up of the LM Unified S-Band (USB) transponder for communications and tracking. However, this resulted in interference with the S-IVB Instrumentation Unit (IU) Command and Communication System (CCS). Both the LM USB and the IU CCS used the same S-Band frequency. Power-on of the LM transponder was not scheduled to occur until after S-IVB lunar impact and after the CSM/LM had entered lunar orbit (Figure 6). Use of the same frequencies by both vehicles complicated tracking in the first 6 hours after the incident.

The first attempt to correct the problem used a modified version of a previously developed procedure. The IU CCS frequency was offset below the center carrier frequency, and the LM USB frequency was offset above the center carrier frequency. However, the Real Time Computer Complex (RTCC) supporting Mission Control reported that LM tracking data was unusable at this frequency. The second work-around was to re-set the LM frequency to the center carrier frequency by turning off the LM USB transponder for 5 minutes. The IU CCS frequency was offset to a new value below the center carrier frequency. Tracking of the LM was re-established and the data was usable. Later investigation revealed that RTCC personnel could have made computer inputs to correct the first work-around resulting in usable LM tracking data. ${ }^{15}$

To conserve LM power, a proposal was made to periodically turn off the LM USB transponder. A tracking plan was developed to support the proposed transponder power-down. However, the available power level permitted the transponder to remain on for the rest of the mission. Continuous S-Band tracking made it easier for the ground navigation team to maintain knowledge of tracking data quality and trajectory determination performance through normal procedures compared to the use of intermittent coverage.

An amplifier was turned off to conserve power. Consequently, less range data was received than normal, but trajectory determination accuracy in support of MCC-7 was equivalent to that achieved on other flights. Spacecraft maneuvers to establish PTC rotation caused glitches observed in Doppler tracking data. ${ }^{27}$

For the first 10 hours after the incident orbit determination was complicated by an orbit determination process restart and a lack of range measurements. An indication of the accuracy of subsequent ground tracking was the prediction of loss and acquisition of signal times when the spacecraft passed behind the Moon and later emerged. The crew reported that the actual times agreed with the predicted times supplied by Mission Control. ${ }^{21}$

\section{Shortening the Return to Earth}

After DPS-1 the spacecraft was on a return trajectory to an Indian Ocean landing. However, extending the viability of the LM power and life support systems until EI was a challenge. Shortening the return time would provide power and life support margin needed for crew survival. In addition, few recovery forces were available to ensure crew rescue after an Indian Ocean landing. A landing on the Mid-Pacific recovery line was preferred since more recovery forces were available there.

\section{A. Spacecraft Status}

After DPS-1 the projected LM power profile improved and the PGNS was kept powered until after the next burn at PC +2 hours. The PGNS would then be powered down as part of a plan to only power the life support and communications systems. By 63:32 GET, Mission Control and other personnel were working on a plan to use CM lithium hydroxide canisters in the LM to remove carbon dioxide from the cabin (Figure 2). A power amplifier was powered off to save power, but this resulted in background noise during air-to-ground communications. Mission Control recommended keeping one crew member on duty at all times while the other two rested. 


\section{B. DPS-2 Options}

The second maneuver, DPS-2, at PC +2 hours was planned to reduce the transit time. DPS-2 options are in Table 3. There was sufficient time after DPS-1 for Mission Control to assess the lifetime of LM consumables and choose a landing time and a PC +2 burn option. The option chosen had a delta-velocity of $\sim 850$ feet/second and targeted the CM for a splashdown in the mid-Pacific at $\sim 143$ hours GET. This option provided approximately 13 hours of margin in spacecraft consumables. Lower sensitivity of the $\sim 850 \mathrm{foot} / \mathrm{second}$ DPS-2 to burn attitude error and the availability of a post-burn speed-up maneuver were also factors. In the event of a partially executed DPS-2 the desired landing site could not be achieved but acceptable trajectory conditions at EI could be attained to ensure a safe entry. For a partially executed $\sim 850 \mathrm{foot} / \mathrm{second} \mathrm{PC}+2$ the appropriate entry corridor conditions at EI could have been achieved with a mid-course maneuver of 4 feet/second or less. For the $4728 \mathrm{foot} / \mathrm{second} \mathrm{PC}+2$ option a partial burn required a subsequent mid-course correction as large as $200 \mathrm{feet} / \mathrm{second}$ to achieve acceptable EI conditions. ${ }^{15,24}$

It was preferred for the $\mathrm{CM}$ to land in the water, as opposed to land. However, there was a possibility that a partial DPS-2 burn followed by a MCC-5 maneuver could result in a land landing in Australia. Mission Planning and Analysis Division (MPAD) personnel conducted a study to determine if land areas could be avoided using entry guidance ranging. The study determined that for a partial burn of between 300 and $450 \mathrm{feet} / \mathrm{second}$, land areas could not be avoided for an entry range of less than $2500 \mathrm{~nm}$, the maximum Apollo entry ranging requirement.

If DPS -2 was not executed at PC +2 hours, a PC +4 hour burn was also computed to achieve a Pacific landing at $\sim 143$ hours GET. Delta-velocity for this burn was 23.1 feet/second higher than the PC +2 burn.

Other options for targeting the DPS-2 maneuver were discussed. The first involved a SM SPS burn to achieve a landing in the Pacific at 118 hours GET. This was ruled out due to uncertainty about the integrity of the SM structure and the SPS.

A second option was to jettison the SM and perform an approximately 4,382 feet/second DPS burn to achieve a Pacific landing at $\sim 118$ hours GET. This was rejected since it required burning the DPS close to propellant depletion, the CM heat shield would be exposed to an extended period of cold soak, and any errors in LM platform alignment could result in large MCC burns later in the return trajectory. A partial DPS-2 burn could result in a MCC-5 of 175 feet/second.

The third option for DPS-2 was to skip it and later perform an MCC burn to ensure an Indian Ocean landing at $\sim 152$ hours GET. This option was rejected since the flight time would come close to exhausting LM consumables and there were fewer recovery forces available in the Indian Ocean as compared to the mid-Pacific.

A fourth option was to use abort burn data already verbally communicated to the crew at 59 hours GET. This option had been verbally communicated to the crew as a part of standard mission procedure to ensure return to Earth capability in the event of an extended loss of communication. This $\sim 1,988$ foot/second burn with the SM still attached would achieve a landing in the Atlantic Ocean at $\sim 133$ hours GET (Table 3). However, this option would burn the DPS close to propellant depletion. MCC-5 delta-velocity for a partial DPS- 2 was 25 feet/second.

\section{IMU Alignment Before DPS-2}

After DPS-1, once the PTC rotation had been established and had stabilized, LM IMU alignment options in preparation for DPS-2 were examined. One option was a platform alignment while the spacecraft was in the shadow of the Moon. Since a 1 degree attitude error at DPS-2 had a small impact on delta-velocity of later MCC burns, the required LM IMU alignment accuracy was relaxed and a Sun check of alignment was deemed adequate. ${ }^{15}$ An Earth-Sun alignment could check the current alignment or be used to re-align the IMU. The Alignment Optical Telescope (AOT, Figure 14) would be used, but the rendezvous radar antenna would have to be rotated out of the AOT field of view. The CM sextant could also be used to check the alignment.

It was decided to perform a LM platform alignment check at 74 hours GET using a Sun sighting through the AOT. Mission Control provided a Sun vector for the PGNS. The PGNS would point the AOT at the Sun as if marks were to be taken for an IMU alignment. If Sun angles indicated platform alignment was sufficient for the burn, then no re-alignment would be required. An alignment accuracy of $+/-1$ degree was determined to be acceptable for DPS-2. Otherwise, a Sun-Earth platform alignment would be performed before the spacecraft passed behind the Moon. This would be followed by a rough alignment check using an AOT star sighting while the spacecraft was in the shadow of the Moon. The rendezvous radar was rotated out of the AOT field of view and the Sun check indicated a platform alignment of 0.5 degrees. A subsequent Sun-Earth alignment was not required. ${ }^{15}$ 


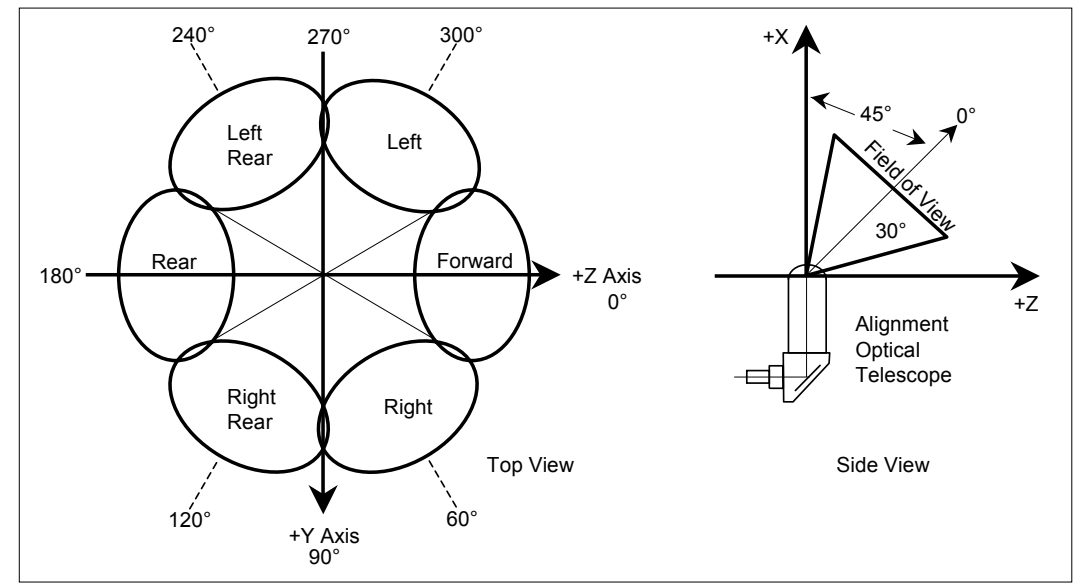

Figure 14. Lunar Module Alignment Optical Telescope (AOT) fields of view. The forward viewing position illustrated in both the top and side views was the only one used during Apollo 13. Axes are the same as those shown in Figure 1.

The crew discovered after the incident that spacecraft debris made it difficult to perform AOT star sightings to check LM IMU alignment. However, the crew later reported that while the spacecraft was in the Moon's shadow a star alignment could have been performed. ${ }^{21}$

\section{DPS-2 Execution}

Mission Control provided the crew with six DPS-2 mission rules based on tight performance limits. The DPS engine was to be shut down if any of the rules were violated since the spacecraft was already on a return to Earth trajectory. If a pre-mature shutdown occurred the DPS would be re-ignited if the shutdown was not due to violation of the six mission rules.

If DPS-2 was not executed the trajectory could remain targeted for an Indian Ocean landing at 152 hours GET. MCC-5, with a predicted delta-velocity of $\sim 4$ feet/second, would be performed at 93 hours GET. If a partial DPS-2 burn occurred (early DPS shutdown) a MCC burn would be required at PC +4 hours. If DPS- 2 was delayed, a burn with a delta-velocity 24 feet/second larger than DPS- 2 would be performed at PC +4 hours to achieve a Pacific landing at $\sim 143$ hours GET. DPS-2 maneuver ignition time was not critical. ${ }^{15}$

The PTC maneuver was stopped at 76:16 GET and a coarse AOT sighting was successfully performed on Nunki to verify that IMU platform alignment was still acceptable for DPS-2. AOT (Figure 15) and LM window (Figure 16) views for the DPS-2 burn attitude were determined by Mission Control for use by the crew as an attitude check. The Moon was on the 14 degree mark of the Landing Point Designator (LPD) in the commander's window (Figure 16). The AGS was used to cross check the PGNS. The TTCA was used to manually control roll and pitch and the ACA was used for yaw. Once the crew achieved the burn attitude by observing the FDAI error needles the PGNS automatically held the burn attitude.

After the maneuver to the burn attitude was completed a second coarse AOT star check on Nunki was performed, and platform alignment was still acceptable. This second check occurred soon after the spacecraft entered the shadow of the Moon at approximately 76:42 GET. Loss of signal due to the spacecraft passing behind the Moon lasted from about 77:09 to 77:34 GET.

LM power-up for DPS-2 began at 78:12 GET. The crew maneuvered to the burn attitude at 79:17 GET. The burn was executed automatically by the PGNS. The DPS throttle profile was 5 seconds at $12.6 \%$ thrust, 21 seconds at $40 \%$ thrust, and 235 seconds at maximum thrust. The crew was postured to provide backup commanding during the burn if it was required. Ignition of the 860.5 foot/second burn occurred at 79:27:38 GET and it was successful.

\section{E. Post DPS-2 PTC Rotation}

After PC+2 the LM was partially powered down. The PGNS and RCS remained powered to support establishment of the PTC rotation in LM yaw. A procedure was devised to maneuver to the PTC attitude with the RCS in minimum impulse to conserve propellant. A manual maneuver was performed since data from LM simulators at the Kennedy Space Center (Florida) and the Manned Spacecraft Center (Houston) indicated that a PGNS auto maneuver to the PTC attitude would require more time and propellant to dampen rotational rates. 


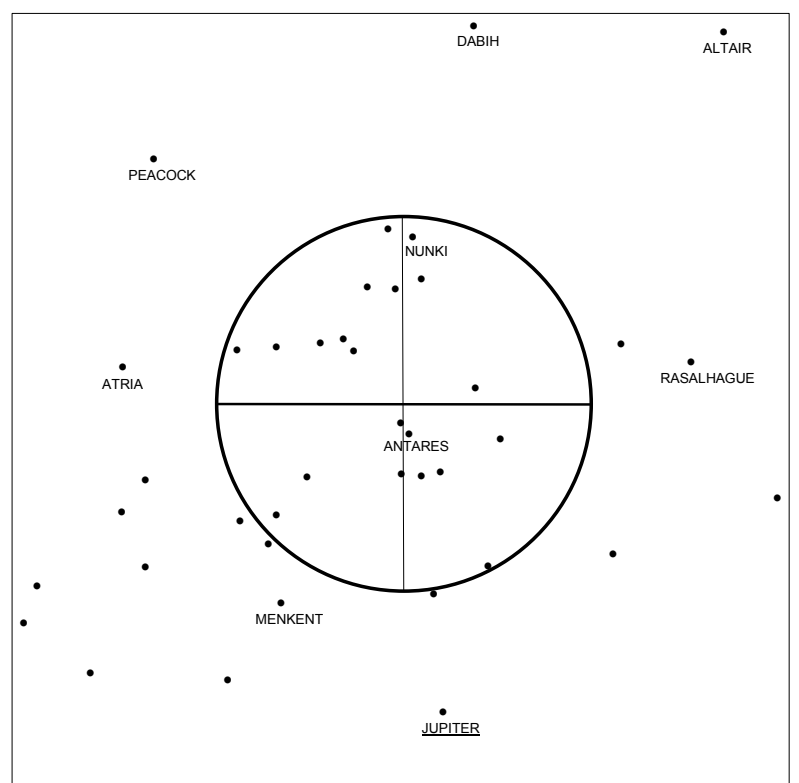

Figure 15. DPS-2 $(\mathrm{PC}+2)$ burn Alignment Optical Telescope (AOT) view. ${ }^{28}$

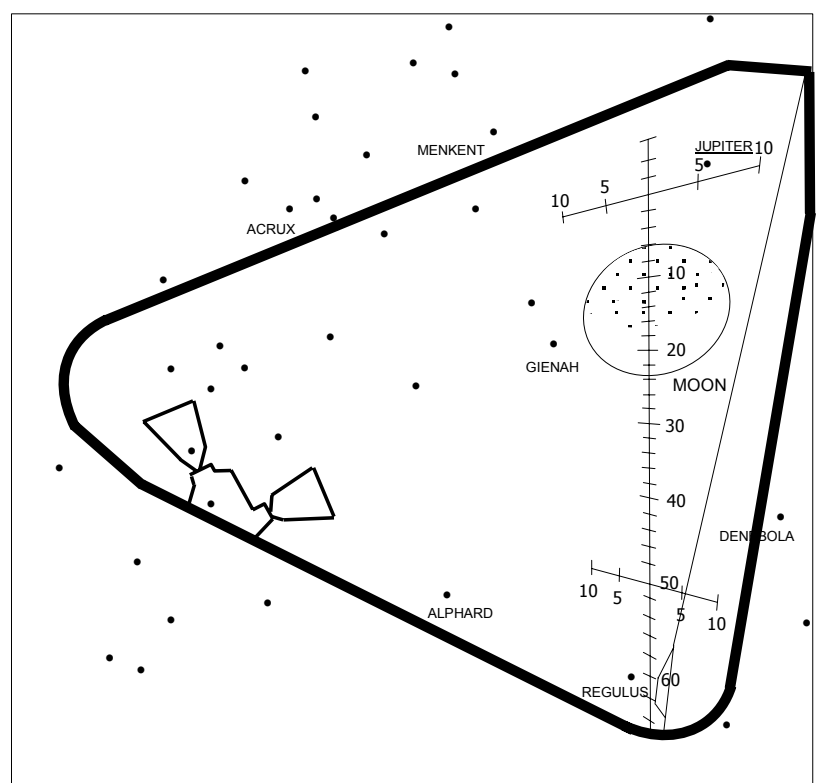

Figure 16. DPS-2 $(\mathrm{PC}+2)$ burn LM commander's window view with Landing Point Designator (LPD) scale. ${ }^{28}$

The PTC attitude was difficult to achieve due to the small moment arm in the LM pitch and roll axes. Furthermore, the large yaw angle (outer IMU gimbal) caused roll commands to cross couple into pitch. Some pieces of debris from the SM were sighted by the crew at this time. ${ }^{15}$ After the problem was recognized the crew zeroed the LM yaw angle and maneuvered to the PTC attitude in LM roll and LM pitch. Once the PTC rotation was established the LM Guidance Computer (LGC) and IMU were powered down. The IMU heater remained powered as was the RCS direct crew attitude control capability.

The PTC rotation did not remain stable. The Earth and Moon moved horizontally as viewed through the LM commander and pilot windows. The crew provided Mission Control with the angles where the Earth and Moon crossed the LPD in the commander LM window (Figure 16). This enabled Mission Control to roughly monitor spacecraft rotational dynamics even though telemetry was not available due to the LM power-down. Half-cone angles of up to 40 degrees occurred during the rotation. However, off-nominal rotation during PTC was deemed acceptable as long as it did not degrade air-to-ground communications.

\section{Mid-Course Correction Maneuvers}

Three opportunities for transearth course corrections were routinely scheduled, on Apollo 13 as for other missions, as discrete opportunities for adjusting the trajectory to achieve the desired Entry Interface conditions including the flight path angle (the angle between the direction the vehicle is traveling and the local horizontal plane). The desired value of the entry flight path angle was -6.5 degrees. The corridor of acceptable flight path angles was from -5.25 degrees to -7.4 degrees.

Processing of MSFN tracking data from two hours past pericynthion passage to after the MCC-5 burn showed a consistent trend of shallow values in the predicted flight path angle at EI. No MCC-6 was executed but it was necessary to adjust for post MCC-5 perturbations by executing MCC-7. An exact cause of the trend was not determined. However, crew reports of a constant stream of particles visible through the windows indicated a possible persistent vent. Use of the LM sublimator for thermal control during periods of LM power-up was also a possible source of propulsive venting. In addition, all attitude maneuvers were performed using the LM RCS jets. Ground personnel reasoned that one or all of these could have been responsible for the undesirable trend in predicted flight path angle at EI. ${ }^{15}$

\section{A. Possible Weather Avoidance Burn}

At approximately 90 hours GET, the weather in the recovery area was good, but there was some uncertainty about the forecast for the recovery day. A weather avoidance burn to change the landing site to avoid the forecast 
weather was considered. Weather avoidance burns were radial delta-velocity maneuvers. The PGNS would be required for the maneuver to burn attitude since the COAS in the LM commander window could not be pointed at the Earth to serve as an attitude reference as it could be for posigrade and retrograde burns (Figures 8, 17, and 18). However, sufficient maneuvering could be performed during entry by the CM PGNCS entry guidance to achieve a landing point with more favorable weather. A weather avoidance burn was not performed.

\section{B. Planning for MCC-5}

DPS-2 had been confirmed as a successful maneuver yielding an EI flight path angle of -7.11 degrees and a corresponding vacuum perigee of $11.2 \mathrm{~nm}$. This confirmation was based on the applied change in velocity as measured by the LM IMU. However, Mission Control orbit determination using MSFN data after DPS-2 indicated a vacuum perigee of $78.9 \mathrm{~nm}$, too high a value for a successful re-entry to occur. ${ }^{24}$

The first correction burn, MCC-5, was moved from 118 hours GET to 104 hours GET to permit more post MCC-5 tracking by the MSFN. Mission Control was confident in the ephemeris accuracy for both the 104 hours GET and 118 hours GET MCC-5 options. An additional consideration was the anticipated rupture of the supercritical Helium burst disk in the LM. The vent would impart a delta-velocity to the trajectory, and it was desired for the vent to occur after MCC-5, while the AGS was still powered, and while a PTC rotation was not in progress. Analysis indicated that the vent would likely occur between 105 hours and 108 hours GET. There was also a desire to minimize the length of time the AGS was powered.

After 95 hours GET, a procedure to power the CSM from the LM was read up to the crew. Mission Control wanted this procedure to be on-board in case there was a loss of communications with the LM. At 100 hours GET, the MCC- 5 burn procedure was read up to the crew by Mission Control.

\section{Maneuvers to Burn Attitude}

After the execution of DPS-1, personnel began investigating methods for attitude alignment for the $\mathrm{PC}+2$ and subsequent MCC burns in case the PGNS was not powered or unavailable. One result of this investigation was the previously mentioned use of the Moon position on the LPD scale in the commander's window to verify the PC+2 burn attitude (Figure 16). In addition, methods were identified for attitude alignment to a previously determined inertial attitude. These methods, using the Earth terminator in the COAS (Figure 8) and the Sun in the AOT (Figure 14), had originally been developed during contingency development for the Apollo 8 mission. An advantage of these procedures was that while the crew had difficulty discerning stars due to venting and debris, the Earth and Sun were easy to observe. The Apollo 13 crew stated after the mission that these procedures were easy to perform. ${ }^{21}$

To correct a shallow flight path angle at EI, a retrograde MCC burn was required. As the crew viewed the Earth through the COAS (along the LM $+\mathrm{Z}$ axis), the LM attitude would be changed so that the LM Y axis would be aligned with the Earth terminator and the horns formed by the terminator and the sunlit Earth surface were pointing in the LM $-\mathrm{X}$ axis direction (Figure 1, Figure 17). The Sun would be available in the AOT as an attitude check. An AGS body axis alignment would then be performed.

A method for both a posigrade (to correct a steep flight path angle at EI) or a radial MCC burn (to control landing longitude for weather avoidance) was to body axis align the AGS after performing the above COAS/AOT retrograde attitude procedure. An AGS maneuver to the burn attitude would then be performed.

An alternate method for a posigrade maneuver was for the terminator to be aligned with the LM Y axis and the horns of the terminator were to be directed along the LM $+\mathrm{X}$ axis (Figure 1, Figure 18). However, the Sun would not be visible in the AOT for an attitude check. ${ }^{24}$

However, use of only the Earth terminator for alignment (no Sun check in the AOT) could result in a yaw misalignment in burn attitude. Analysis indicated that the post $\mathrm{PC}+2$ burn trajectory was inclined 8 degrees to the ecliptic plane. Since the most critical direction for the burn was along the local horizontal, the LM yaw attitude error was deemed acceptable.

A computer window view program was used by Houston personnel to provide LM window and AOT views for MCC burns (this had also been done in support of DPS-2). The program created views showing what stars and planets (including the Moon and Sun) would be visible in the windows and the AOT for a particular attitude. ${ }^{28}$ 


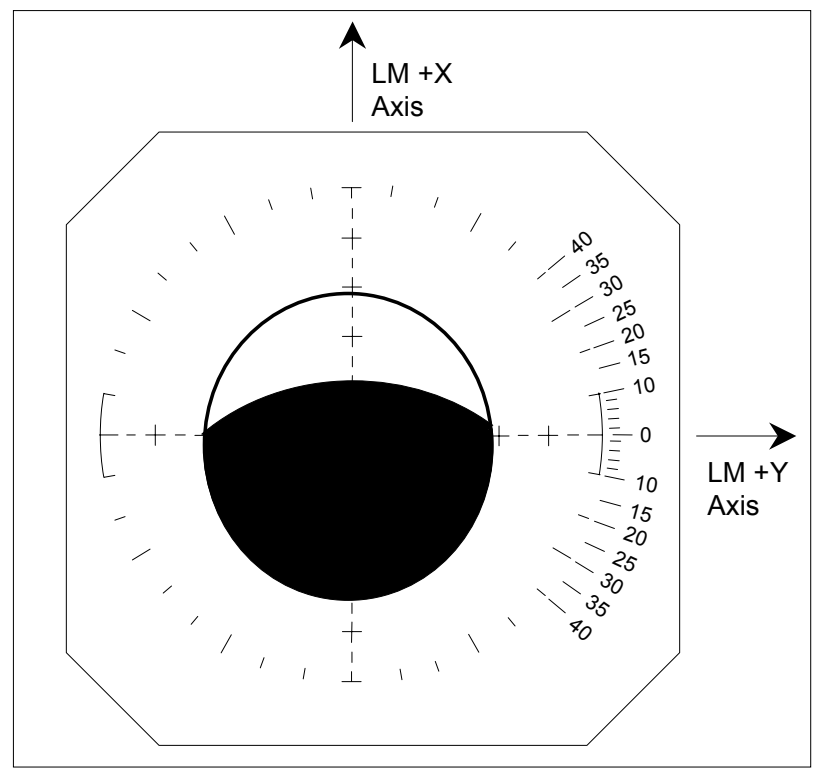

Figure 17. COAS view of Earth for a retrograde trajectory correction burn. ${ }^{15}$

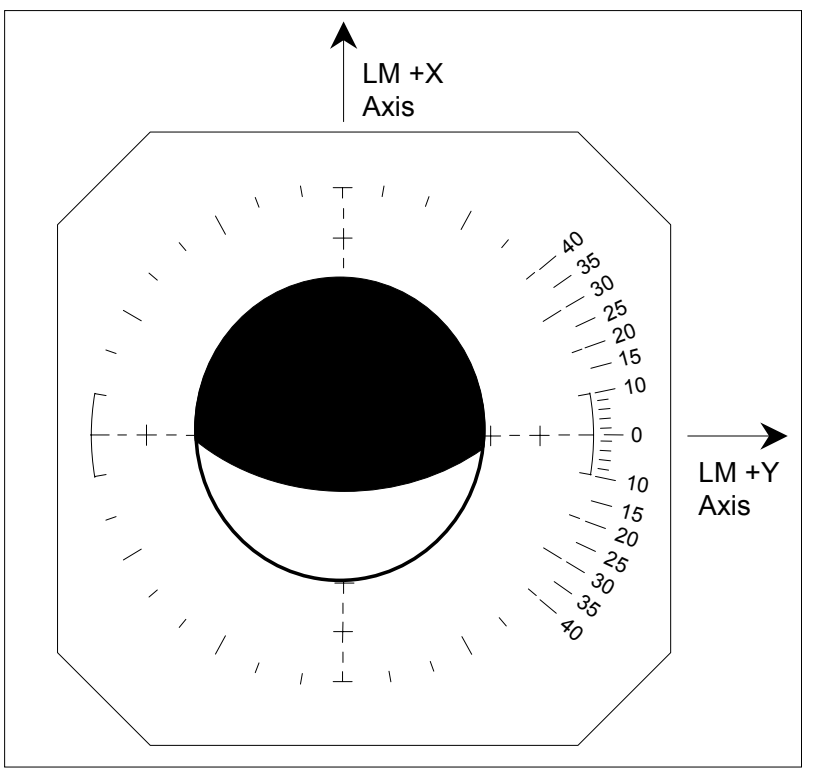

Figure 18. COAS view of Earth for a posigrade trajectory correction burn. ${ }^{15}$

\section{MCC-5 Execution}

LM power-up for MCC-5 was begun at 104:36 GET using an updated 30 minute contingency checklist. The PTC rotation was stopped and the crew powered up the AGS and ASA. The PGNS was not used for MCC-5 to save power. For MCC-5, the previously mentioned retrograde attitude procedure was used to achieve the burn attitude for AGS body axis alignment. The cusps of the Earth terminator were placed on the Y axis of the COAS (Figure 17, Figure 19). The illuminated part of the Earth was placed at the top of the reticle. Pitch attitude was achieved by placing the Sun in the upper portion of the AOT (Figure 20). This procedure aimed the LM $+\mathrm{Z}$ axis at the Earth and aligned the LM $+\mathrm{X}$ axis retrograde along the local horizontal. An AGS body axis alignment was performed, followed by transitioning the AGS to the automatic attitude hold mode. A maneuver to burn attitude was performed, followed by another body axis alignment.

MCC-5 was performed with the AGS and the DPS. Execution of MCC-5 with the LM RCS was ruled out since the RCS burn duration would exceed the LM RCS deflector plume impingement constraint of 40 seconds. The DPS would perform the burn at $12.6 \%$ thrust. While the AGS was used by the crew for burn monitoring data, attitude control and burn ignition and cut-off were controlled manually by the crew. The DPS gimbals were disabled and the crew would control roll and pitch using the TTCA. Analysis indicated low angular accelerations could be expected during the burn. The crew was to shutdown the engine manually one second early to prevent an over-burn. A -X LM RCS trim to correct an over-burn could exceed the 15 second CSM plume impingement constraint. Although an External Delta-Velocity guidance mode was available in the AGS, there was concern about AGS accelerometer performance due to the long period of low temperatures, therefore a manual burn was performed. In addition, Mission Control was confident that the burn duration predicted by ground analysis was accurate.

AGS driven FDAI pitch and roll error needles were used for attitude control cues by the crew during the burn. The commander controlled roll with his TTCA and LM pilot controlled pitch with his TTCA. Yaw was controlled by the AGS in the automatic attitude hold mode. The CM pilot called out engine on and off events and tracked time-to-go to the end of the burn. The DPS was shut down by the crew based on the burn duration supplied by Mission Control. MCC-5 was scheduled for 105:30 GET. However, the crew was ahead of the timeline and the burn time of ignition was not critical, so the burn was executed early at 105:18 GET. After the burn the crew nulled the LM $+X$ delta-velocity residual to the desired value minus the uncompensated ASA accelerometer bias observed before the burn. The burn was successful. 


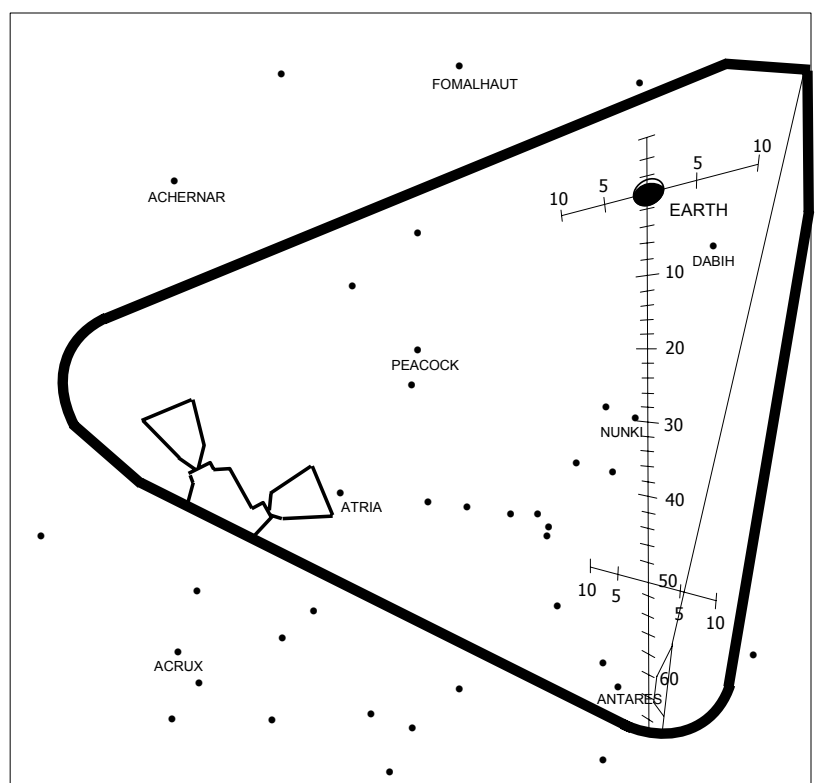

Figure 19. MCC-5 burn LM commander's window view. ${ }^{28}$

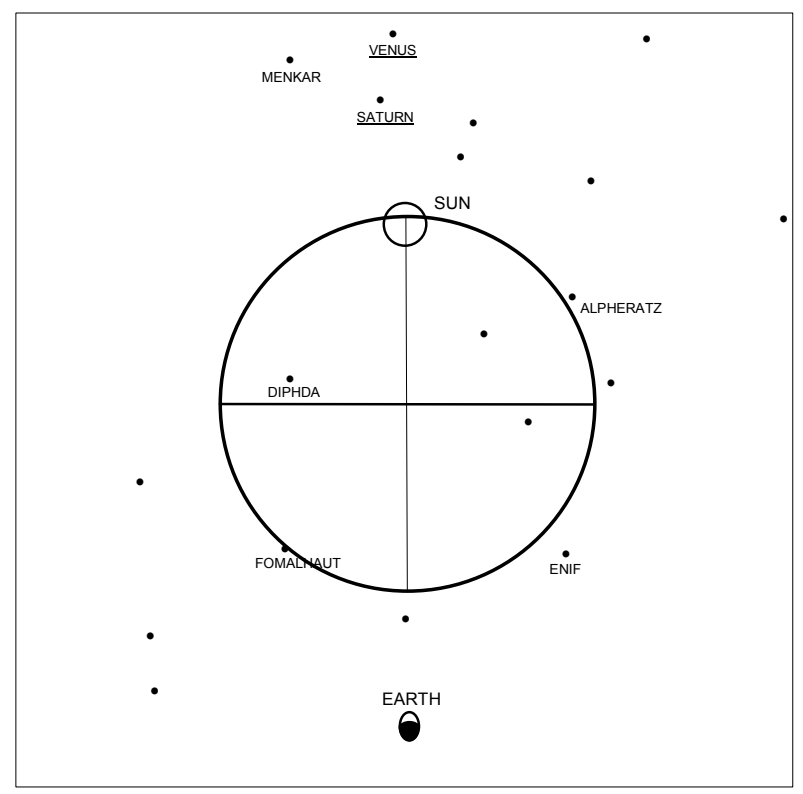

Figure 20. MCC-5 burn AOT view. ${ }^{28}$

\section{E. Post MCC-5 Activities}

After MCC-5, most LM systems were powered down. The crew maneuvered to the PTC rotation attitude in pitch and roll using the TTCA. The FDAI error needles, driven by the AGS, were used for piloting cues. Once in attitude the PTC rotation was started manually in LM yaw.

The supercritical helium burst disk ruptured at 108:54 GET and vented 27.5 pounds of helium into space. The vent stopped the 0.3 degree/second PTC rotation, started a reverse yaw rate, and imparted a small pitch rate. The crew had been told that the vent would be non-propulsive since the helium vent was designed to nullify thrust and analysis predicted that the vent would impart no more than 0.003 feet/second to the spacecraft. The rotational motion was allowed to continue since it did not negatively impact spacecraft thermal control. The roll rate increased from 18 minutes/revolution to 2 minutes/revolution. This increased antenna switching. The crew was given the option of not switching antennas and accepting data dropouts, but the crew elected to continue manual switching of antennas. The vent had little observable impact on tracking data. ${ }^{15,29}$

Due to the large amount of small debris around the LM/CSM stack from the tank incident through SM separation, the crew was not able to reliably sight stars. After the first urine dump, Mission Control stated no more would be performed for a while as the dump degraded crew visibility of stars and could perturb the return to Earth trajectory. ${ }^{1,15}$ However, the crew misinterpreted this to mean for the duration of the mission. The SM vented periodically during the mission and this also reduced star visibility. At one point after MCC-5, when there was no SM venting, the crew was able to identify some constellations while looking through the AOT.

Mission Control briefed the crew on the plan for pre-entry CM power-up at 120:22 GET. The crew chose not to wear their space suits during the entry, and Mission Control agreed with the decision. Changes to the CM and LM stowage lists in preparation for LM jettison and CM entry were verbally communicated to the crew. Later, at 130 hours GET, stowage activities resulted in a CM re-entry lift to drag ratio (L/D) of 0.29. The nominal value of L/D was 0.31 .

\section{F. MCC-6}

The MCC-6 burn had been scheduled for 118 hours GET. It was canceled since the predicted MCC-7 burn was only $\sim 3$ feet/second.

\section{G. MCC-7 Planning}

A ten hour meeting of Mission Control and other personnel was held on Wednesday, April 15, 1970, to develop an integrated crew checklist covering the eight hours before EI. Activities to be conducted during this period were the MCC-7 burn, SM separation, CM power-up, CM computer initialization, PGNCS IMU alignment, 
and LM jettison. MCC-7 was originally scheduled for EI-4 hours. However, both MCC-7 and SM separation were moved one hour earlier, to EI-5 hours and EI-4.5 hours respectively, to provide more time for the crew to execute the pre-entry timeline. This recommendation was based on input after evaluation of the checklist by astronauts.

By approximately 127 hours GET, MCC navigation solutions based on MSFN tracking indicated an EI flight path angle of -6.0 degrees. An MCC-7 delta-velocity of 2.7 feet/second was computed. It was desirable to not perform MCC-7 unless absolutely necessary to improve conditions at EI. A study was performed that determined that the acceptable range of flight path angles at EI could be increased. ${ }^{24}$ The crew reported that the CM windows were covered with condensation, and that the crew would try to remove the water before the SM separation to facilitate photography.

\section{H. MCC-7 Attitude Alignment}

At 133:19 GET the crew reported that the PTC rotation had degraded to the point that the Sun was illuminating the SPS engine bell rather than the entire spacecraft, and did not illuminate the LM cabin windows. This lowered the temperature in the LM cabin and prevented the crew from resting. Sufficient water and power margins permitted a 3 hour early LM power-up that began at 133:24 GET. The PTC rates were nulled and the AGS and PGNS were activated.

A decision was made to perform a PGNS alignment with the AOT, followed later by a reverse docked transfer alignment to the CSM PGNCS. A transfer alignment was preferred over a PGNCS alignment using the sextant since that option required the LM to maneuver to the CSM sextant sighting attitudes. The AGS was body axis aligned using crew sightings on the Earth terminator using the COAS. The LM PGNS was powered up and a coarse alignment was performed to the AGS.

A Sun/Moon sighting was then performed to refine the PGNS alignment. Acquisition of the Sun and Moon was accomplished by pitching in a plane roughly parallel to the ecliptic plane. Attitude was controlled by the LM pilot. The commander gave commands when the AOT reticle lines bisected the Sun and Moon. The crew had difficulty controlling the stack with the TTCA for alignment. The MCC-7 alignment was maintained throughout the entry preparation period.

After the alignment was complete it was transferred by the crew to the CMC. The crew maneuvered the spacecraft to the MCC-7 burn attitude so that the Sun and Earth were correctly positioned in the AOT (Figure 21) and the commander's window (Figure 22). The crew positioned the "horns" of the Earth terminator in the COAS (Figure 17). FDAI error needles (Figure 9), driven by PGNS, were to be used to trim the burn attitude, but the error needles were fully deflected due to the procedures used to bring up the PGNS. However, the computer's displayed digital attitude was in agreement with the out-the-window view and data supplied by Mission Control.

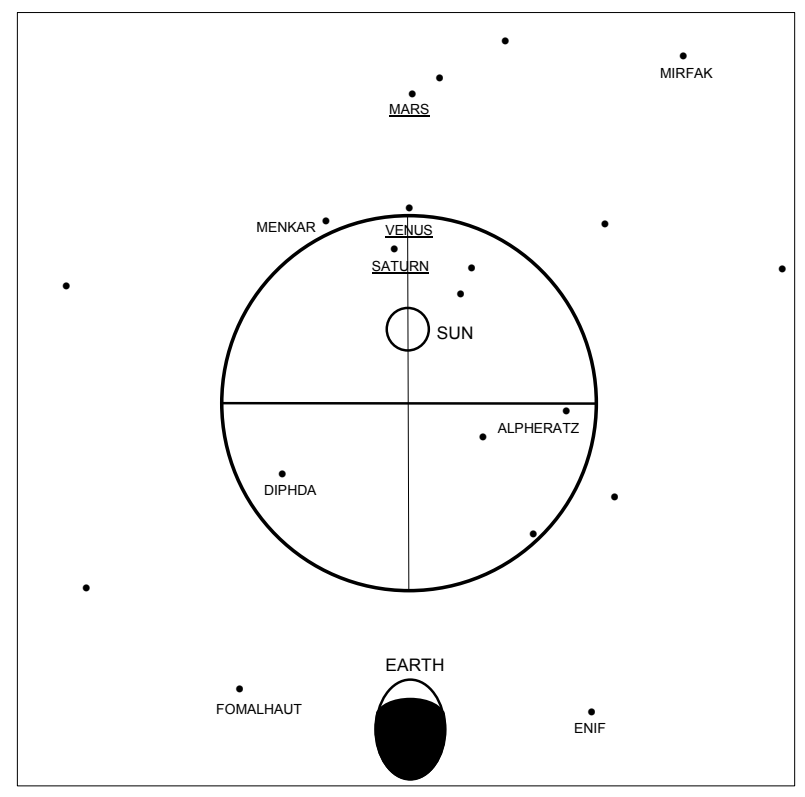

Figure 21. MCC-7 burn Alignment Optical Telescope (AOT) view. ${ }^{28}$

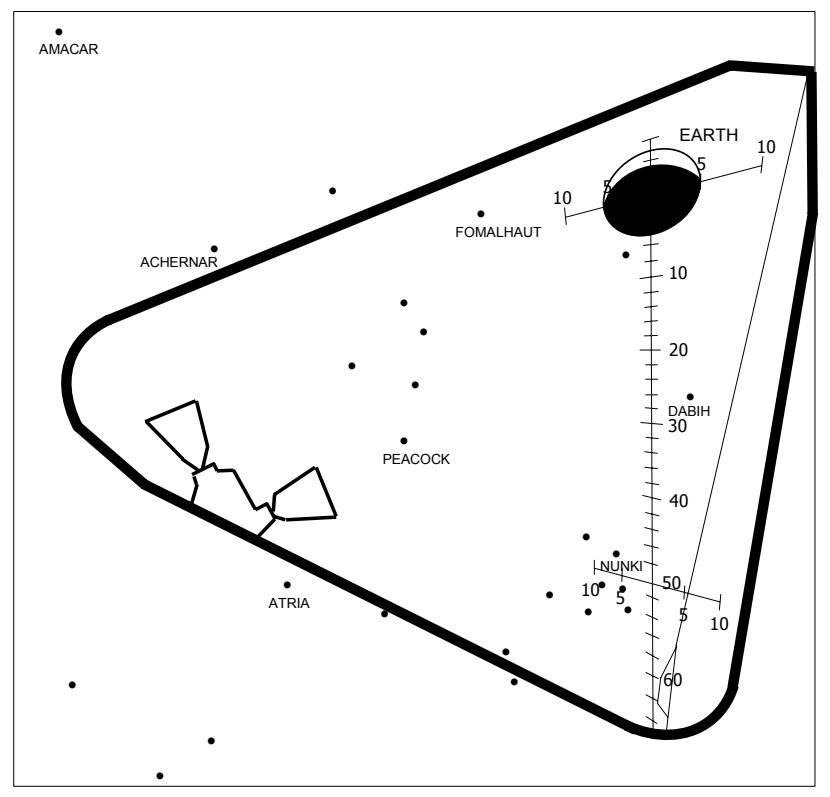

Figure 22. MCC-7 burn LM commander's window view. ${ }^{28}$ 


\section{MCC-7 Execution}

The MCC-7 checklist was prepared to support either a DPS or RCS burn. However, the predicted low deltavelocity ( $2.8 \mathrm{feet} / \mathrm{second})$ resulted in selection of RCS. The original plan had been to use the PGNS for monitoring and backup attitude control. Mission Control later decided to use the PGNS to execute the burn. However, the onboard crew procedures were for the burn to be performed with the AGS and the TTCA, with the PGNS providing data to the crew for burn monitoring. A PGNS to AGS transfer alignment was performed to ensure the AGS had an accurate alignment.

The crew manually maneuvered the spacecraft in minimum impulse mode to roughly the MCC-7 attitude, and then a PGNS auto maneuver was performed to more precisely achieve the burn attitude. The auto maneuver consumed more propellant than expected and the crew went back to the minimum impulse mode. The PGNS driven FDAI error needles did not zero at the burn attitude leading to some concern about the validity of the PGNS. Due to the full deflection of the FDAI error needles and higher than expected RCS propellant consumption while under PGNS control, Mission Control changed the plan a second time and elected to use the AGS for MCC-7 instead of the PGNS. With AGS selected the crew maneuvered to the burn attitude in pulse mode using the TTCA.

MCC-7 was performed at EI-5 hours (137:39 GET). The same manual piloting technique used for MCC-5 was used for control during MCC-7. This was manual crew pitch and roll control with the TTCA and automatic yaw control by the AGS. MCC-7 was performed with LM RCS using the $+\mathrm{X}$ translation push button. It steepened the flight path angle at EI to -6.49 degrees. After MCC-7, the crew maneuvered the spacecraft to the SM separation attitude. The CM re-entry RCS system was activated and a firing test of the thrusters was successful.

\section{SM and LM Separation}

Before re-entry the SM and LM had to be separated from the CM. A contingency procedure for LM separation at EI-1 hour had been developed earlier in the Apollo Program. The procedure optimized separation distances and directions while maintaining nominal EI trajectory conditions for the CM. ${ }^{15}$ This procedure was modified for use during Apollo 13. ${ }^{24}$ The SM was jettisoned first as the SM systems were not required for crew survival or to prepare the CM for re-entry. SM separation planning objectives included post separation photography that could be critical to the post-flight investigation. Mitigation of re-contact risk during the remainder of the flight was a concern.

After SM separation, the LM continued to provide life support, communications, power, and GNC functionality. LM power was necessary to accomplish CM systems power-up for re-entry. LM separation planning included re-contact risk mitigation during dual vehicle entry and use of a non-RCS method to achieve separation. The crew timeline during the separations was critical as many activities had to be completed prior to EI (Figure 23).

\section{A. SM Separation}

Studies were conducted to create post SM separation attitude timelines that permitted photography of the damaged SM from the LM/CM. Photographs of the SM would aid the post-flight investigation of the incident. The objective was to minimize required attitude maneuvers while providing the lighting conditions appropriate for photography. Studies included examining gimbal angles to ensure gimbal lock could be avoided during separation and SM photography.

Separation of the CM and SM was normally performed approximately 15 minutes before EI (400,000 feet). In a nominal mission the SM separation was performed posigrade (19 degrees above the local horizontal) and out-ofplane (45 degrees) and the SM RCS thrusters were fired after separation to maximize the separation distance during re-entry. $*$ However, the loss of SM power prevented the use of the SM RCS system for separation. Apollo 13 separation procedures were also designed so the LM power and RCS propellant would be used and the CM battery power and RCS propellant would be conserved for re-entry.

\footnotetext{
For Apollo missions through 12 the SM +roll RCS jets were fired for 5.5 seconds and the $-\mathrm{X}$ jets were fired to propellant depletion or loss of SM power to maximize the separation distance between the CM and SM. However, on Apollo 11 tip-off moments caused SM propellant slosh, changed the rotational dynamics, and introduced retrograde translational motion. The Apollo 11 crew observed the SM tumbling as it passed them about 5 minutes after separation and the $-X$ jets were still firing. Photographic data of the SM and CM entry indicated that the SM did not skip out of the atmosphere into a high apogee orbit as expected but disintegrated near the CM. In November of 1969, in preparation for Apollo 13, the SM Jettison Controller was changed to fire the +roll jets for 2 seconds and the $-\mathrm{X}$ jets for 25 seconds. However, due to the loss of SM power during Apollo 13 the new procedure was not executed until Apollo 14. ${ }^{30}$
} 


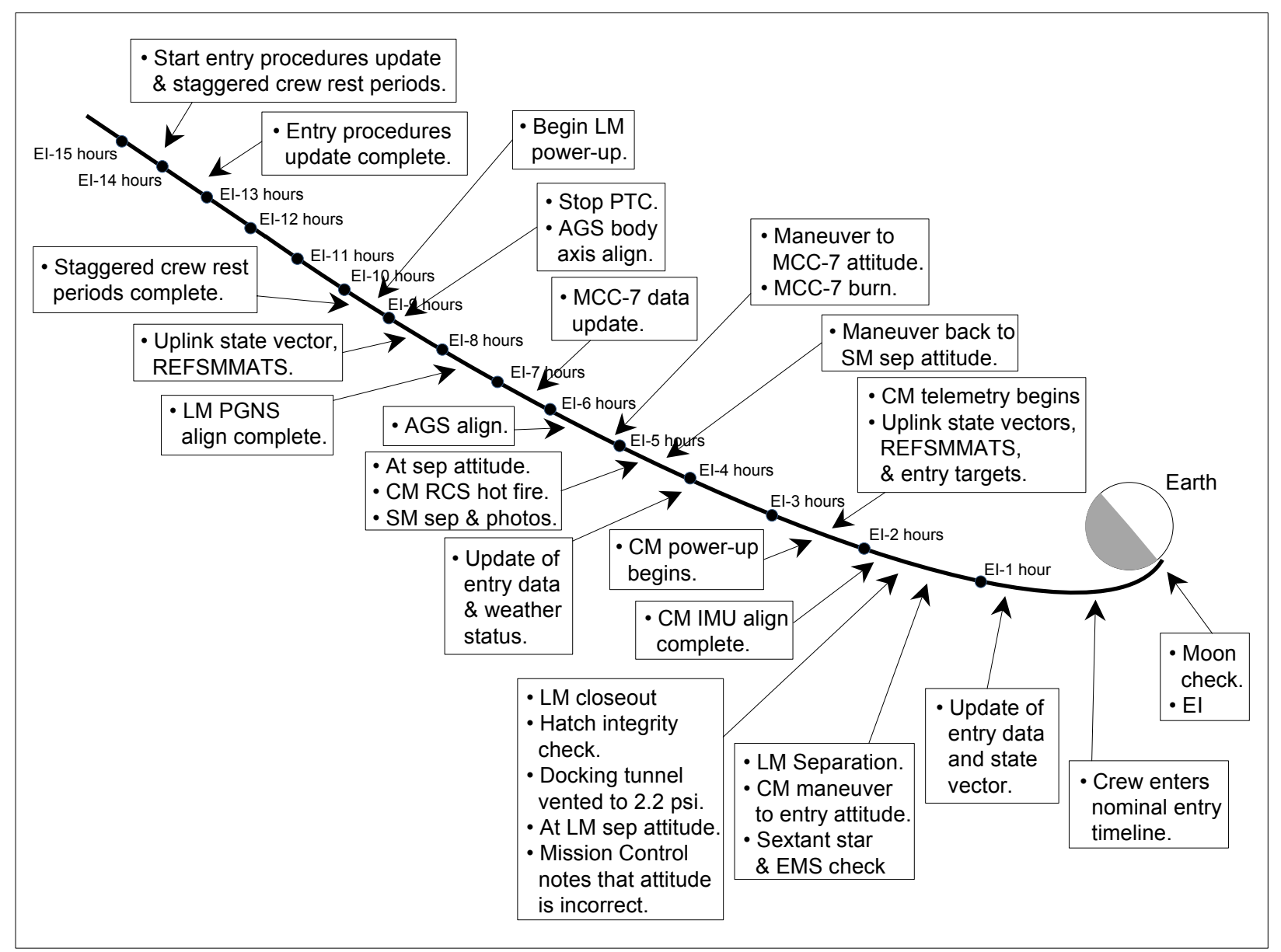

Figure 23. Pre-Entry Interface (EI) key events. ${ }^{17}$

For Apollo 13, SM separation was changed to an in-plane radial separation at EI-4.5 hours that placed the SM well behind the CM when the CM reached EI. The in-plane separation at EI-4.5 hours reduced the risk of undesirable re-contact before and during re-entry, and provided more time for CM/LM separation and CM re-entry preparation (Figure 24). Re-contact risk for the EI-15 minute out-of-plane separation on nominal missions was low under nominal separation conditions.

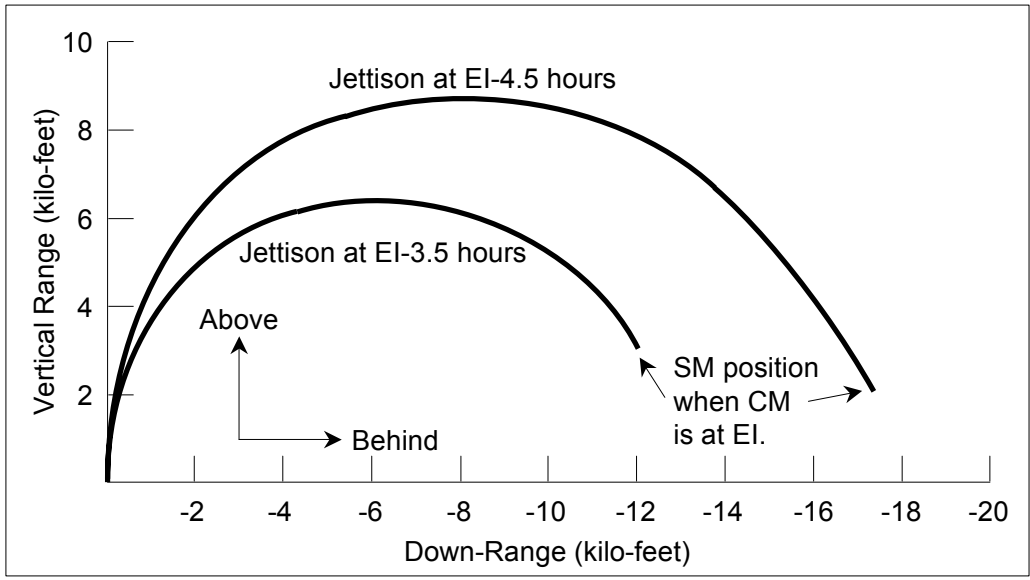

Figure 24. Mission planning plot of Service Module (SM) relative motion after separation from the Lunar Module/Command Module (LM/CM) stack for separation times of EI-3.5 and EI-4.5 hours. ${ }^{24}$ 


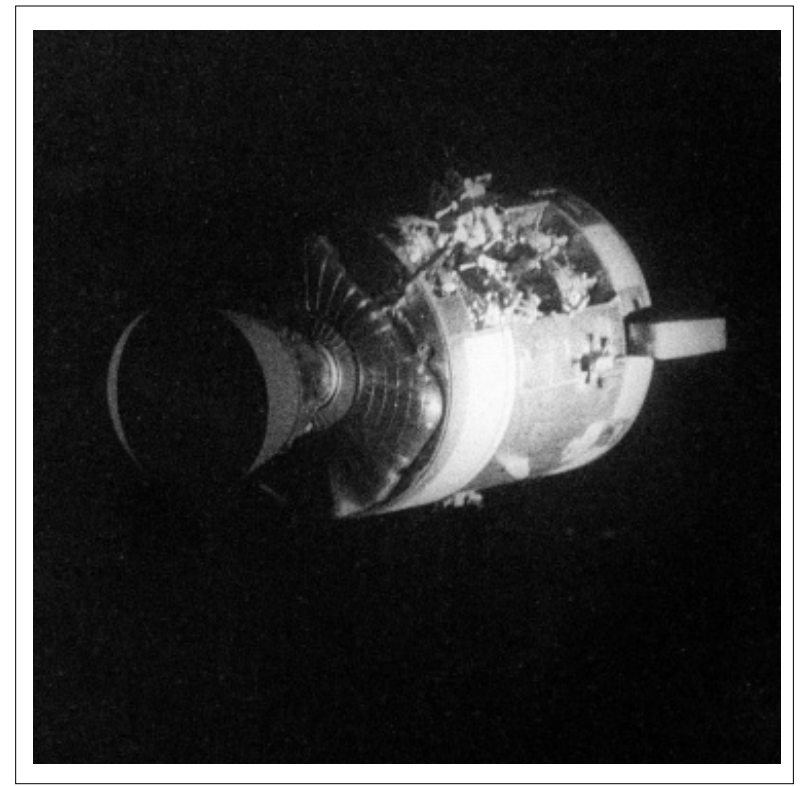

Figure 25. Service Module photographed after separation from the Lunar Module and Command Module.

The crew maneuvered to the SM jettison attitude immediately following MCC-7 using the AGS pulse mode and the TTCA. After the jettison attitude was achieved attitude control was maintained using the PGNS in minimum impulse. SM separation occurred at EI-4.75 hours with the crew using the LM RCS to perform a pushpull separation maneuver. The intent was to impart a zero net delta-velocity to the $\mathrm{LM} / \mathrm{CM}$. The initial SM jettison delta-velocity of 0.5 feet/second along the $\mathrm{LM}+\mathrm{X}$ body axis was commanded using the $+\mathrm{X}$ translation push button in the LM, after which the CM pilot in the CM jettisoned the SM. The subsequent 0.5 feet/second along the LM $-\mathrm{X}$ body axis was commanded with the TTCA in the LM. The separation was successful, but it was later estimated that $\sim 1$ foot/second was imparted to the LM/CM. ${ }^{15}$

LM active attitude control after SM jettison was performed with the Attitude Controller Assembly (ACA) rather than the Thrust/Translation Controller Assembly (TTCA). SM jettison changed the spacecraft mass properties such that the ACA commanded LM RCS jet firings could provide sufficient attitude control authority in roll and pitch. The ACA was normally used for manual attitude control during LM only flight.

The crew had been told that CM window \#5 would provide the best view for SM photography after separation. The LM pitched down during separation, and as a result, the SM was not visible through CM window \#5. The crew pitched the vehicle up to see the SM through LM commander's overhead docking window. Manual attitude control of a LM/CM stack without a SM had not been practiced by the crew during training, nor had this spacecraft configuration ever been flown.

Since no photographs could be taken through CM window \#5, the CM pilot transferred to the LM to help with SM photography through the LM windows. The spacecraft was maneuvered so the SM was visible through the right hand LM pilot front window (Figure 25).

\section{B. CM IMU Alignment}

After the SM photo session was complete the spacecraft was maneuvered back to the SM jettison attitude. LM umbilical power was removed from the CM at 140:10 GET (EI-2.5 hours) and the CM power-up was begun. On a normal mission the CM batteries were brought on-line 30 minutes before EI.

The SM separation attitude was used during the alignment instead of a Moon sighting attitude as it was anticipated that stars might be visible to the crew after SM separation. The crew attempted to perform a CM IMU alignment with the sextant. Light reflecting from the LM sublimator and a LM RCS quad prevented star identification using the CM scanning telescope. Maneuvering the stack by 20 degrees in an attempt to reduce the reflections did not improve star visibility. Particles originating from the CM/SM umbilical area also made star identification difficult. 
A reverse docked coarse alignment of the CM platform to the LM platform was to be performed with the LM holding the spacecraft at the SM separation attitude. Mission Control was to compute and verbally communicate to the crew corresponding CM IMU gimbal angles so that the CM IMU coarse alignment could be performed. While the reversed docked coarse alignment would have been sufficient for re-entry, a star alignment was desired to ensure platform alignment accuracy. This coarse alignment was intended to permit the crew to acquire the stars Vega and Altair so that sextant marks could be taken. ${ }^{15,23,29}$

If the command module pilot could not identify stars after the coarse align, Mission Control would have provided FDAI angles to the commander so that the LM could be maneuvered to Moon and Sun sighting attitudes. The command module pilot would then have performed a Sun-Moon alignment using the CM optics.

Mission Control verbally communicated CM gimbal angles to the command module pilot. Both the CM IMU coarse alignment and the sextant alignment were successfully completed by 140:55 GET and a Sun-Moon alignment was not required.

Poor communications, caused by spacecraft attitude, complicated execution of the pre-entry timeline and reception of data needed by the crew. The quality of voice and high-bit-rate telemetry communications was poor at times. High-bit-rate communications could not be maintained and the upload from Mission Control of CMC parameters for re-entry was performed at the low bit rate. This activity took longer than normal. Required uplinks were delayed until 140:40 GET due to difficulty maintaining lock on the spacecraft. The impact of spacecraft attitude on communications quality had not been foreseen by the crew or Mission Control. ${ }^{25}$

\section{LM Separation}

After CM IMU alignment was complete (140:55 GET) the spacecraft was maneuvered to the LM jettison attitude using the LM RCS. Once the maneuver was complete at 141:02 GET the spacecraft was placed in an AGS attitude hold with wide attitude error dead bands. The LM was maneuvered to an incorrect roll (LM body frame) attitude that placed the CM IMU platform near gimbal lock. The desired LM roll was 135 degrees but the spacecraft was maneuvered to 235 degrees LM roll. While the LM $-\mathrm{X}$ axis had been correctly aligned along the positive radius vector during the maneuver, the vehicle was yawed (CM body frame) 45 degrees on the north side of the CM entry ground track rather than 45 degrees on the south side (Figures 26, 27, and 28).

By the time Mission Control had recognized the attitude error the CM and LM hatches were being installed by the crew. The minimum LM/CM separation was predicted to be 4,000 feet at EI. The initial CM roll angle after EI would steer the CM to the north, but subsequent modulation of the lift vector would move it away from the LM orbital plane. The in-plane separation of the vehicles was judged to be adequate for a nominal entry. The separation was not optimum if the crew flew a roll right (CM body frame) constant $4 \mathrm{~g}$ entry due to PGNCS and EMS failures, but the separation was judged to be adequate. Due to these factors and the time-critical nature of the pre-entry timeline, Mission Control chose not to correct the spacecraft attitude before LM separation. ${ }^{15}$

The maneuver to the LM separation attitude was complicated by efforts to avoid CM platform gimbal lock. This required close coordination between the commander in the LM and the CM pilot in the CSM. The maneuver consumed a considerable amount of propellant. Had a gimbal lock occurred, a recovery procedure would have been executed to re-establish platform alignment before entry. Recovering from gimbal lock would have complicated the remaining part of the pre-EI timeline. ${ }^{25}$

The docking probe and drogue hardware, along with many other items, were left in the LM as a part of the stowage plan to achieve the desired CM L/D for re-entry. Before leaving the LM the crew placed the spacecraft in an AGS controlled attitude hold with wide attitude error deadbands. ${ }^{29}$ After the hatches were in place Mission Control closely monitored the CM IMU gimbal angles. If maintenance of the attitude hold by the LM AGS drove the CM IMU close to gimbal lock the crew would have performed the separation early. LM attitude control between hatch closure and separation was nominal and the CM IMU gimbal lock did not occur.

The separation used delta-velocity, imparted from air venting, from the docking tunnel at separation. The CM RCS could not be used since CM RCS propellant was required for re-entry. Before undocking, the tunnel pressure was reduced to 2.2 psi to achieve the desired delta-velocity of $\sim 2$ feet/second. Apollo 10 (May 1969) LM jettison data was used to determine the appropriate docking tunnel pressure differential to achieve the desired deltavelocity. $\S$

$\S$ During Apollo 10 the crew could not vent the docking tunnel as required before both undockings. Post flight investigation revealed that the vent line was terminated with a plug rather than the required fitting with holes in it. The pre-flight end-to-end docking tunnel vent test had been waived for Apollo 10. For Apollo 11 and subsequent flights the pre-flight vent test was performed. 


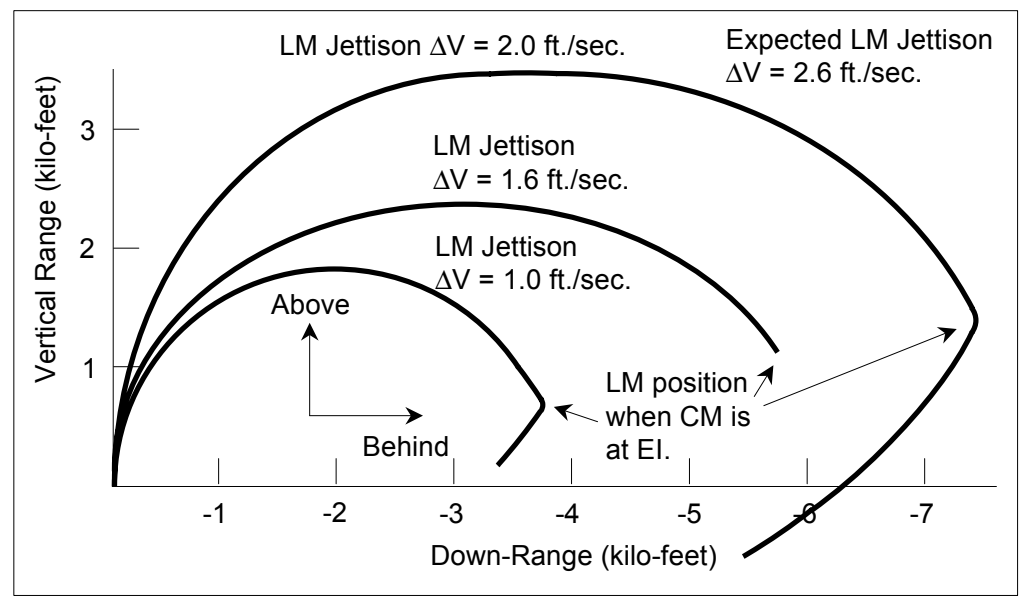

Figure 26. Mission planning plot of Lunar Module (LM) altitude versus down-range relative motion after separation from the Command Module (CM). ${ }^{24}$

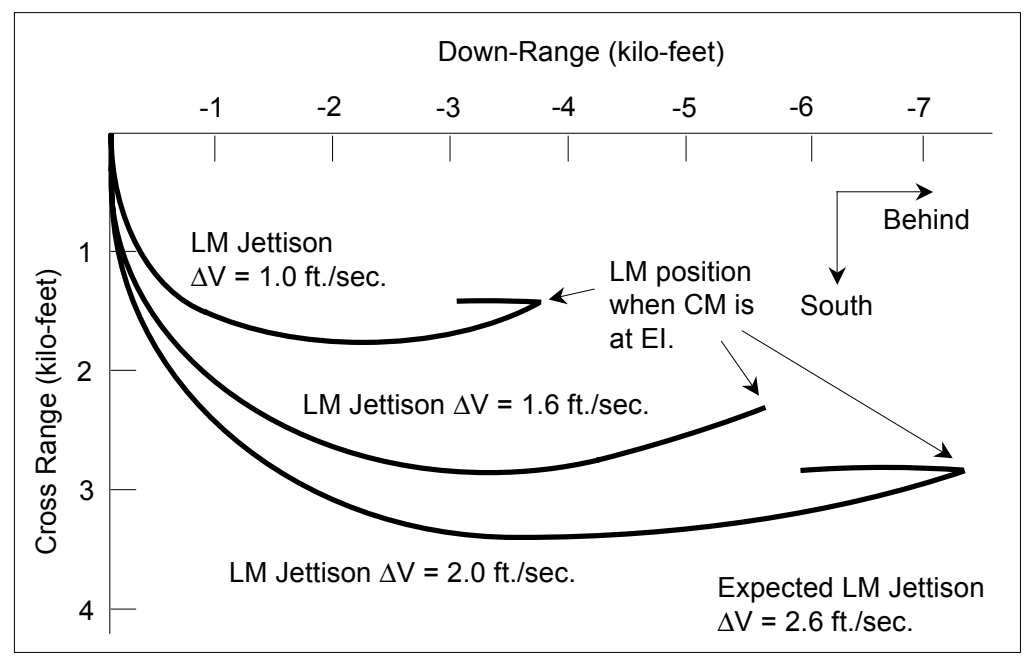

Figure 27. Mission planning plot of Lunar Module (LM) cross-range versus down-range relative motion after separation from the Command Module (CM). The actual cross-range relative motion was on the north side of the CM trajectory. ${ }^{24}$

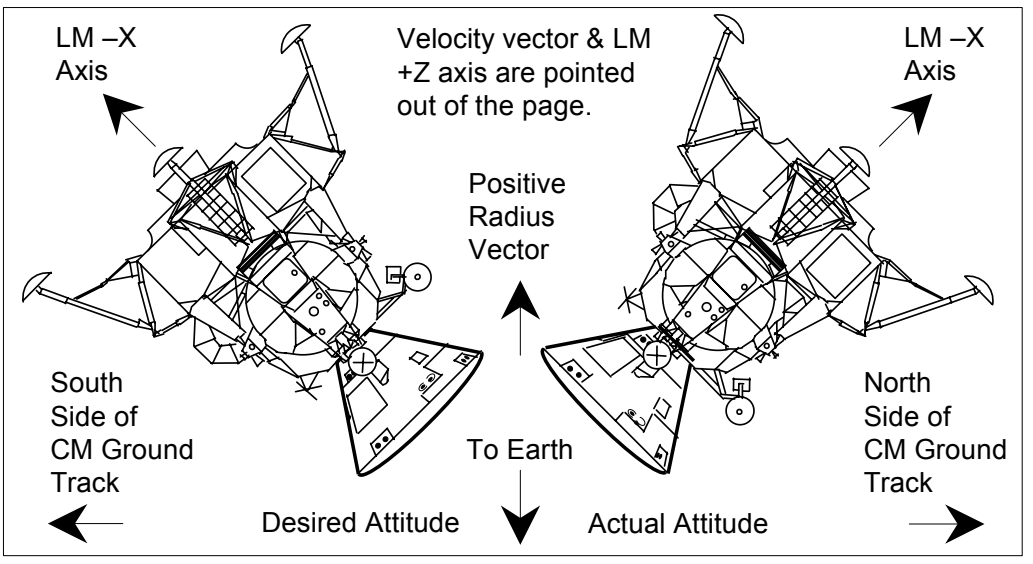

Figure 28. Desired and actual Lunar Module separation attitudes.

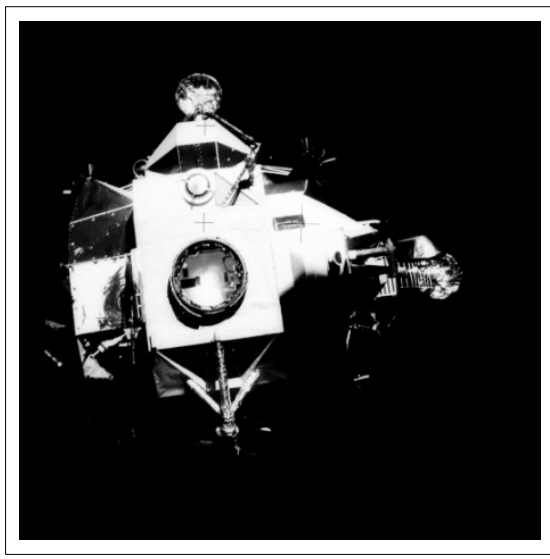

Figure 29. Lunar Module photographed after separation from the Command Module. 
The LM was jettisoned 70 minutes before EI, 10 minutes earlier than planned, at 141:30 GET (Figure 29). Sensed velocity at LM jettison was -0.65 feet/second along the LM X and -0.02 feet/second along the LM Y axis. The separation was stable and the LM continued to be stable within the AGS 5 degree attitude error deadband until LM loss-of-signal at 142:38 GET.

\section{Ground Preparations for Entry and Landing}

In addition to the development of $\mathrm{CM}$ power-up procedures a significant amount of analysis was performed to ensure that the crew could perform a safe entry and landing. ${ }^{24}$ The use of four Mission Control teams allowed the entry and landing team (the White Team) to withdraw from the shift rotation and spend two days developing a new entry timeline and procedures in conjunction with MPAD, and other NASA and contractor personnel. The White Team later supported the pre-entry and entry phase of the mission in Mission Control. ${ }^{15}$

\section{A. IMU Alignment and Performance}

Normally a pre-EI check of IMU alignment was performed by observing the Earth horizon through the center hatch window. A scale along the edge of the window enabled the crew to check attitude of the CM with respect to the horizon. However, analysis indicated that the Earth horizon was dark until just before EI. The Apollo 10 and 12 crews had observed the Moon above the Earth horizon before EI. ${ }^{21,31}$ Apollo 13 analysis also indicated that the Moon would be visible just above the horizon before EI. As a result the pre-EI horizon check was replaced with a moonset check. The crew was provided with an inertial attitude that placed the almost full moon in the CM left front window at the 36 degree mark (Figure 30). This attitude was to be maintained until the Moon set at EI-2.5 minutes. It also minimized CM RCS propellant needed to maneuver to the entry attitude.

Once the horizon became visible the IMU alignment check was performed. If the IMU passed the check, the crew would change the $\mathrm{CM}$ pitch attitude to achieve the re-entry trim attitude. If the horizon check indicated an IMU misalignment the crew would track the horizon through the window until the $0.05 \mathrm{~g}$ deceleration point was reached and closed loop entry guidance was initiated.

Analysis was performed to determine if the cold environment of the $\mathrm{CM}$ could negatively impact PGNCS performance during entry. A crack in an IMU accelerometer bellows caused by the low temperatures could cause an accelerometer bias. This bias could in turn result in an entry target miss distance of approximately $30 \mathrm{~nm}$. However, premission simulations indicated that an accelerometer bias and target miss at this level would not complicate crew monitoring of the trajectory during re-entry. In spite of the extended period of low temperature in the CM, Mission Control judged the PGNCS "go" for entry.

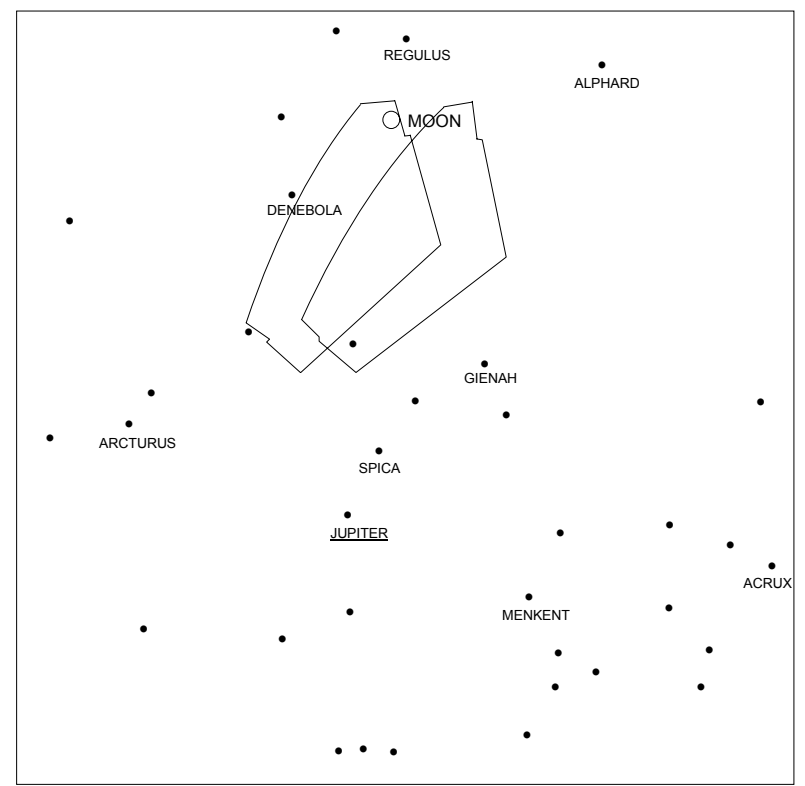

Figure 30. Pre-Entry Interface (EI) Command Module left front window view of Moon. ${ }^{28}$

\section{B. Entry Guidance}

In the event of both PGNCS and EMS failures, a constant $4 \mathrm{~g}$ entry could be flown using the secondary g-meter and the roll attitude indicator display. A new landing point for the constant $4 \mathrm{~g}$ entry procedure was determined.

The mission abort resulted in an L/D ratio that was slightly lower than nominal. The actual L/D value was outside the update limits for several entry guidance parameters that were determined pre-mission. Due to the complex crew timeline before EI, it was desirable to avoid having the crew update the entry guidance parameters in the CMC. A study determined that for an entry range of approximately $1250 \mathrm{~nm}$ the pre-mission parameter values were acceptable. Therefore, an update of the entry guidance parameters was not required. 
The mission abort also changed the orbital inclination of the entry trajectory from the nominal 40 degrees to 30 degrees. This trajectory difference changed pre-entry parameters that were displayed to the crew. Analysis was performed to determine changes in displayed parameters resulting from the inclination difference. The analysis was later used to verify numbers seen by the crew before entry.

\section{Debris Impact Analysis}

Orbital debris and re-entry footprint analysis was performed for nominal entry for each Apollo mission for the SM and the S-IVB Saturn Launch Adapter panels. This data was used to compute land impact and casualty probabilities. It was also supplied to the Federal Aviation Administration to request air corridor reservations. However, entry dispersion analysis had not been performed for a re-entering LM. Computation of LM entry dispersion ellipses required considerable effort.

The capability existed to compute the impact point of the ALSEP Graphite LM Fuel Cask (GLFC). The GLFC contained radioactive fuel for the SNAP-27 radioisotope thermal generator. However, impact dispersion ellipses had never been calculated for a re-entering GLFC. This was done as part of the entry preparation.

Dispersion analysis was performed to ensure that the CM and debris from the SM and LM avoided land and populated areas. One aspect of the dispersion studies included variations in SM and LM separation delta-velocity. Due to the potential safety hazard, these issues received attention from NASA Headquarters. Analysis indicated that the re-entering vehicles posed no hazard to land or populated areas. Furthermore, dispersion studies indicated that the GLFC would impact in deep water.

The 10 minute early LM jettison, the $\sim 90$ degree LM jettison yaw error (CM body frame), and trajectory changes moved the impact predictions approximately $60 \mathrm{~nm}$. However, the original dispersion analysis was judged to still be valid. ${ }^{24}$

\section{Entry and Landing}

After separation, the crew maneuvered away from the near-gimbal lock attitude to the entry attitude. Entry attitude accuracy and IMU platform alignment were confirmed by a sextant star check. Tracking data showed a slight change in the EI flight path angle to -6.2 degrees. However, this was within expectations and did not require a change to the normal heads to Earth orientation of the $\mathrm{CM}$ at the start of re-entry to re-orient the lift vector.

The pre-entry check and initialization of the EMS were normal. The Moon set at the predicted time (EI-2.5 minutes) and the location of the Moon in the left front window (Figure 30) indicated a good IMU alignment. ${ }^{21}$ The $\mathrm{CM}$ was then maneuvered to the EI attitude.

Although tropical storm Helen in the mid-Pacific caused some concern early in the mission it had dissipated by the landing day. The USS Iwo Jima covered the PGNCS and EMS landing points. The naval research ship USS Granville S. Hall covered the constant $4 \mathrm{~g}$ entry target point.

The crew entered the nominal entry checklist 20 minutes before EI. GNC procedures for entry were the same as for a nominal lunar mission. However, the EMS was initiated manually when the $0.05 \mathrm{~g}$ light remained off three seconds after the actual $0.05 \mathrm{~g}$ deceleration time. In addition, the EMS trace of load factor versus velocity was unexpectedly narrow and required concentration to read. Entry guidance and flight control performance was normal. The first deceleration peak reached approximately $5 \mathrm{~g}$.

The spacecraft splashed down into the Pacific Ocean on Friday, April 17, 1970 at 12:07:41 p.m. Central Standard Time (CST) after a mission duration of $142 \mathrm{hrs,} 54$ minutes, and 41 seconds. The splashdown point was $21^{\circ} 38^{\prime}$ south latitude, $165^{\circ} 22^{\prime}$ west longitude, and southeast of American Samoa. Splashdown was about $1 \mathrm{~nm}$ from the targeted point and $3.5 \mathrm{~nm}$ from the recovery ship USS Iwo Jima. The commander later reported that the landing decelerations were mild in comparison to his previous flight on Apollo 8. ${ }^{21}$ The CM remained in the stable upright attitude after parachute release. Crew egress from the CM occurred at 12:35 pm CST and the crew was onboard the USS Iwo Jima by 12:53 pm CST (Figure 31). ${ }^{15}$

Due to the limited power available, the data storage equipment recorder was not run during entry. No entry data were available for post-flight analysis. The CM IMU was not heated for approximately 80 hours during the mission. The accurate landing indicated that IMU alignment and performance was nominal in spite of the extended power-down. ${ }^{23}$

Parts of the LM that survived atmospheric entry, including the SNAP-27 radioisotope electric power generator, that had been planned to power the ALSEP apparatus on the lunar surface and contained $8.6 \mathrm{lb}$ of plutonium, fell into the Pacific Ocean northeast of New Zealand. 


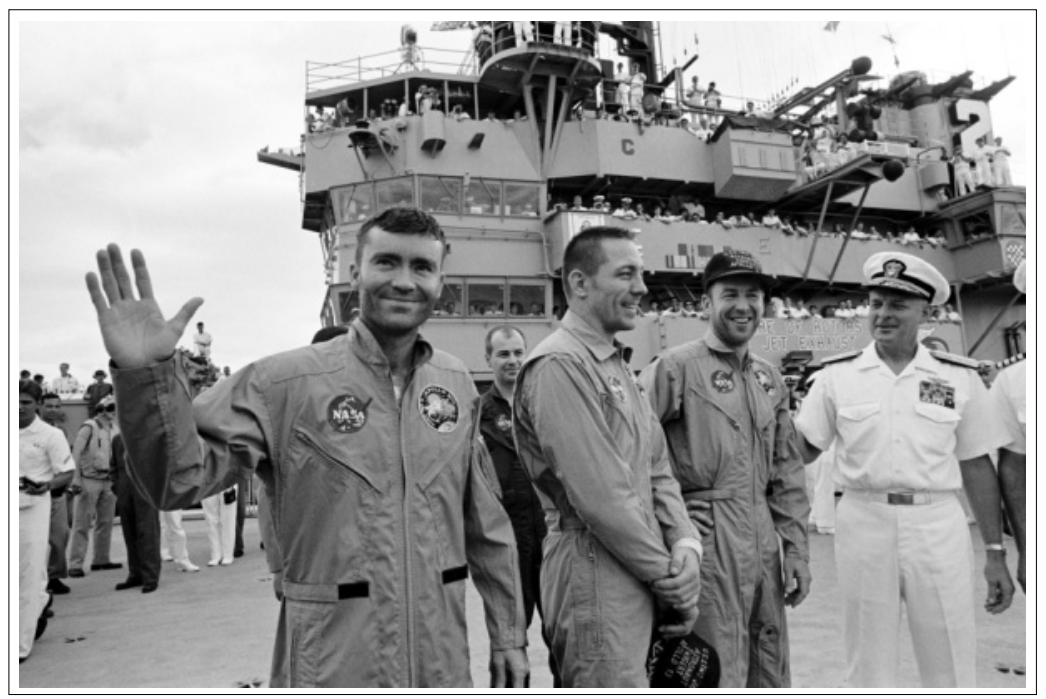

Figure 31. Haise, Swigert, and Lovell aboard the USS Iwo Jima.

\section{Observations on Apollo 13 GNC Challenges}

Personnel who participate in spacecraft development today may never have performed flight operations to recover from a spacecraft emergency. Simulations can provide flight control teams with some experience after a vehicle has been designed and built. Studying past spacecraft emergencies may be of benefit to development and flight operations personnel when defining and designing vehicle systems and operating procedures. ${ }^{32,33}$ Flexibility in both on-board systems and the ground support organizations is required. Previous spacecraft emergencies can provide lessons and observations that could be useful for other flight programs.

Responses to failures that occur during time critical powered ascent or entry (phases also known as "high speed flight") do not permit real-time development of contingency procedures. Responses during high speed flight must be scripted. The Challenger and Columbia accidents occurred during high speed flight. There was little or no action that could have been taken to save the Challenger crew if the Solid Rocket Booster O-ring burn-through had been recognized after lift-off, or the compromised Columbia thermal protection system had been recognized after the de-orbit burn. However, had the compromised thermal protection system been recognized while Columbia was on-orbit, it is possible that action could have been taken to conserve Columbia consumables long enough for a rescue orbiter to be launched. ${ }^{34,35}$

\section{A. Ground Support is Essential}

Recovery of the Apollo 13 crew required a considerable amount of systems insight and analysis not directly available to the crew on-board the spacecraft. ${ }^{\pi}$ A wide variety of ground personnel and supporting organizations throughout the United States played a critical role in the safe return of the crew. Considerable effort by ground personnel was required to resolve the S-IVB/LM S-Band frequency conflict, compute LM impact dispersion ellipses, develop new burn procedures, develop SM separation procedures to facilitate crew photography, ensure the safety of dual vehicle (LM and CM) entry, develop CM power-up procedures, devise a method for scrubbing $\mathrm{CO}_{2}$ from the $\mathrm{LM}$ using $\mathrm{CM} \mathrm{LiOH}$ canisters, develop alignment and attitude control procedures, and develop and verify new procedures for other systems.

Some teams may only support specific phases of a nominal mission, but may be required to provide round-theclock support during a spacecraft emergency. Personnel that conducted pre-mission planning provided key replanning and analysis support to the flight control teams.

I The level of spacecraft autonomy is an important consideration to meet mission requirements for some spacecraft. Reference 36, "Challenges of Orion Rendezvous Development," contains a detailed discussion of the appropriate balance between autonomy, automation, and crew or ground authority over the spacecraft. 


\section{B. Spacecraft Recovery with Limited Systems Functionality May be Required}

Options available for spacecraft recovery may be limited due to physical damage, malfunctions, or systems limitations not directly related to the system in question. For example, Apollo 13 did not involve physical damage or malfunction of CSM or LM GNC hardware and software. However, the functionality of the SM SPS and RCS propellant and propulsion system was questionable, as was the ability of the SM structure to support a SPS burn. LM and CSM GNC functionality was limited, due to power and thermal control limits. In addition, the debris environment around the CSM/LM limited the usefulness of the CSM sextant and LM AOT to perform IMU alignments based on star sightings.

An incident might prevent the use of some backup equipment and procedures. The CSM power-down made the cis-lunar navigation and return to Earth targeting programs unavailable to the crew. These would have been needed in the event of an extended communications outage with Mission Control. These backup capabilities were not available in the LM GNC system.

\section{Create New or Modified Plans and Procedures}

Like ascent and entry, some on-orbit failures can be of a time critical nature. Once vehicle systems have been stabilized and vehicle systems status is known, additional time may be available to develop contingency procedures and alternative mission plans. Checklists and procedures (both ground and on-board) may require considerable modification during a spacecraft emergency. Many procedures used in the recovery of Apollo 13 had been previously developed and some new procedures were developed as well. Contingency procedures will evolve as a flight progresses. ${ }^{15}$

Contingency procedure development during a spacecraft emergency is a rapid process and entails some risk. It does not have the luxury of a long pre-mission development and verification period. Pre-mission procedure development is lower risk due to careful attention to detail by multiple organizations, extensive testing and simulation, and training of crew and ground personnel. However, it is not possible to anticipate, develop, and certify contingency procedures to counter every systems anomaly that might arise.

Quick and simple procedures for power-up, power-down, and other activities are needed that can be performed with minimal oversight from ground personnel. It is important to focus on essential tasks and keep the procedures simple. These procedures should be defined and verified before flights begin. Flight experience and evolving knowledge of vehicle systems performance can be used to improve contingency procedures over the life of a flight program.

During the recovery of Apollo 13, ground personnel discovered they could do procedures with fewer systems powered up than originally anticipated. Low power modes of operation should be identified and appropriate procedures and crew training developed to facilitate their use.

Limited electrical power and LM GNC system software functionality designed to support the low lunar orbit phase and lunar landings necessitated the modification of previously developed or new contingency procedures. In some cases these procedures were labor intensive. For example, the manual burn procedure used for MCC-5 and MCC-7 required the efforts of all three crew members.

Some procedures required for spacecraft recovery may never have been executed during a mission. For example, the $\mathrm{CM}$ had never been powered down and powered up in space. The Apollo $13 \mathrm{crew}$ did not have a CSM activation checklist. ${ }^{21}$ The crew had to perform manual attitude control of the CM/LM stack after SM separation. This was not a normal spacecraft configuration, and crew members had never been trained to perform this piloting task. Limited power required the power-down of the LM FDAIs and the use of digital gimbal angles to avoid gimbal lock. Use of computer displayed digital angles during piloting was challenging and had not been practiced during training.

\section{Clearly Define the Problems to be Solved}

During a spacecraft emergency, confusion may exist among ground support personnel concerning vehicle status and what tasks must be worked to recover the vehicle and crew. During the first hours after the oxygen tank incident, confusion about vehicle systems status and current mission plan led personnel to work false problems or ones that were not clearly defined. ${ }^{24}$

Effective leadership and communication is required so that vehicle status, tasks to be worked, personnel required, and resources needed (simulators, software tools, labs, etc.) is understood by all organizations. A significant amount of effort may be required to define which ground support tasks must be worked to recover from a spacecraft emergency and to develop a coordinated mission recovery plan. If tasks and objectives are not clearly 
defined, ground support personnel may waste time and resources attempting to solve ill-defined problems. This in turn adds risk to recovering from the spacecraft emergency.

Additional personnel may be called in during spacecraft emergencies that do not normally provide real-time support. These personnel must be integrated with the rest of the flight control team so that they are kept up-to-date on vehicle status and evolving mission event requirements. This integration and continuous, clear communication can avoid confusion and wasted effort. A need for new tools or the identification of new trajectory techniques may occur during a spacecraft emergency. Roles and responsibilities of flight control team members and additional personnel brought in to provide support must be clearly defined.

\section{E. Avoid Procedural Errors and Associated Risk}

During a time-critical spacecraft emergency crew and ground support personnel may be acting on incorrect or incomplete information. Personnel may also be working long hours with little opportunity for rest, exercise, and proper eating. Under these conditions it is easy for personnel to make mistakes when using analysis tools, developing procedures, performing tasks, and communicating important information. Attempts to perform rapid analysis in a high pressure, time critical spacecraft emergency can lead to errors in analysis and faulty conclusions.

For example, the spacecraft was maneuvered to the wrong LM/CM separation attitude, $\sim 45$ degrees on the north side of the CM ground track rather than the desired 45 degrees on the south side of the $\mathrm{CM}$ ground track (Figure 28). This attitude was close to CM IMU gimbal lock and complicated manual piloting.

Capability limitations and mission-to-mission reconfiguration requirements of software tools should be well understood before a spacecraft emergency to reduce the possibility of errors. These errors can result in time consuming attempts to understand questionable or incorrect data. Ground personnel must be thoroughly familiar with software tool operation and configuration to avoid incorrect initialization and procedural errors. Additional knowledgeable personnel can perform quality assurance checks of initialization data, output data, procedures, and analysis to ensure accuracy and adherence to best practices and appropriate processes.

\section{F. Ensure Good Air-To-Ground Communication and Manage the Crew Work Load}

Good communications were essential to the successful return of the crew to Earth. The crew of Apollo 13 could not have autonomously returned to Earth. Although many previously existing contingency procedures were used by the crew, many of these procedures required modification by Mission Control. These modified procedures had to be accurately communicated to the crew. However, in the final hours before entry the vehicle attitude resulted in degraded communications. This complicated information transfer required to properly configure the CM for entry.

The ability of Mission Control to look over the shoulder of the crew and assist them, greatly speeded-up time critical procedure execution such as LM systems activation. During time critical periods when there is uncertainty about vehicle systems status, ground and crew actions can be difficult to coordinate.

Although there was near continuous communications with the spacecraft, Mission Control permitted the crew to set the work and rest periods. Non-critical procedures and requests were passed to the crew only when a crew member was available. ${ }^{15}$

\section{G. Mitigating Risk of Development Does Not Always Mitigate Operational Risk}

Careful selection of technology, at an appropriate maturity level, may reduce cost, schedule, and technical risk during vehicle development. However, reduction of development risk does not necessarily result in reduced risk during the flight phase of the program. For example, a three gimbal IMU was chosen for Apollo as it was believed to represent a lower cost, schedule, development, and technical risk than a four gimbal IMU. It also weighed less than a four gimbal IMU. However, the need to avoid loss of IMU platform alignment due to gimbal lock complicated piloting procedures and mission planning. This led to greater overall operational complexity and cost. However, the Gemini spacecraft successfully flew human missions in 1965 and 1966 with a four gimbal IMU that did not require special piloting and mission planning procedures to avoid a gimbal lock condition. 


\section{H. Orbital Lighting Conditions Challenge Humans and Electro-Optical Sensors}

The Apollo spacecraft relied on crew sightings of stars or planets for IMU alignment. An orbital debris cloud, venting from the SM, and reflections from LM structure, complicated or prevented crew identification of stars for IMU alignments. Window visibility was also periodically limited by condensation. In spite of these challenges the Earth, Moon, and Sun were easily discernable, as was the terminator on the Earth. Sightings on the Sun, Moon, and Earth were used instead of star sightings for LM IMU alignment. However, alignments using the Earth, Moon, and Sun could not be practiced in the Apollo simulators. The crew later reported that manual control of spacecraft attitude is easier if one has an easily discernable celestial body to use as a reference, such as the Earth or Moon. ${ }^{21}$

Apollo 13 GNC systems were not equipped with cameras or star trackers. Space Shuttle experience has shown that the human eye is more adaptable to orbital lighting conditions than electro-optical devices. Furthermore, orbital debris and reflections can complicate or prevent attitude determination by electro-optical devices such as star trackers and cameras. The value of human eye or electro-optical sightings of easily discernable celestial bodies (Earth, Sun, Moon, planets, etc.) during extreme orbital lighting conditions should not be overlooked.

\section{Conclusion}

Successful recovery of the Apollo 13 crew was facilitated by pre-mission development of contingency procedures. However, many of these procedures required extensive modification during the mission. Pre-mission development of simple contingency procedures can posture a flight program to more effectively handle spacecraft emergencies. Contingency procedures such as systems power-up should be quick and executable with a minimum of support required from ground personnel. Contingency procedures and crew interfaces should be designed so only one crew member is required for execution. Rapid execution of existing contingency procedures may be required to respond to unforeseen performance anomalies and systems limitations. A spacecraft system may be fully functional, but performance issues in other systems (such as thermal control and power generation) may limit the use of a healthy system. Furthermore, crew execution of new or modified procedures may be complicated due to a lack of training.

The Apollo 13 mission underlined the difficulty presented by orbital lighting conditions, an experience that has been encountered in other flight programs. Use of advanced electro-optical sensors may be limited due to orbital lighting and debris conditions. The human eye is more adaptable than electro-optical sensors under a wide variety of extreme lighting conditions. Simple methods of attitude determination using the Sun, Moon, and Earth can overcome poor visibility conditions caused by debris that prevent star sightings.

Unforeseen conflicts between spacecraft may arise, such as the frequency conflict between the LM and S-IVB S-Band transponders. Simple tools, such as the COAS, AOT, and window scribe marks, were used to accomplish GNC tasks while consuming minimal spacecraft power and thermal control resources. A particular technology may be chosen during spacecraft development to mitigate cost and schedule risk, but it could complicate ground and crew tasks during the flight phase of a program. Input from an operations perspective must be sought and considered during selection of systems and technology for a vehicle. Multiple spacecraft that participate in the same mission must be considered in an integrated fashion from the beginning of the vehicle design phase.

The flexibility of the crew, ground support personnel, and the Apollo spacecraft systems was a key to the successful recovery of the crew. Systems flexibility across the vehicles is needed to facilitate unforeseen use of systems in an effective manner in the event of a spacecraft emergency while conserving power and thermal control resources. Continuous communication between the crew and Mission Control, and between various ground support organizations, facilitated timely development of new procedures and resolution of technical issues. 


\section{Appendix A - LM GNC Architecture}

The LM Guidance, Navigation, and Control Subsystem (GN\&CS) has two sections, the Primary Guidance and Navigation Section (PGNS) and the Abort Guidance Section (AGS) (Figure 32). The PGNS provided GNC functionality during all LM mission phases. The AGS provided minimal GNC functionality to enable the LM to return to the CSM in the event of a PGNS failure. Both the PGNS and AGS relied on common hardware in the Control Electronics Section (CES).

This appendix provides a basic overview of the PGNS, AGS, LM GN\&CS Architecture Components, and LM propulsion. Not all details of LM GN\&CS design, operation, and functionality are addressed. ${ }^{11,37,38}$

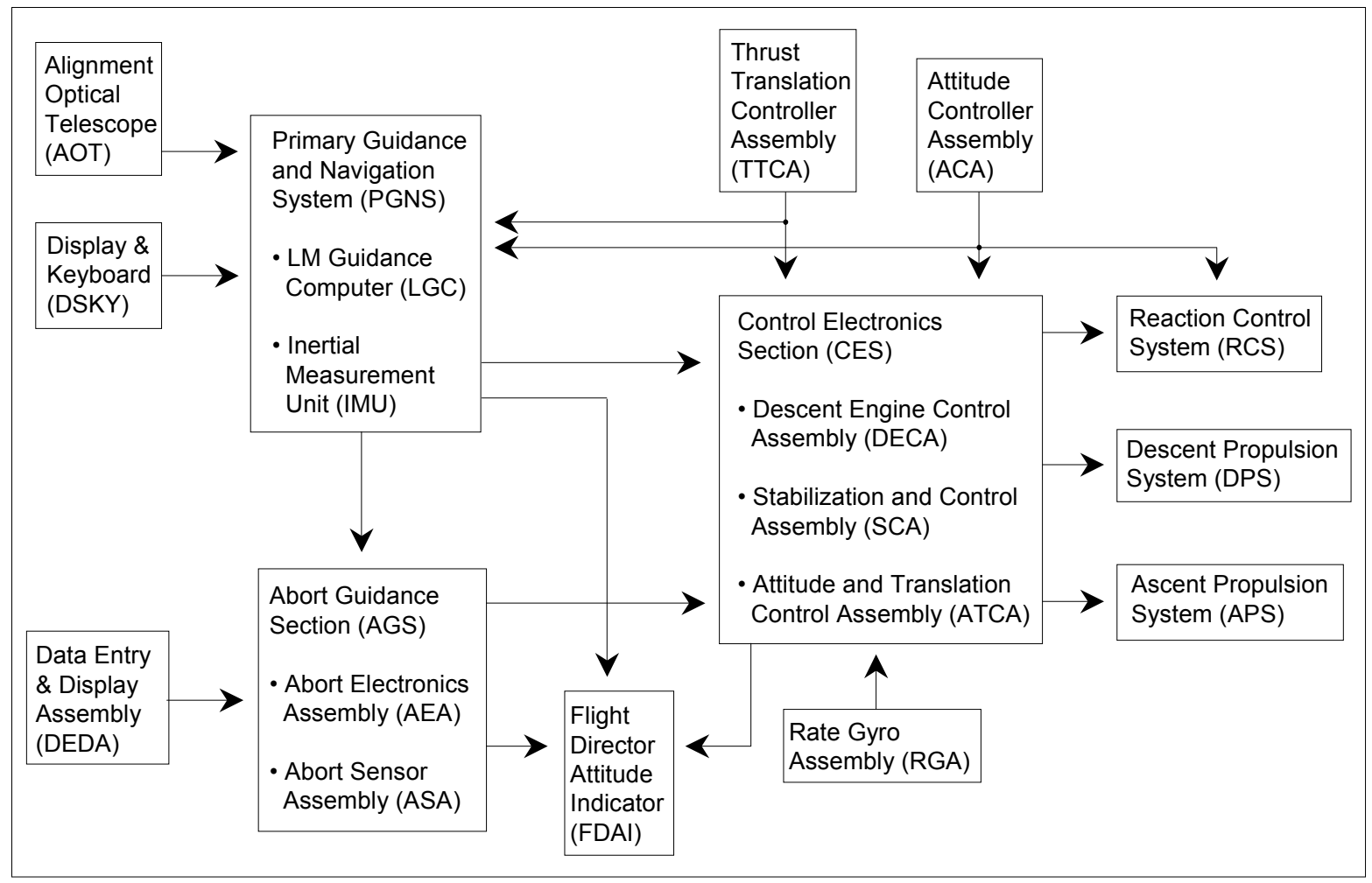

Figure 32. Simplified Lunar Module (LM) Guidance, Navigation, and Control (GNC) architecture.

\section{A. Primary Guidance and Navigation Section (PGNS)}

The PGNS provided primary GNC during all phases of LM flight and could support all LM mission phases. These phases included post undocking, descent orbit insertion, powered descent and landing, lunar surface operations, powered ascent, rendezvous, docking, and backup flight control while the LM is mated to the CSM. Unlike the Command Module Computer (CMC), the LM PGNS could not compute return to Earth and trajectory mid-course correction maneuvers, nor could it support optical cis-lunar navigation.

PGNS provided automatic flight control using a digital autopilot. Manual or computer assisted manual flight control by the crew was also provided. PGNS digital autopilot was designed to control three spacecraft configurations: 1) LM ascent and descent stages, 2) LM ascent stage, and 3) LM docked to the CSM (backup to the CMC flight control that is normally primary). It was not originally intended to control a CSM/LM ascent stage stack. The CSM Primary Guidance Navigation, and Control System (PGNCS) performed that function.

\section{B. Abort Guidance Section (AGS)}

The AGS was the backup LM GNC section with a dedicated strapdown inertial sensor unit. In the event of a PGNS failure, the AGS provided basic functionality to permit the crew to achieve insertion into a safe orbit. Furthermore, the AGS supported LM active rendezvous with the CSM. The AGS was available during all LM flight phases (pre-descent orbit coast, powered descent, lunar surface, powered ascent, rendezvous and docking). 
However, the AGS could not support a lunar landing, as a functioning PGNS was required for landing. The CES provided flight control functionality for the AGS.

The LM PGNS was normally used for GNC during all phases of LM flight, with the AGS running in parallel in the event of a PGNS failure. During nominal lunar flight phases (PGNS operational), the LM pilot performed AGS procedures so that the AGS could assume control of the vehicle at any time.

AGS hardware and software were developed by different contractors than the PGNS hardware and software. This development and verification philosophy was similar to the later Space Shuttle Backup Flight System.

\section{LM GN\&CS Architecture Components}

This section details components of the LM GNC architecture. Some of these components were used by both the PGNS and AGS, while others were exclusive to one section. Many, but not all, components of the LM GNC architecture were used by the Apollo $13 \mathrm{crew}$, while performing attitude and burn procedures. Components not used during the flight of Apollo 13 are identified.

\section{PGNS Inertial Measurement Unit (IMU)}

The PGNS IMU was a three gimbal stable member unit that provided measurements of integrated acceleration and integrated rate with respect to an inertial frame to the LM Guidance Computer. The PGNS was aligned using angular measurements obtained by the Alignment Optical Telescope. The same type of IMU was used in the CM.

\section{Abort Sensor Assembly (ASA)}

The ASA was a strapdown inertial sensor unit that provided measurements of integrated acceleration and integrated rate with respect to the LM body axis frame to the AGS Abort Electronics Assembly. The ASA provided sufficient accuracy to recover from mission aborts while also providing a size and weight savings over the PGNS stable member IMU. However, the ASA required periodic transfer alignments from the PGNS to maintain accuracy. The ASA could also be aligned on the lunar surface using the ASA accelerometers to sense the local vertical. A body axis align could be performed on the lunar surface or in orbit. This alignment, used during the Apollo 13 mission, set the AGS inertial reference frame equal to the LM body axes.

\section{Alignment Optical Telescope (AOT)}

The LM crew performed PGNS IMU alignments using the AOT (Figures 13 and 14) while in lunar orbit or on the lunar surface. These alignments were accomplished by AOT angular measurements of two celestial objects, usually stars. Once the PGNS IMU was aligned the alignment could be transferred to the AGS.

The AOT was a $1 \mathrm{x}$ power manual periscope with 6 viewing positions providing 360 degrees of coverage in 60 degree increments. The center of the field of view in each position was 45 degrees above the LM Z/Y body axis plane (a plane parallel to the floor of the crew compartment). The crew rotated the AOT to the appropriate viewing position of the 6 available. However, the available AOT positions were limited while the LM was docked to the CSM due to blockage of the field of view.

Only the forward looking position with a field of view above and forward of the LM crew windows and lunar surface hatch was used during Apollo 13 as the other AOT positions were blocked by the CM. Use of the AOT during Apollo 13 expanded the field of view of the crew beyond that provided by the commander and pilot landing windows.

\section{LM Navigation Base}

The PGNS IMU, AGS ASA, and AOT were mounted on a light-weight navigation base designed to minimize relative misalignment.

\section{LM Guidance Computer ( $L G C$ )}

The LGC used the same model of high speed general purpose computer as the CM primary GNC system. However, it contained software specific to the lunar module flight phases. The LGC received input data from the PGNS IMU, the landing radar, rendezvous radar, the AOT, the Attitude Controller Assembly, and the Thrust/Translation Controller Assembly. The crew could command the LGC and view LGC data through the Display and Keyboard (DSKY, Figure 12). 


\section{Display and Keyboard Panels (DSKY)}

The DSKY (Figure 12) permitted the crew to issue commands to the LGC and view LGC data. One DSKY was located on the main control panel between the commander and LM pilot. The LM DSKY differed from the CSM PGNCS DSKY only in caution and status indicators.

\section{Abort Electronics Assembly (AEA)}

The AEA was the AGS high speed digital flight computer that performed backup GNC functions including ASA alignment, strapdown navigation, guidance, and targeting. Guidance included powered flight to achieve orbit insertion and execution of on-orbit maneuvers. Targeting included rendezvous maneuver computation. The AEA processed data from the ASA, PGNS LGC, and crew inputs from the DEDA. It also provided data to crew displays. As long as the PGNS was operating, the AEA could accept radar data automatically from the LGC. If the AGS was in control (PGNS failure) rendezvous radar data was manually input into the AEA by the LM pilot.

\section{Data Entry and Display Assembly (DEDA)}

The DEDA permitted the LM pilot to issue commands to the AEA and view AEA data.

\section{Control Electronics Section (CES)}

The CES processed both PGNS and AGS translation and attitude signals, as well as manual crew inputs. These signals were routed by the CES to the appropriate propulsion system (RCS, ascent engine, descent engine). Components of the CES included two Attitude Controller Assemblies (ACA), the Rate Gyro Assembly (RGA), the Descent Engine Control Assembly (DECA), two Gimbal Drive Actuators (GDA), and the Ascent Engine Arming Assembly (AEAA).

\section{Rate Gyro Assembly (RGA)}

The RGA supplied the ATCA with damping signals to limit attitude rates and facilitate manual attitude control by the crew.

\section{Attitude and Translation Control Assembly (ATCA)}

When the LM was under PGNS control, the ATCA processed RCS jet commands from the AGC and transmitted them to the RCS jets. Under AGS control, the ATCA processed translation and attitude rate commands from the AEA and rate signals from the RGA. This information was processed in an analog autopilot that issued RCS jet commands.

\section{Attitude Controller Assembly (ACA)}

Both LM crew stations were equipped with an attitude hand controller (Figure 11) for manual adjustment of LM attitude using RCS thrusters. The ACA was also used by the commander during landing as part of the Landing Point Designator function.

\section{Thrust/Translation Controller Assembly (TTCA)}

Both the commander and pilot stations were equipped with a TTCA (Figure 10). It was used for 3 axis RCS translational maneuvers. During DPS firing (normally powered descent) it provided manual lateral (2 axis) translation control and throttle control. The TTCA provided better pitch and roll control of the CSM/LM stack than the ACA, and was used by the Apollo 13 crew for this reason.

\section{Landing Point Designator (LPD)}

The LPD was used by the LM commander to redefine the targeted landing point during the latter phase of powered lunar descent. The ACA was also used during the LPD procedure. LPD scribe marks on the commander's window were used by the Apollo 13 crew to monitor attitude dynamics during PTC rotation and to check the DPS-2 burn attitude. (Figure 16).

\section{Flight Director Attitude Indicator (FDAI)}

The FDAI (Figure 9) provided a visual display of spacecraft attitude, attitude errors, and rates in the roll, pitch, and yaw axes. Both the commander and pilot had an FDAI. The gimbal lock region of the FDAI ball was red to help the crew avoid gimbal lock. 


\section{Crewman Optical Alignment Sight (COAS)}

The LM COAS (Figures 8 and 13) could be mounted in one of two positions. The first position was in the LM commander's window. After rendezvous but before docking, the COAS was moved to the overhead docking window (above the commander, Figure 13)). This enabled the commander to align the LM with the CSM docking target in a CSM rendezvous window. However, the CSM was normally active during docking. Apollo 9 was the only Apollo mission during which the LM was active for docking. During Apollo 13, the COAS was used in the commander's window for burn attitude cues (Figure 17). Celestial sightings could also be performed with the COAS for alignment.

\section{Rendezvous Radar (RR)}

The RR provided measurements of range, range rate, trunnion and shaft angles, and inertial line-of-sight rates during rendezvous. These measurements were sent to the PGNS and crew displays. The RR was not used during the flight of Apollo 13. However, the RR antenna was rotated by the PGNS, out of the field of view of the AOT to permit an IMU alignment check using the Sun, before the DPS-2 burn.

\section{Landing Radar (LR)}

The LR measured slant range and velocity during powered descent and landing. The PGNS used this data for navigation. The LR was not used during the flight of Apollo 13.

\section{LM Propulsion}

The LM had three propulsion systems. The descent and ascent propulsion systems were independent of each other. The Reaction Control System was used to provide attitude control during ascent and descent engine firings, and during coasting flight. All three propulsion systems used nitrogen tetroxide and unsymmetrical dimethyl hydrazine hypergolic propellants.

\section{Descent Propulsion System (DPS)}

The LM DPS consisted of one variable thrust (9,900 pounds maximum) pressure fed engine in the LM descent stage. It was normally used during powered descent. The Descent Orbit Insertion maneuvers on Apollo 10, Apollo 11 and Apollo 12 were also executed with the DPS. If an abort occurred during powered descent the DPS could also be used to insert the LM into a safe orbit for a subsequent rendezvous with the CSM. The DPS could be gimbaled by computer or by crew command using the Thrust/Translation Controller Assembly. It was used for three Apollo 13 maneuvers (DPS-1, DPS-2, and MCC-5) after the oxygen tank incident.

\section{Ascent Propulsion System (APS)}

The APS was a constant thrust (3,500 pounds nominal) pressure fed engine in the LM ascent stage. On a nominal lunar mission the APS was used from lunar lift-off through orbit insertion. The APS was not gimbaled and attitude control during the burn was provided by the LM RCS. If an abort during powered descent occurred it was used to place the LM ascent stage in a safe orbit so that a rendezvous could be conducted. The APS was not used during the flight of Apollo 13.

\section{LM Reaction Control System (RCS)}

The LM RCS consisted of sixteen $100 \mathrm{lb}$ thrust jets mounted in groups of four on the ascent stage of the LM. The RCS provided rotational and translational control for both the combined LM ascent and descent stages and the ascent stage alone. It also performed ullage burns (acceleration along the $\mathrm{LM}+\mathrm{X}$ axis) to settle propellant before ascent and descent engine firings. The RCS could be commanded by the PGNS, AGS, or manually by the crew. An interconnect with the APS propellant system permitted the RCS to burn APS propellant if the APS propellant system was pressurized and either the APS or DPS was firing.

During Apollo 13, the LM RCS provided attitude control of the LM/CSM stack for most of the mission following the oxygen tank incident. The MCC-7 trajectory correction and SM separation maneuvers were also performed by the LM RCS. 


\section{Appendix B - CSM GNC Architecture}

The CSM GNC architecture was composed of two systems, the Primary Guidance, Navigation, and Control System (PGNCS) and the Stabilization and Control System (SCS). The PGNCS provided GNC functionality during all CSM mission phases. This included digital autopilot and manual control, absolute navigation, relative navigation, entry guidance, burn targeting, and powered flight guidance. The SCS provided backup flight control. Both the PGNCS and SCS possessed independent rotational rate sensors and translational acceleration sensors. Both systems supplied commands to the SM RCS, SM SPS, and CM RCS (entry only).

This appendix provides a basic overview of the PGNCS and SCS. Not all details of CSM GNC design, operation, and functionality are addressed. ${ }^{11,37,38}$

\section{A. Primary Guidance, Navigation, and Control System (PGNCS)}

The PGNCS consisted of three subsystems. The Computer Sub-System (CSS) contained the Command Module Computer (CMC) and the Display and Keyboard Panels (DSKY). The Inertial Sub-System (ISS) consisted of a stable member IMU and other supporting electronics. The Optical Sub-System (OSS) consisted of a sextant and scanning telescope used for IMU alignments. The PGNCS was equipped with a Digital Auto Pilot (DAP) in the $\mathrm{CMC}$ that provided either automatic or manual crew control of spacecraft attitude.

\section{B. Stabilization and Control System (SCS)}

The SCS served as a backup flight control system for the PGNCS. The SCS also served as the interface between the PGNCS and the RCS and SPS propulsion systems. Crew displays such as the FDAI were also supported by the SCS. However, the SCS was not dependent on the PGNCS for flight control functionality. Unlike the PGNCS the SCS did not possess navigation, burn targeting, or guidance functions. SCS did not have software.

\section{CSM GNC Architecture Components}

This section details components of the CSM GNC architecture. Many, but not all, components of the CSM GNC architecture were used by the Apollo 13 crew during the mission. Components not used during the flight of Apollo 13 are identified.

\section{PGNCS Inertial Measurement Unit (IMU)}

The PGNCS IMU was a three axis IMU identical to the LM primary IMU. It provided measurements of integrated acceleration and integrated rate with respect to an inertial frame to the CMC. The PGNCS was aligned using angular measurements obtained by the sextant.

\section{Sextant}

The sextant was a 28 power optical device with a 1.8 degree field of view. It measured the included angle between two lines of sight. For IMU alignments, star sightings were used. Star/horizon sightings could be performed to support back-up cis-lunar navigation. The sextant was also used to measure relative line-of-sight angles to the LM during rendezvous.

\section{Scanning Telescope}

The Scanning Telescope was a unity power telescope with a 60 degree field of view. It was used to locate stars for sextant sightings. It was also used to obtain Lunar landmark sightings for backup orbital navigation.

\section{Navigation Base}

The IMU, sextant, and scanning telescope were mounted on a navigation base that ensured an accurate, known relative alignment between the three units.

\section{Minimum Impulse Controller (MIC)}

The MIC was located in the CM lower equipment bay, close to the sextant and scanning telescope. It provided fine manual attitude control during sextant and telescope operation by the crew. 


\section{Command Module Computer (CMC) or Apollo Guidance Computer (AGC)}

The CMC (or AGC) hardware was identical to that of the LGC. The CMC contained software for absolute and relative navigation, IMU alignment, and automatic or manual attitude control of the CSM, CSM/LM, and CSM/LM ascent stage. It also provided burn targeting and burn guidance functions. In the event of a Saturn Instrumentation Unit (IU) failure, during open loop Saturn guidance (first stage and part of second stage), the CMC had software that provided automatic guidance commands to the IU. Once the IU Iterative Guidance Mode was in operation, the crew could manually steer the vehicle through the CMC, in the event of an IU failure.

\section{Display and Keyboard Panels (DSKY)}

The DSKY permitted the crew to issue commands to the CMC and view CMC data. One DSKY was located on the main control panel. The other was in the Lower Equipment Bay. The CSM DSKY differed from the LM PGNS DSKY only in caution and status indicators.

\section{Stabilization and Control System (SCS)}

The SCS was a backup to the PGNCS to provide rotational and translational control of the vehicle. The crew could switch back and forth between PGNCS and SCS control of the vehicle. The SCS also provided the interface for the PGNCS with the SPS and RCS propulsion systems. SCS hardware included two Flight Director Attitude Indicators (FDAI), one Translational Controller (TC), two Rotational Controllers (RC), a Gimbal Position and Fuel Pressure Indicator (GP/FPI), an Attitude Set Control Panel (ASCP), two Gyro Assemblies (GA), a Gyro Display Coupler (GDC), Electronic Display Assembly (EDA), Electronic Control Assembly (ECA), Thrust Vector Servo Amplifier (TVSA), and RCS Jet Engine Control (RJEC).

\section{Flight Director Attitude Indicator (FDAI)}

Two FDAIs provided a visual display of spacecraft attitude, attitude errors, and rates in the roll, pitch, and yaw axes. Attitude and attitude error from either the PGNCS or SCS could be displayed. Displayed angular rate data was provided by the SCS. The gimbal lock region of the FDAI ball was colored red to help the crew avoid gimbal lock.

\section{Entry Monitoring System (EMS)}

The EMS was a backup to the PGNCS for entry guidance and was equipped with its own accelerometer. ${ }^{39}$ It provided manual piloting cues and trajectory evaluation data to the crew. The crew monitored automatic PGNCS entry guidance performance with the EMS. In the event of a PGNCS failure before or during entry, the crew could manually fly the entry using the EMS. The EMS also displayed sensed delta-velocity during powered flight and VHF ranging data during rendezvous.

For example, during transposition and docking the crew monitored sensed delta-velocity displayed on the Entry Monitoring System, elapsed time, vehicle attitude, and attitude rates. However, during transposition and docking no measurements of relative range were available for piloting cues.

\section{VHF Ranging}

Starting with Apollo 10 VHF ranging provided relative range data to the LM, to supplement relative line-ofsight data obtained with the sextant. VHF ranging was not used on Apollo 13.

\section{Crewman Optical Alignment Sight (COAS)}

The COAS (Figure 8) provided lateral and angular alignment cues to the CM pilot during final approach and docking.

\section{CSM and CM Propulsion}

The CSM had three propulsion systems. The Service Propulsion System was used for large orbit adjustment burns. The Service Module Reaction Control System provided attitude control for the CSM and CSM/LM configurations. The Command Module Reaction Control System provided attitude control of the CM from SM separation just before EI and during re-entry. 


\section{Service Propulsion System (SPS)}

The SPS was a gimbaled 20,500 lbs constant thrust engine. The SCS gimbaled the engine to align the thrust vector with the vehicle center of mass. The SPS used nitrogen tetroxide and unsymmetrical dimethyl hydrazine hypergolic propellants.

\section{Service Module Reaction Control System (SM RCS)}

Four groups (called quads) of four $100 \mathrm{lbs}$ thrust RCS jets were distributed around the SM at 90 degrees (Figure 1). Each quad had its own propellant tanks. The SM RCS used nitrogen tetroxide and mono-methyl hydrazine hypergolic propellants.

\section{Command Module Reaction Control System (CM RCS)}

The CM possessed two independent RCS systems each having six $93 \mathrm{lb}$ thrust RCS jets. These systems were only used for attitude control during re-entry. The CM RCS used nitrogen tetroxide and mono-methyl hydrazine hypergolic propellants.

\section{Appendix C - Acronyms}

ACA - Attitude Controller Assembly

AGS - Abort Guidance Section

ALSEP - Apollo Lunar Surface Experiment Package

APS - Auxiliary Propulsion System

AOT - Alignment Optical Telescope

ASA - Abort Sensor Assembly

CCS - Command and Communication System

CECO - Center Engine Cut-Off

CES - Control Electronics Section

$\mathrm{CM}$ - Command Module

CMC - Command Module Computer

COAS - Crewman Optical Alignment Sight

CSM - Command Service Module

CST - Central Standard Time

DAP - Digital Auto Pilot

DOI - Descent Orbit Insertion

DPS - Descent Propulsion System

DSKY - Display and Keyboard

EI - Entry Interface

EMS - Entry Monitoring System

EST - Eastern Standard Time

EVA - Extra Vehicular Activity

FDAI - Flight Director Attitude Indicator

GET - Ground Elapsed Time

GLFC - Graphite LM Fuel Cask

GNC - Guidance, Navigation, and Control

GN\&CS - Guidance, Navigation, and Control System

IGM - Iterative Guidance Mode

IMU - Inertial Measurement Unit

IU - Instrumentation Unit

L/D - Lift to Drag Ratio

LM - Lunar Module

LOI - Lunar Orbit Insertion

LPD - Landing Point Designator

MCC - Mid-Course Correction

MPAD - Mission Planning and Analysis Division

MSFN - Manned Space Flight Network 
OECO - Out-board Engine Cut-Off

ORDEAL - Orbital Rate Display - Earth and Lunar

PC - Peri-Cynthion

PDI - Powered Descent Initiation

PGNCS - Primary Guidance, Navigation, and Control System

PGNS - Primary Guidance and Navigation Section

PTC - Passive Thermal Control

RCS - Reaction Control System

REFSMMAT - Reference Stable Member Matrix

RTCC - Real Time Computer Complex

SM - Service Module

SPS - Service Propulsion System

TEI - Trans Earth Injection

TLI - Trans Lunar Injection

TTCA - Thrust/Translation Controller Assembly

USB - Unified S-Band

USS - United States Ship

VHF - Very High Frequency

\section{Acknowledgments}

The Apollo 13 trajectory reconstruction in Figures 7 and 23 was performed by former Space Shuttle Orbit and Rendezvous Flight Dynamics Officer Daniel R. Adamo. ${ }^{17}$

\section{References}

${ }_{1}^{1}$ Apollo 13: To the Edge and Back, Documentary on DVD, WGBH Boston, 1994.

2“Apollo 13 - Houston, We've Got a Problem,” EP-76, NASA, Washington, D.C.

${ }^{3}$ Cooper, H. S. F., Thirteen: The Apollo Flight That Failed, The Johns Hopkins University Press, Baltimore, MD, 1995.

${ }^{4}$ Kelly, T. J., Moon Lander: How We Developed the Apollo Lunar Module, Smithsonian, 2001.

${ }^{5} \mathrm{Kraft}, \mathrm{C} .$, Flight: My Life in Mission Control, Dutton Adult, 2001.

${ }^{6}$ Kranz, E. F., Failure Is Not an Option: Mission Control from Mercury to Apollo 13 and Beyond, Berkley Trade, 2001.

${ }^{7}$ Lovell, J., and Kluger, J., Apollo 13, Mariner Books, 2006.

${ }^{8}$ Lunney, G. S, "Discussion of Several Problem Areas During the Apollo 13 Operation," $7^{\text {th }}$ AIAA Annual Meeting And Technical Display, AIAA, Reston, VA, 1970.

${ }^{9}$ Murray, C., and Cox, C. B., Apollo, South Mountain Books, 2004.

${ }^{10}$ Pellegrino, C. R., and Stoff, J., Chariots for Apollo - The Making of the Lunar Module, Anthenum, New York, 1985.

${ }^{11}$ Apollo 13 Press Kit, News Release No: 70-50K, NASA, April 2, 1970.

${ }^{12}$ Apollo 13 Lunar Trajectory Notes, MSC Internal Note No. 70-FM-78, MSC-02415, Mission Planning and Analysis Division, NASA Manned Spacecraft Center, Houston, TX, April 8, 1970.

${ }^{13}$ Baker, D., The History of Manned Space Flight, Crown Publishers, Inc., New York, NY, 1981.

${ }^{14}$ Baird, A., "How to Land Next to a Surveyor: Bill Tindall and the Apollo Pinpoint Lunar Landing," Quest: The History of Spaceflight Quarterly, Vol. 14, No. 2, May 2007, pp. 19-27.

${ }^{15}$ Mission Operations Report, Apollo 13, NASA Manned Spacecraft Center, Houston, TX, April 28, 1970.

${ }^{16}$ Berry, R. R., "Launch Window and Trans-lunar, Lunar Orbit, and Transearth Trajectory Planning and Control for the Apollo 11 Lunar Landing Mission,” 8th AIAA Aerospace Sciences Meeting, AIAA, Reston, VA, 1970.

${ }^{17}$ Adamo, D. R., "Apollo 13 Trajectory Reconstruction Via State Transition Matrices," AIAA Journal Of Guidance, Control, And Dynamics, Vol. 31, No. 6, Nov.-Dec. 2008, pp. 1772-1781.

${ }^{18}$ Chandler, D. C., and Smith, I. E., "Development of the Iterative Guidance Mode With its Application to Various Vehicles and Missions," AIAA Journal of Spacecraft and Rockets, Vol. 4, No. 7, July 1967, pages 898-903.

${ }^{19}$ Apollo/Saturn V Postflight Trajectory, AS-508, DS-15560-8, The Boeing Company, Huntsville, AL, June 10, 1970.

${ }^{20}$ Saturn V Launch Vehicle Flight Evaluation Report, AS-508, Apollo 13 Mission, NASA-TM-X-64422, Saturn Flight Evaluation Working Group, NASA George C. Marshall Space Flight Center, Huntsville, AL, June 20, 1970.

${ }^{21}$ Apollo 13 Technical Crew Debriefing, NASA Manned Spacecraft Center, Houston, TX, April 24, 1970.

${ }^{22}$ Guidance, Navigation, and Control Systems Performance Analysis, Apollo 13 Mission Report Supplement 1, MSC-02680, NASA Manned Spacecraft Center, Houston, TX, September 1970. 
${ }^{23}$ Apollo 13 Mission Report, MSC-02680, NASA Manned Spacecraft Center, Houston, TX, September 1970.

${ }^{24}$ MPAD Real-Time Support of the Apollo 13 Mission, MSC Internal Note No. 70-FM-109, MSC-02552, Mission Planning and Analysis Division, NASA Manned Spacecraft Center, Houston, TX, July 7, 1970.

${ }^{25}$ Report of the Apollo 13 Review Board, NASA, Washington, D.C., June 1970.

${ }^{26}$ Apollo 9 (AS-504) Mission, Post Launch Mission Operation Report, NASA, May 6, 1969.

${ }^{27}$ Apollo 13 Navigation Results, MSC Internal Note No. 70-FM-101, MSC-02533, Mission Planning and Analysis Division, NASA Manned Spacecraft Center, Houston, TX, June 17, 1970.

${ }^{28}$ Lunde, A. N., Views from the Returning Apollo 13 Spacecraft, MSC Internal Note No. 70-FM-90, MSC-02500, Mission Planning and Analysis Division, NASA Manned Spacecraft Center, Houston, TX, May 15, 1970.

${ }^{29}$ Apollo 13 Technical Air-To-Ground Voice Transcription, NASA Manned Spacecraft Center, Houston, TX, April 1970.

${ }^{30}$ Merchant, D. H., Gates, R. M., and Murray, J. F., "Prediction of Apollo Service Module Motion After Jettison," AAS/AIAA Astrodynamics Conference, AIAA, Reston, VA, 1970.

${ }^{31}$ Apollo 12 Technical Crew Debriefing, NASA Manned Spacecraft Center, Houston, TX, December 1, 1969.

${ }^{32}$ Goodman, J. L., and Dannemiller, D. P., "Flight Safety Education For Current and Future Space Flight Programs," Proceedings of the AIAA Space 2006 Conference, AIAA, Reston, VA, 2006.

${ }^{33}$ Goodman, J. L., Lessons Learned From Seven Space Shuttle Missions, NASA Contractor Report NASA/CR-2007213697, NASA Johnson Space Center, January 2007. See the NASA Technical Reports server at http://ntrs.nasa.gov/, or the Johnson Technical Reports server at http://ston.jsc.nasa.gov/collections/TRS/. Accessed August 17, 2009.

${ }^{34}$ Columbia Accident Investigation Board Report, Volume I, U.S. Government Printing Office, Washington, DC, August 2003.

${ }^{35}$ Report of the Presidential Commission on the Space Shuttle Challenger Accident, U.S. Government Printing Office, Washington, DC, June 6, 1986.

${ }^{36}$ Goodman, J. L., Brazzel, J. P., and Chart, D. A., "Challenges of Orion Rendezvous Development," AIAA Guidance, Navigation and Control Conference and Exhibit, AIAA, Reston, VA, 2007.

${ }^{37}$ Mindell, D. A., Digital Apollo: Human and Machine in Spaceflight, MIT Press, Cambridge, MA, 2008.

${ }^{38}$ Nevins, J. L., "'Man-Machine Design for the Apollo Navigation, Guidance, and Control System—Revisited: Apollo, a Transition in the Art of Piloting a Vehicle,' Charles Stark Draper Laboratory, Cambridge, MA, January 1970.

${ }^{39}$ Frank, A. J., Knotts, E. F., and Johnson, B. C., "An Entry Monitor System for Maneuverable Vehicles," AIAA Journal of Spacecraft and Rockets, Vol. 3, No. 8, August 1966, pp. 1229-1234. 


\section{Apollo 13 Guidance, Navigation, and Control Challenges}

John L. Goodman

United Space Alliance, LLC

AIAA SPACE 2009 Conference

Pasadena, California

September 14-17, 2009

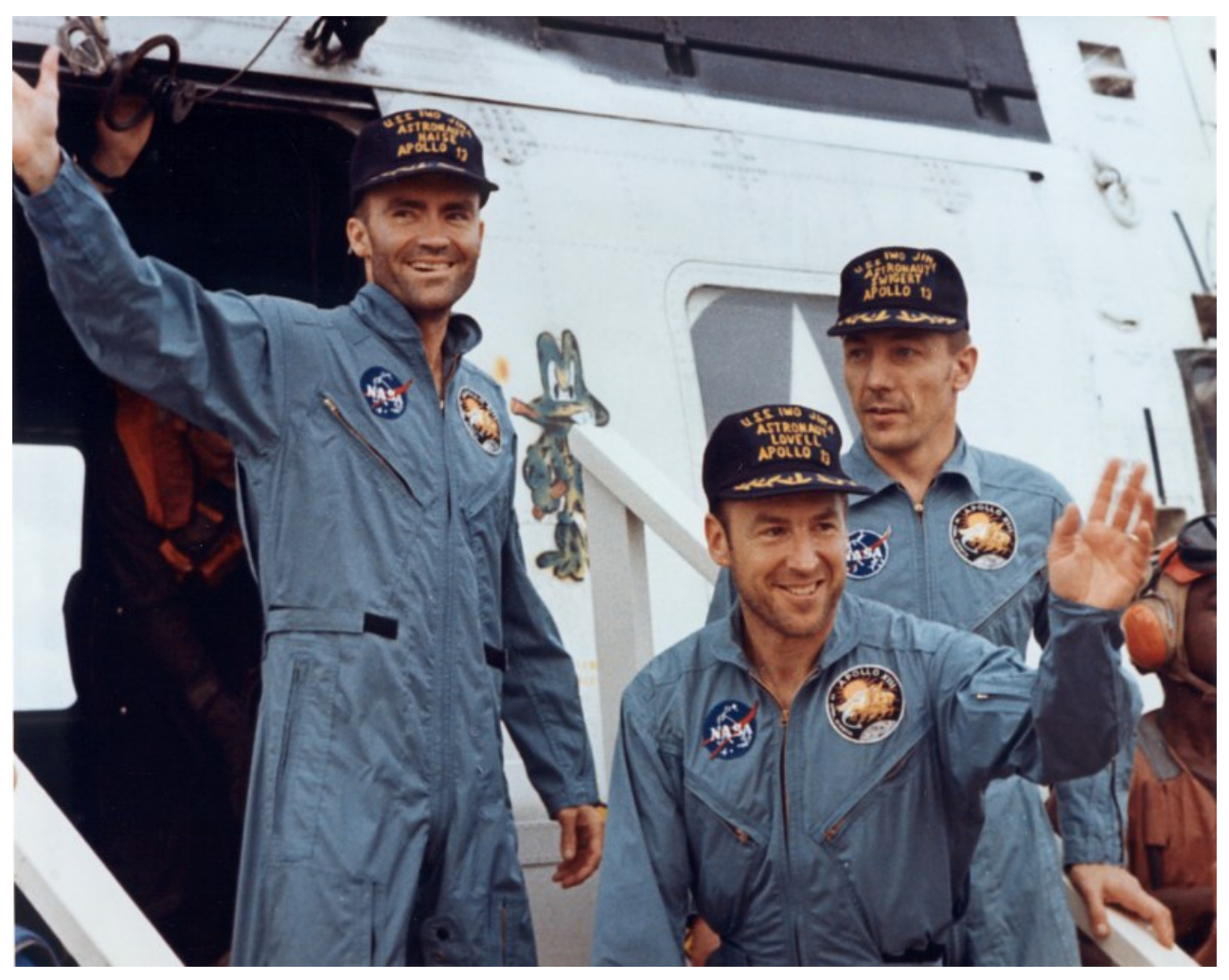




\section{Agenda}

Aborted Mission Overview

Vehicle Status After the Incident

Simplified Lunar Module GNC Architecture

Post Incident Challenges

Re-establish Return to Earth Trajectory

Passive Thermal Control Rotation Challenges

Shorten Return and Move Landing to Pacific

Body Axis Alignment Procedure

Mid-Course Correction Burns to Adjust the Entry Interface Flight Path Angle
Pre-Entry Crew Timeline

Challenges

Service Module Separation

Lunar Module Separation

Re-entry

Challenges That Apollo 13 Did Not Face

Observations on Apollo 13 


\section{Aborted Mission Overview}

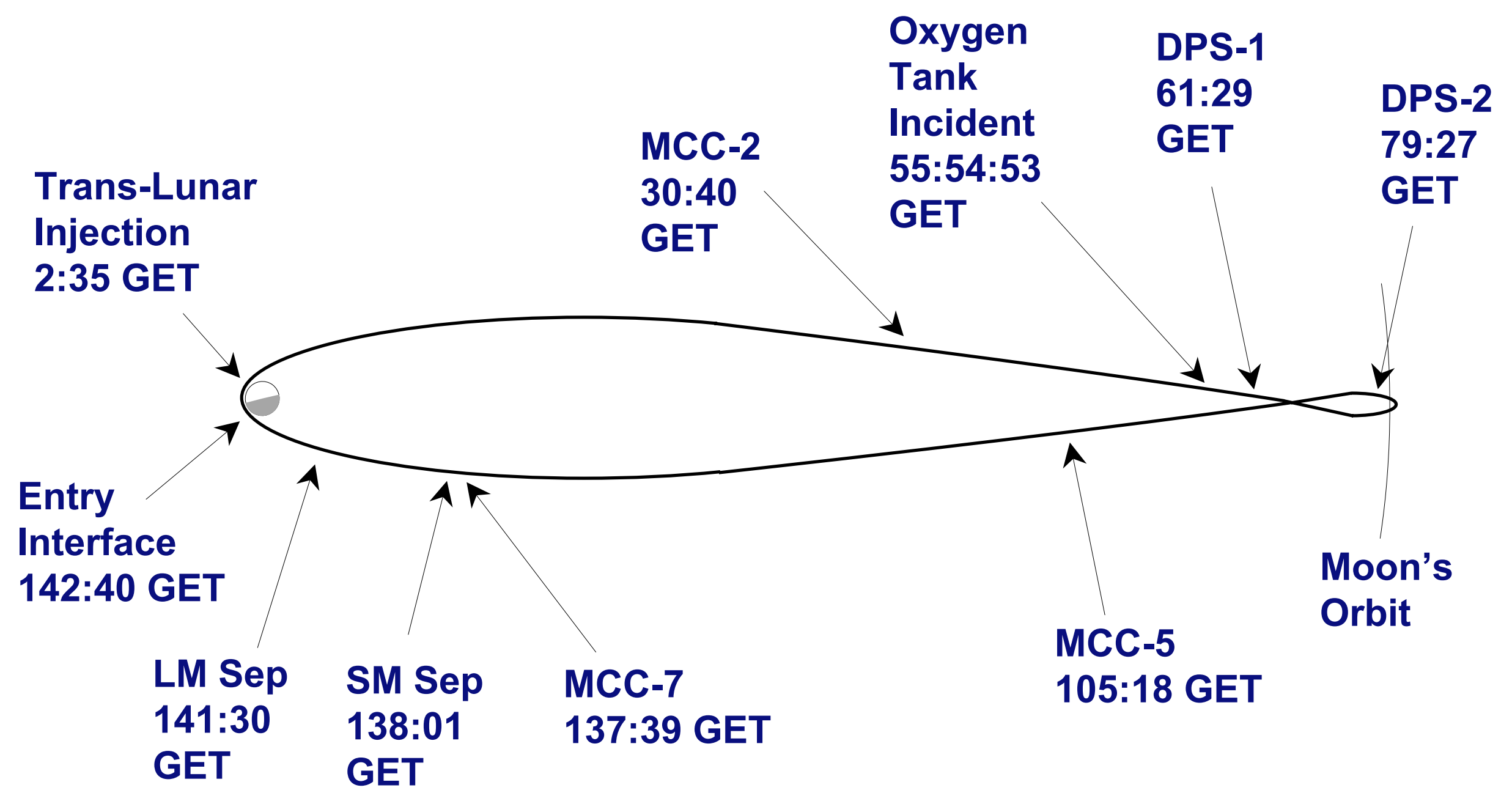

GET - Ground Elapsed Time 


\section{Vehicle Status After the Incident}

SM oxygen gone. Fuel cells cannot generate power. Service Propulsion System integrity questionable. CM battery power conserved for entry. CM GNC not available until entry due to power.

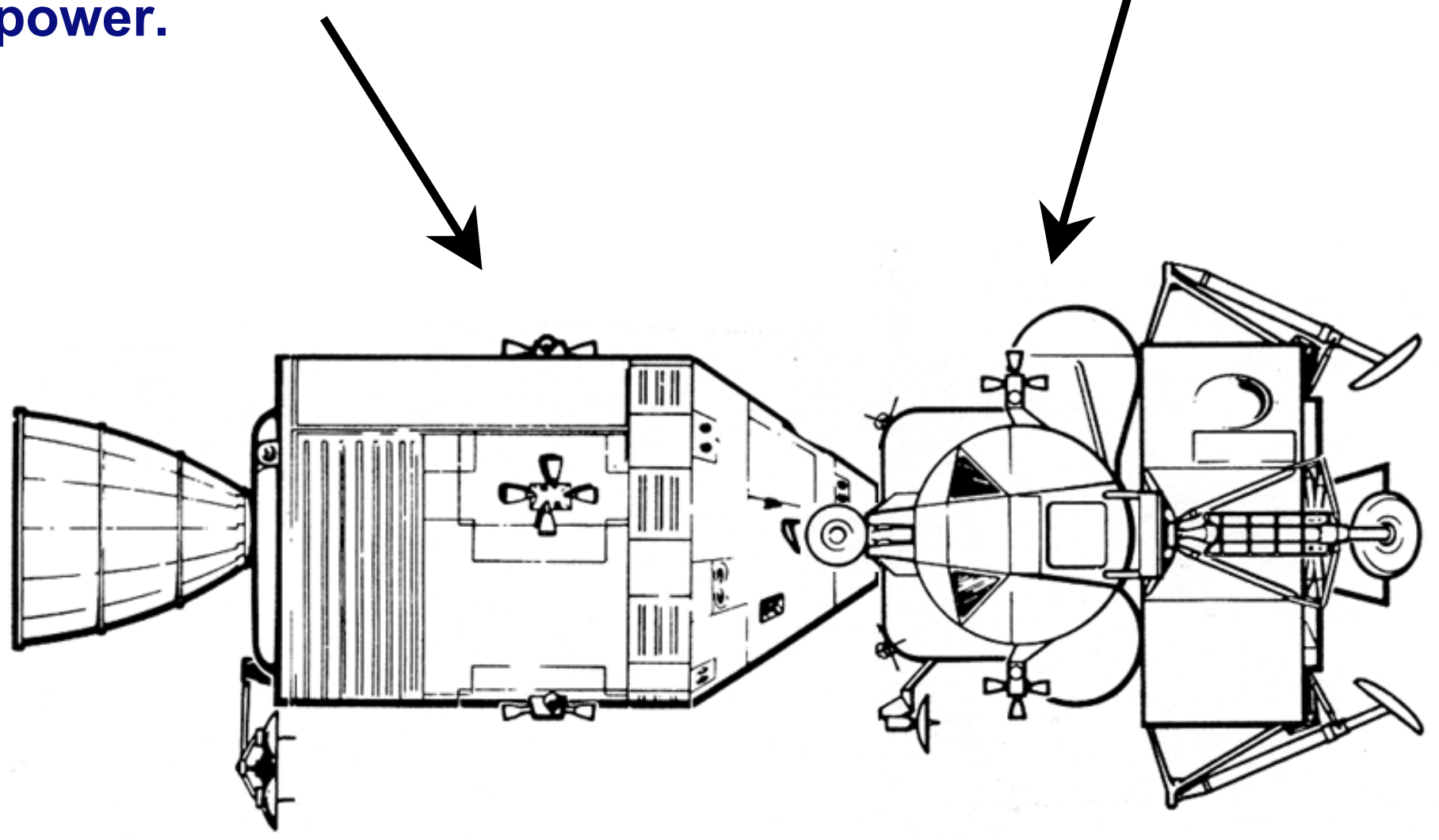

LM used as lifeboat until re-entry. LM GNC and propulsion used for return to Earth and attitude control. Limited power available for LM GNC. 


\section{Simplified Lunar Module GNC Architecture}

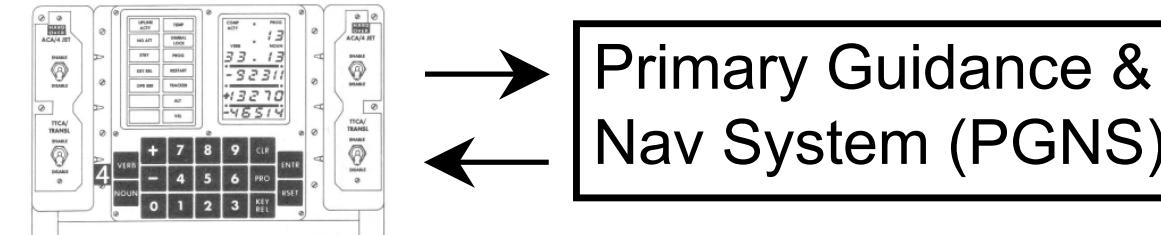

PGNS Interface
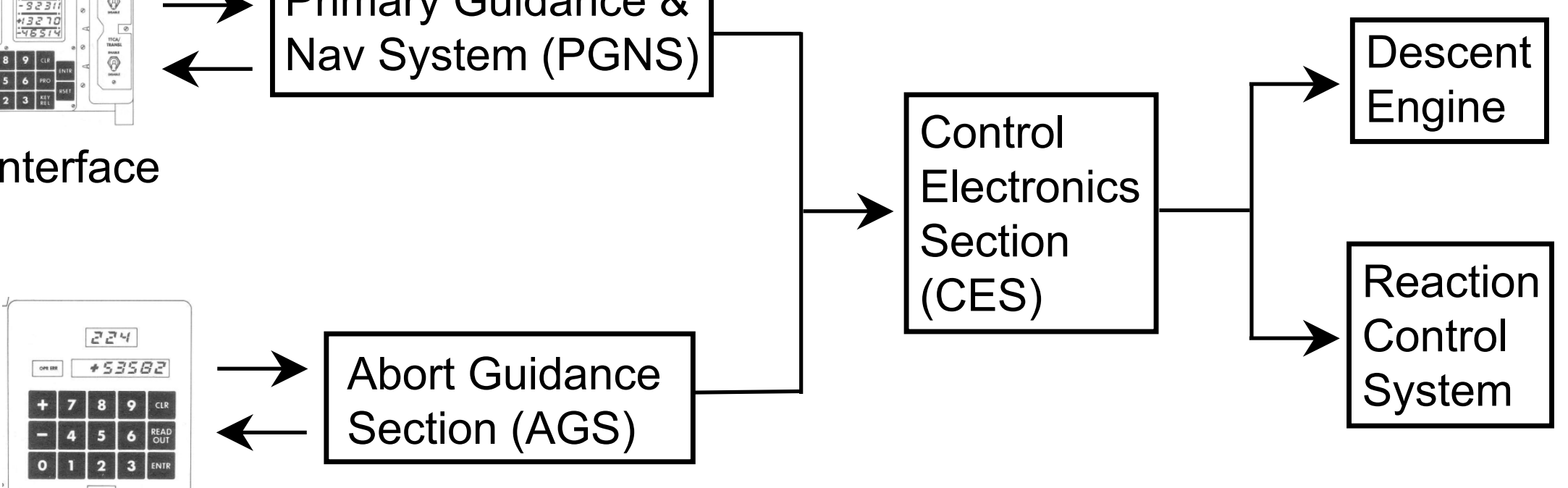

AGS Interface

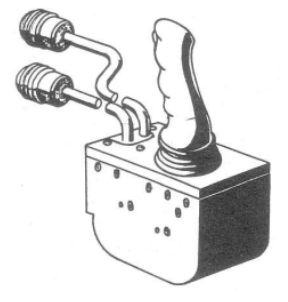

Attitude Hand Controller

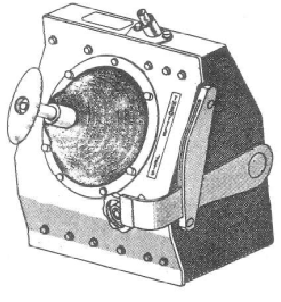

Thrust \& Translation Hand Controller

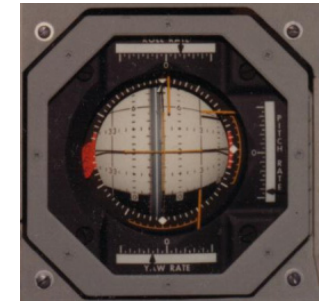

Attitude Indicator

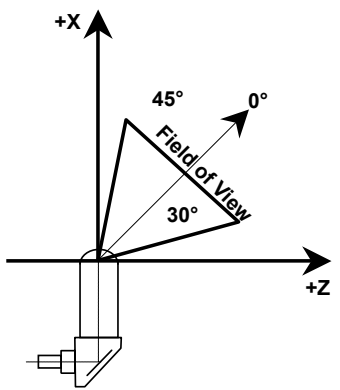

Alignment Optical Telescope
Crewman Optical Alignment Sight 


\section{Post Incident Challenges}

Maintaining attitude control in presence of Service Module oxygen venting.

Solar illuminated debris from Service Module prevented star identification needed for normal IMU star alignments.

Docked transfer alignment of Lunar Module IMU.

Frequency conflict between Lunar Module and S-IVB S-Band transponders complicated ground tracking for $\sim 6$ hours.

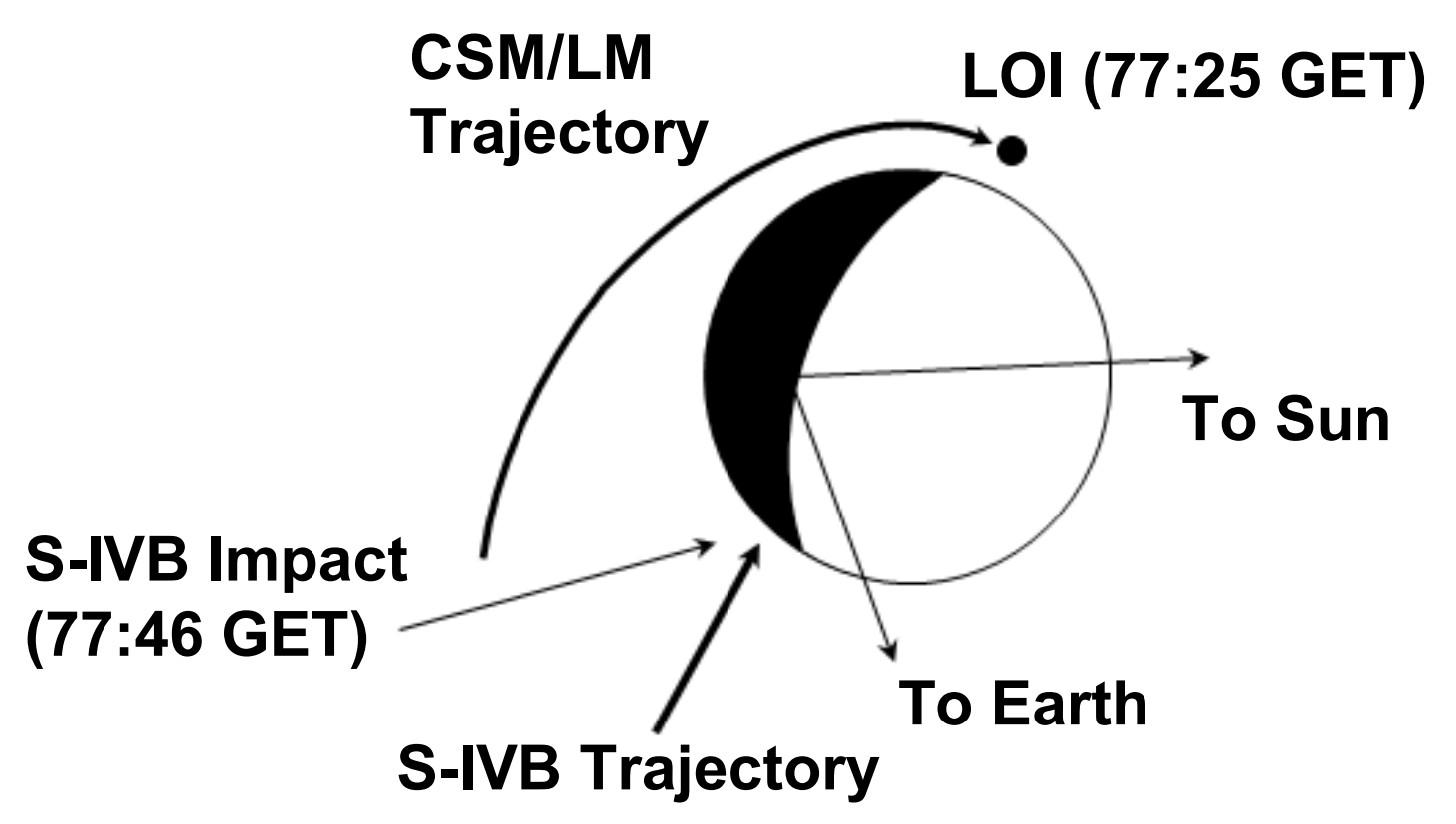




\section{Re-Establish Return to Earth Trajectory}

Direct return or Lunar fly-by?

Choice of return time and location. Pacific, Atlantic, or Indian Ocean?

Ensure Lunar Module consumables margin to support safe return.

Jettison Service Module or keep it until just before re-entry?

Lunar fly-by chosen.

Indian Ocean splashdown with option to change to Pacific and speed up return after lunar fly-by.

Service Module kept attached to Command Module due to thermal concerns. 


\section{DPS-1 Burn}

Executed $\sim 5.5$ hours after incident.

Spacecraft now on return trajectory for Indian Ocean landing at $\sim 152$ hours.

Both PGNS and AGS powered for the burn.

PGNS kept powered up until next burn 2 hours after lunar fly-by. 


\section{Passive Thermal Control Rotation Challenge}

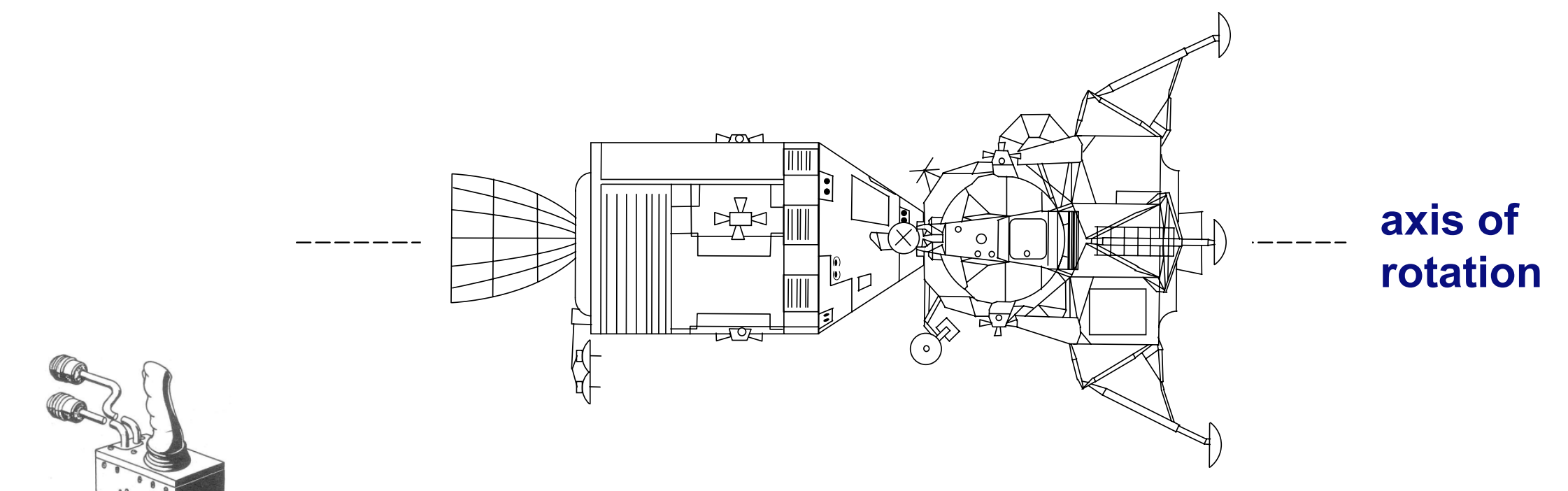

Attitude Hand

Controller (yaw)

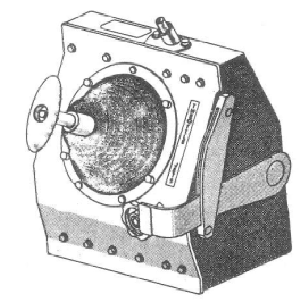

Thrust \& Translation Hand Controller (roll and pitch)

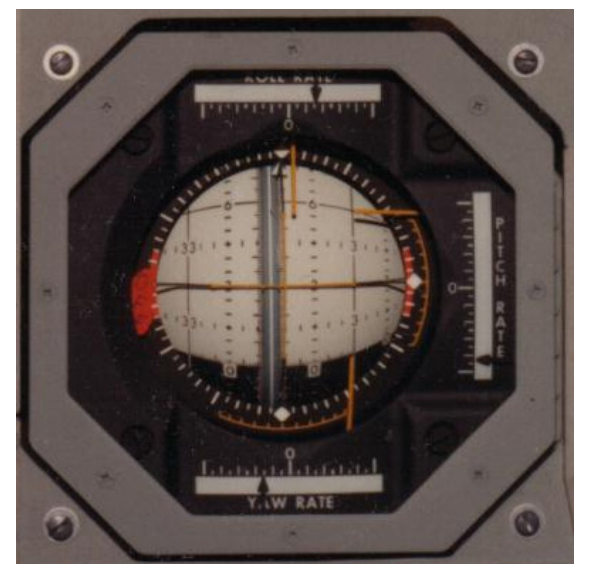

Flight Director Attitude Indicator powered off.

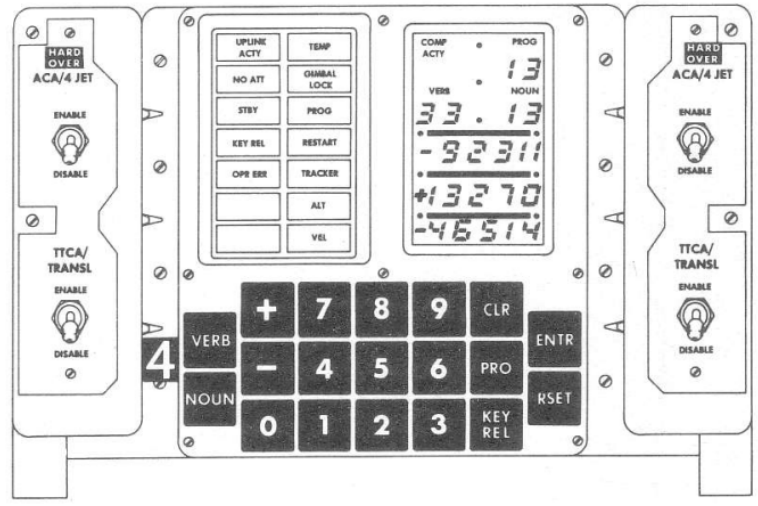

Crew used computer display to establish rotation \& avoid IMU gimbal lock. 


\section{Shorten Return and Move Landing to Pacific}

More recovery forces available in the Pacific than in the Indian Ocean.

Splashdown at $\sim 143$ hours provided $\sim 13$ hours margin in Lunar Module consumables.

PGNS alignment performed at Lunar Module activation still accurate enough for DPS-2 burn.

DPS-2 (PC+2) burn successfully executed using PGNS. 


\section{Passive Thermal Control Rotation}

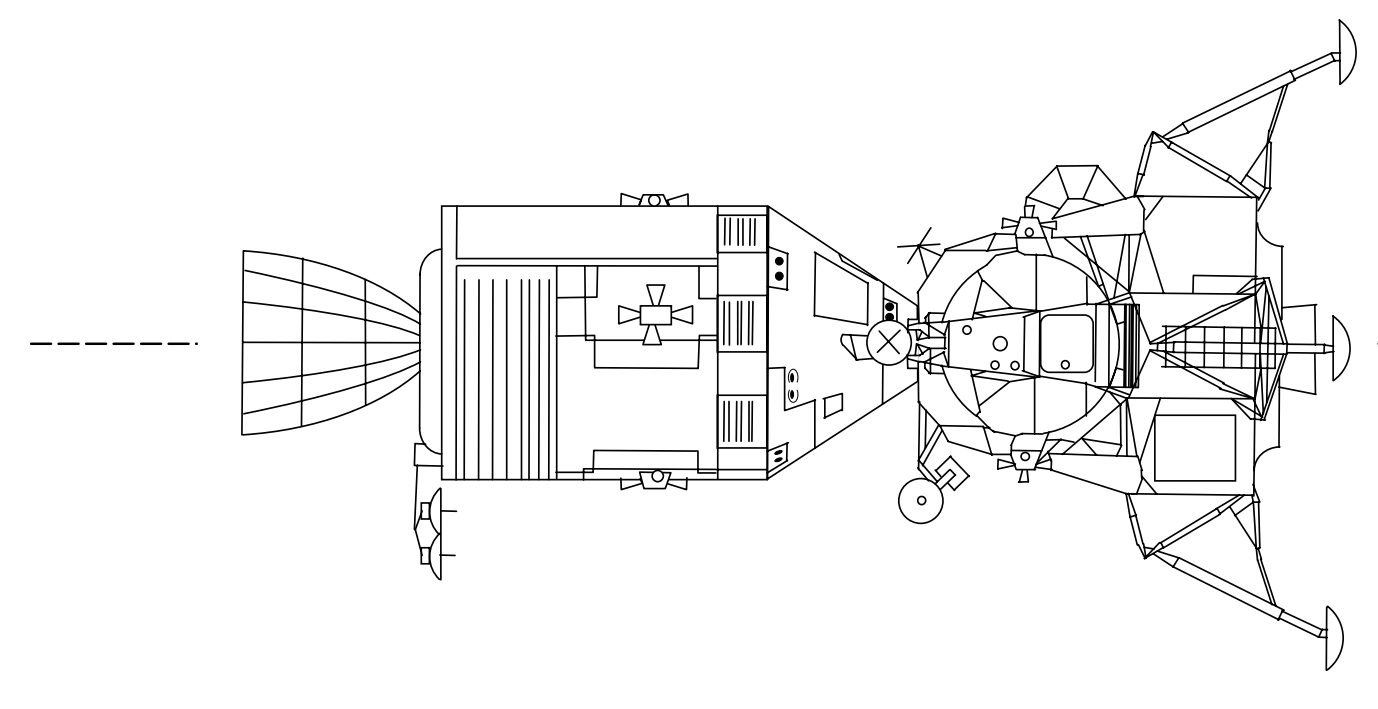

No telemetry for Mission Control monitoring of rotation.

Crew reported Earth and Moon crossing of Landing Point Designator to Mission Control.

axis of rotation

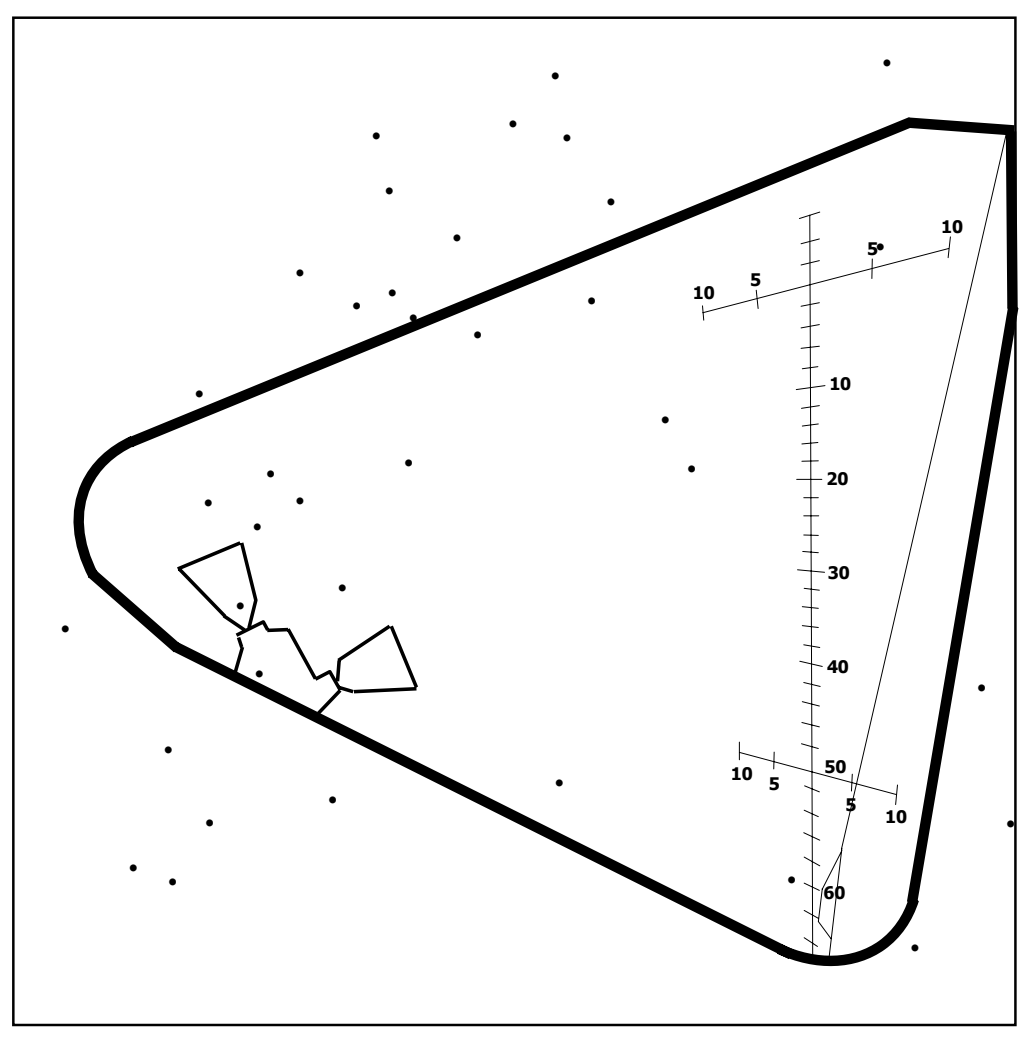




\section{MCC-5 Burn to Correct Entry Conditions}

Predicted flight path angle at El trending to smaller values.

Mid-Course Correction (MCC) burns required to ensure proper El flight path angle.

PGNS and AGS powered off since PC+2 burn.

AGS used for MCC-5 since it used less power than PGNS.

Contingency procedure required to place Lunar Module at burn attitude and perform AGS body axis align.

Sun illuminated debris prevent Alignment Optical Telescope sightings on stars for IMU alignment. 


\section{Body Axis Alignment Procedure}

Contingency procedure developed before Apollo 8.

Earth in COAS for retrograde or posigrade correction burns. For retrograde Sun then positioned in Alignment Optical Telescope to achieve pitch attitude.

AGS body axis align then performed.

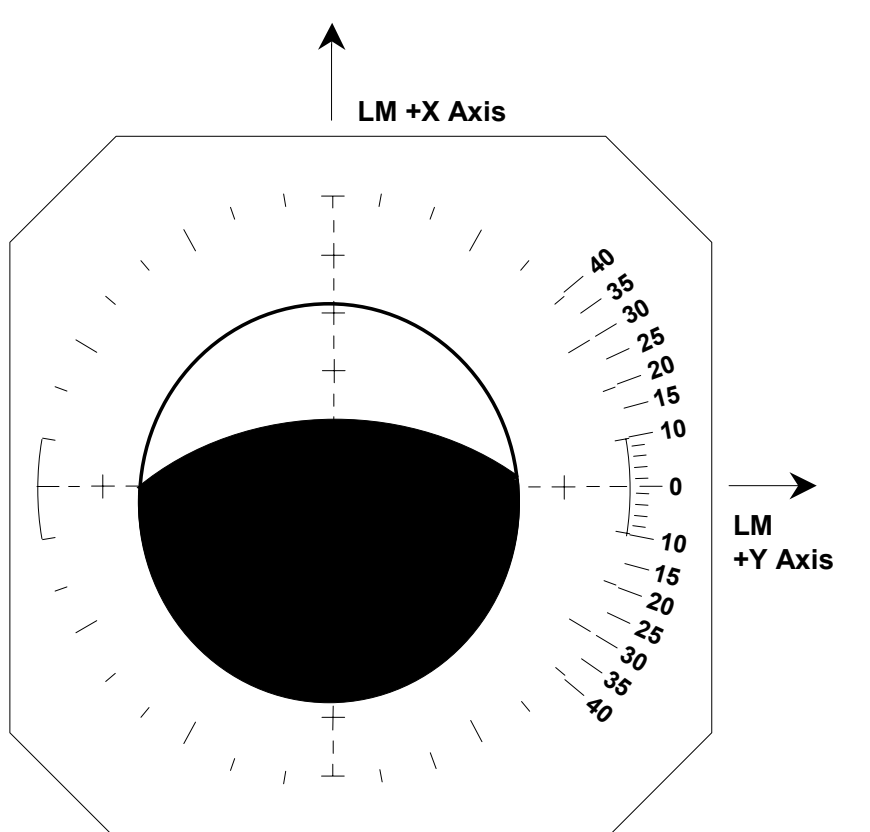

retrograde

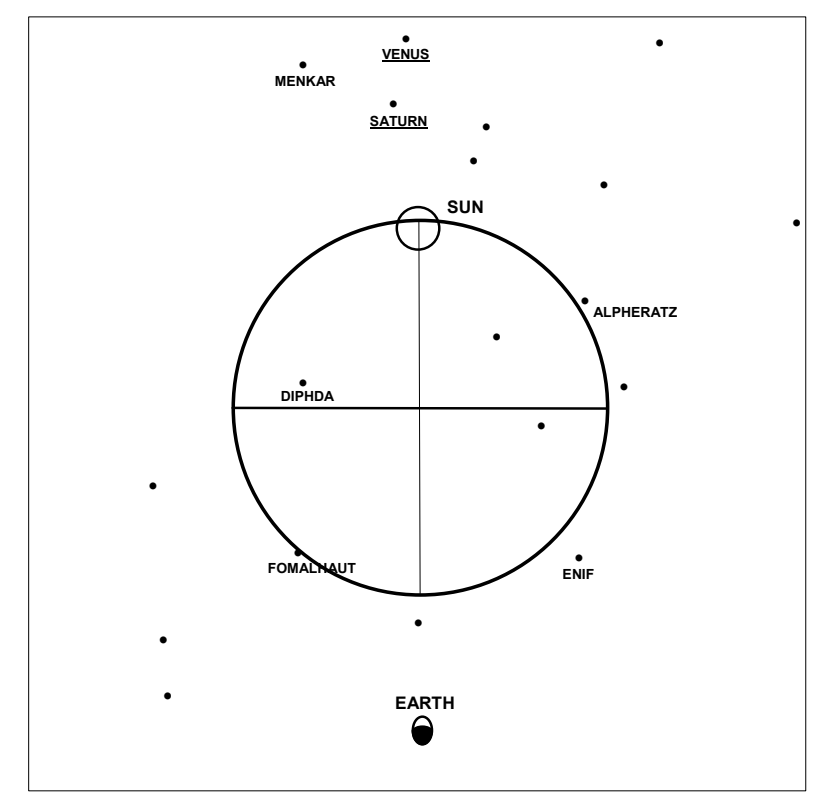

retrograde

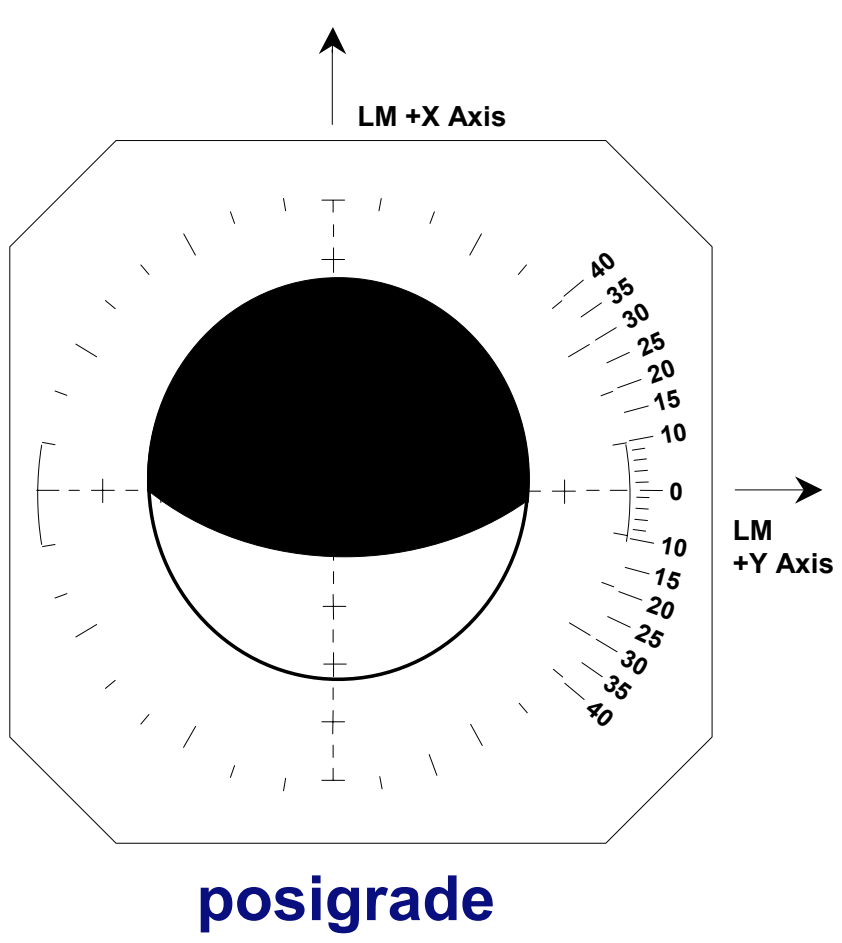

USA 


\section{MCC-5 Execution}

Burn performed manually due to AGS accelerometer performance concerns due to exposure to low temperatures (unheated).

AGS controlled yaw automatically.

Crew controlled pitch and roll using cues from Attitude Indicator error needles.

Roll controlled with Thrust \& Translation Hand Controller.

Pitch controlled with Thrust \& Translation Hand Controller.

Burn terminated with cue from watch.

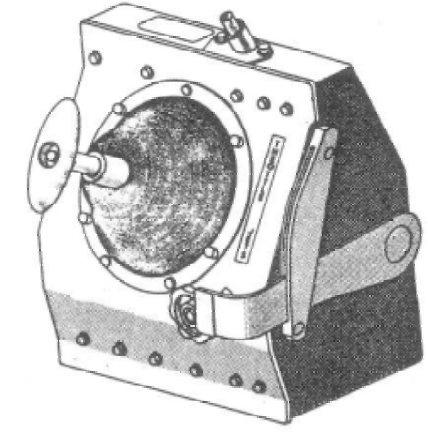

Thrust \& Translation Hand Controllers

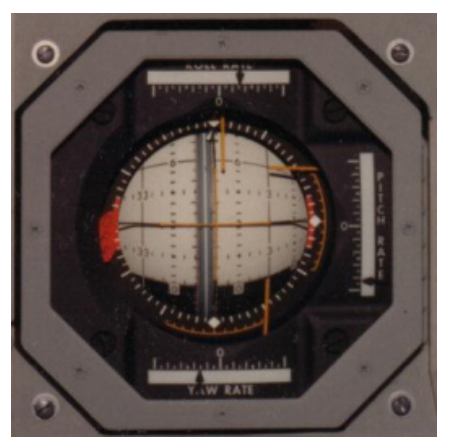

Attitude Indicator 


\section{Pre-Entry Crew Timeline Challenging}

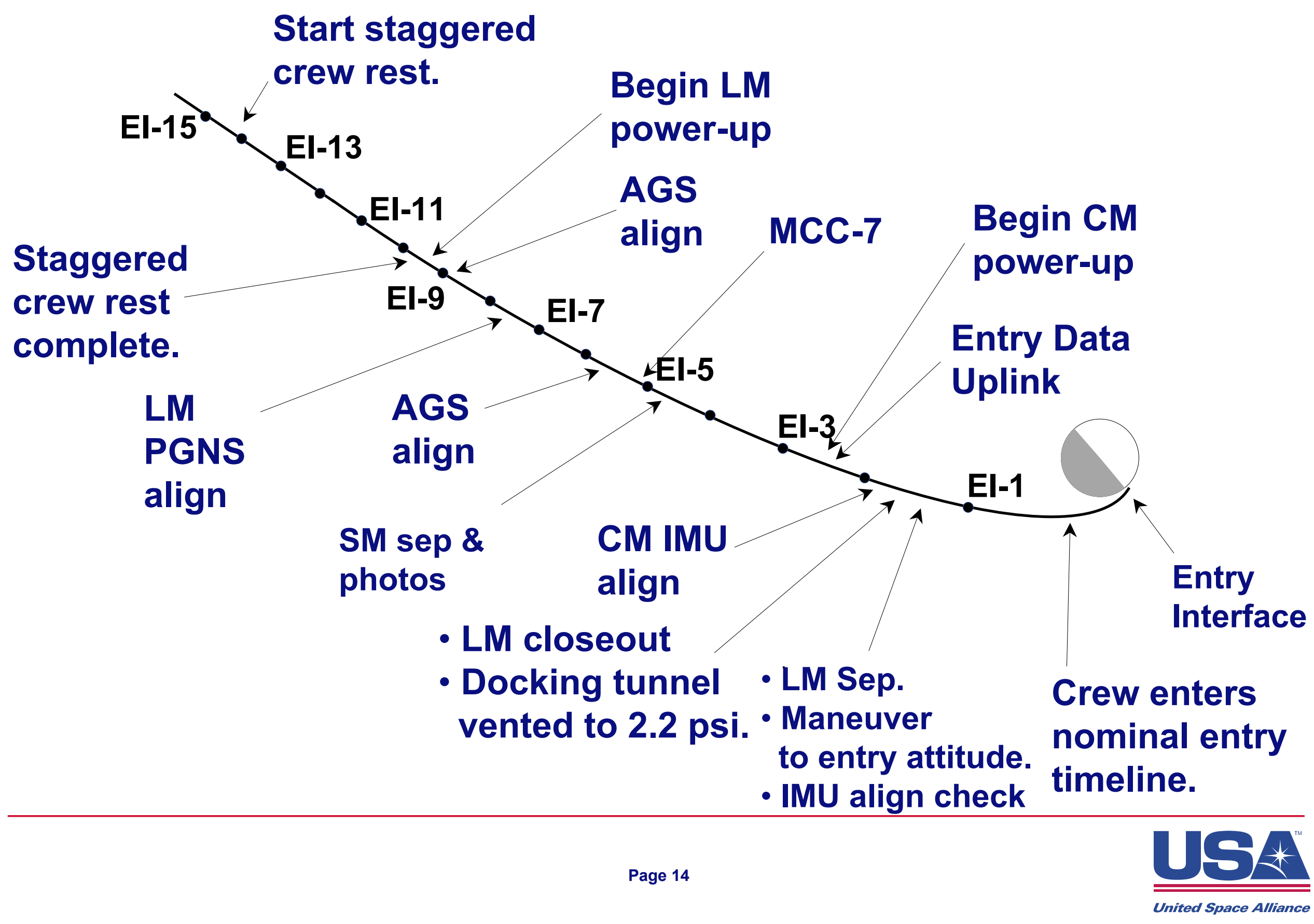




\section{MCC-7 Burn to Adjust El Flight Path Angle}

Both PNGS and AGS powered due to margin in power and consumables.

AGS alignment, PGNS alignment from AGS, then PGNS Sun/Moon align.

AGS used for burn due to PGNS RCS propellant consumption.

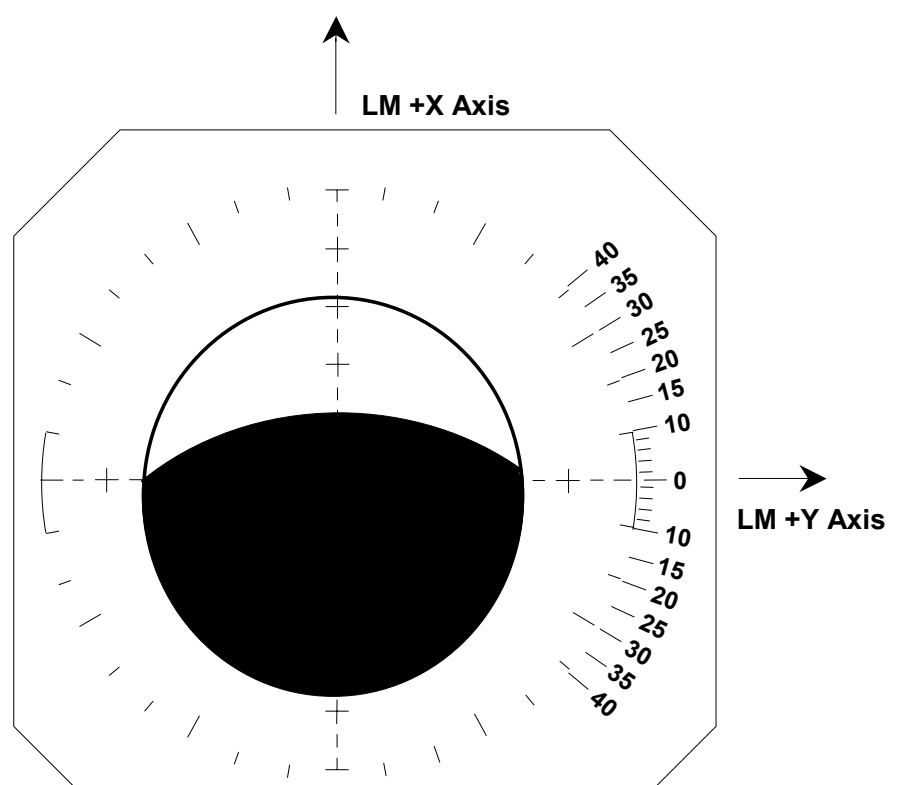

retrograde

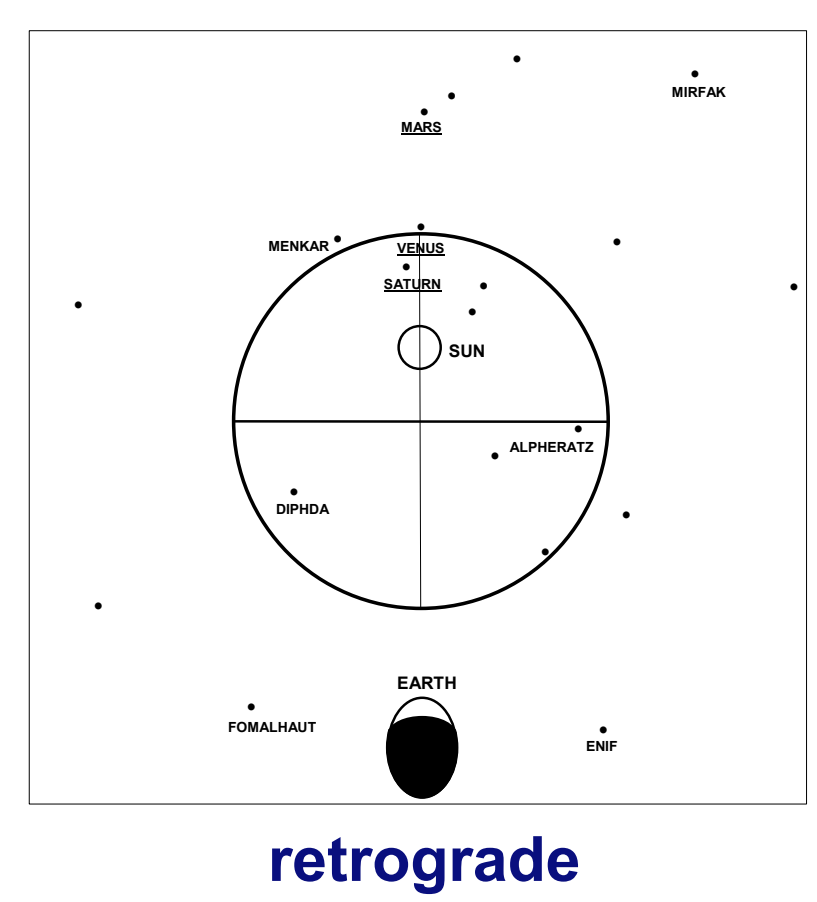




\section{MCC-7 Execution}

Same manual AGS procedure used for MCC-5.

AGS controlled yaw automatically.

Crew controlled pitch and roll using cues from Attitude Indicator error needles.

Roll controlled with Thrust \& Translation Hand Controller.

Pitch controlled with Thrust \& Translation Hand Controller.

Burn terminated with cue from watch.

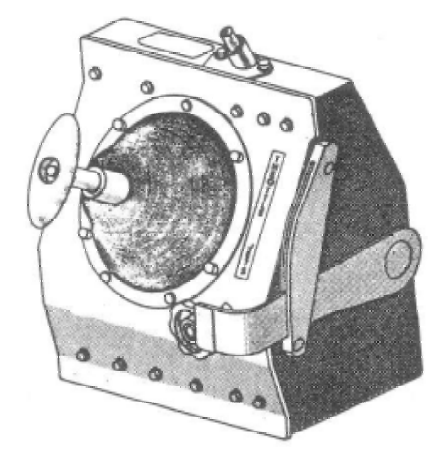

Thrust \& Translation Hand Controllers

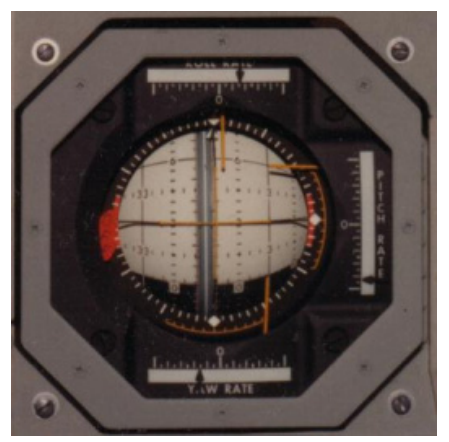

Attitude Indicator 


\section{Service Module Separation}
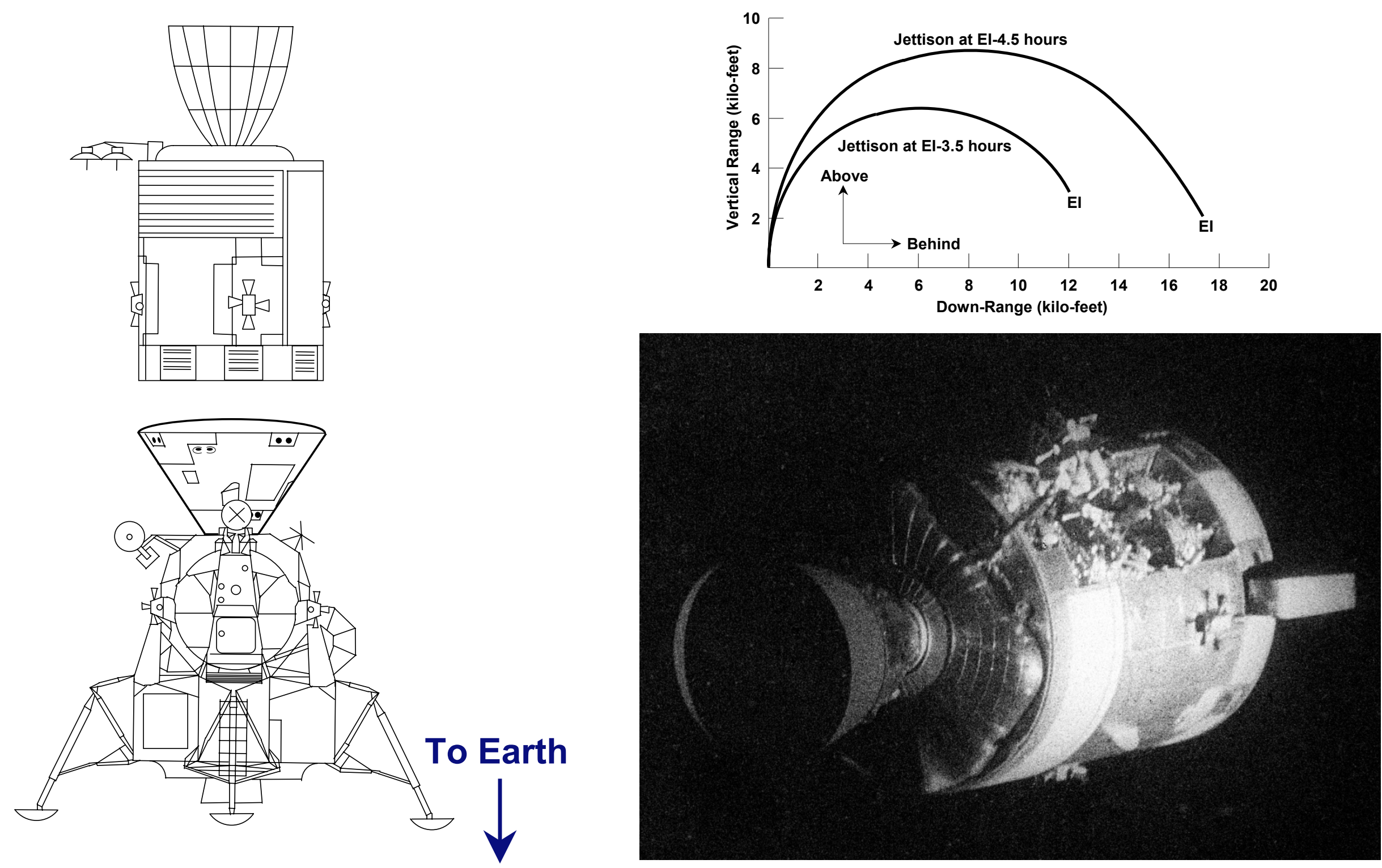


\section{Lunar Module Separation}

LM RCS jets not used for separation.

CM RCS jets for entry attitude control only.

Docking tunnel vented to 2.2 psi to provide sep $\Delta V$ of $\sim 2 \mathrm{ft} / \mathrm{sec}$.

\section{South}

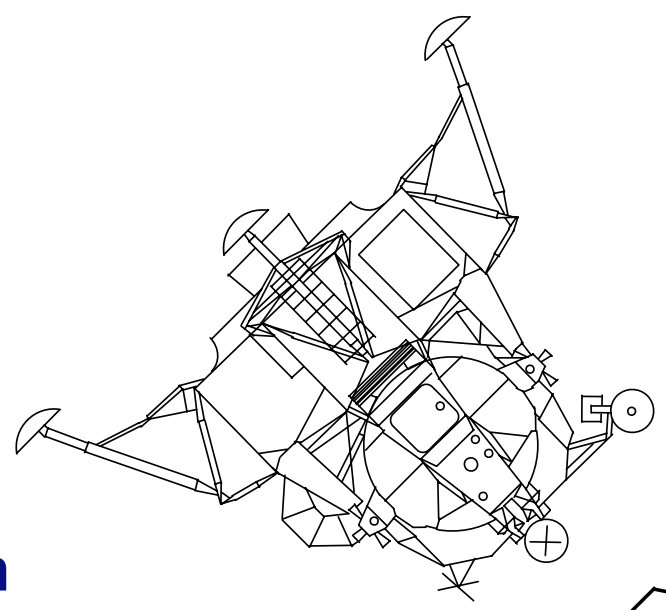

Side of To Earth Orbit
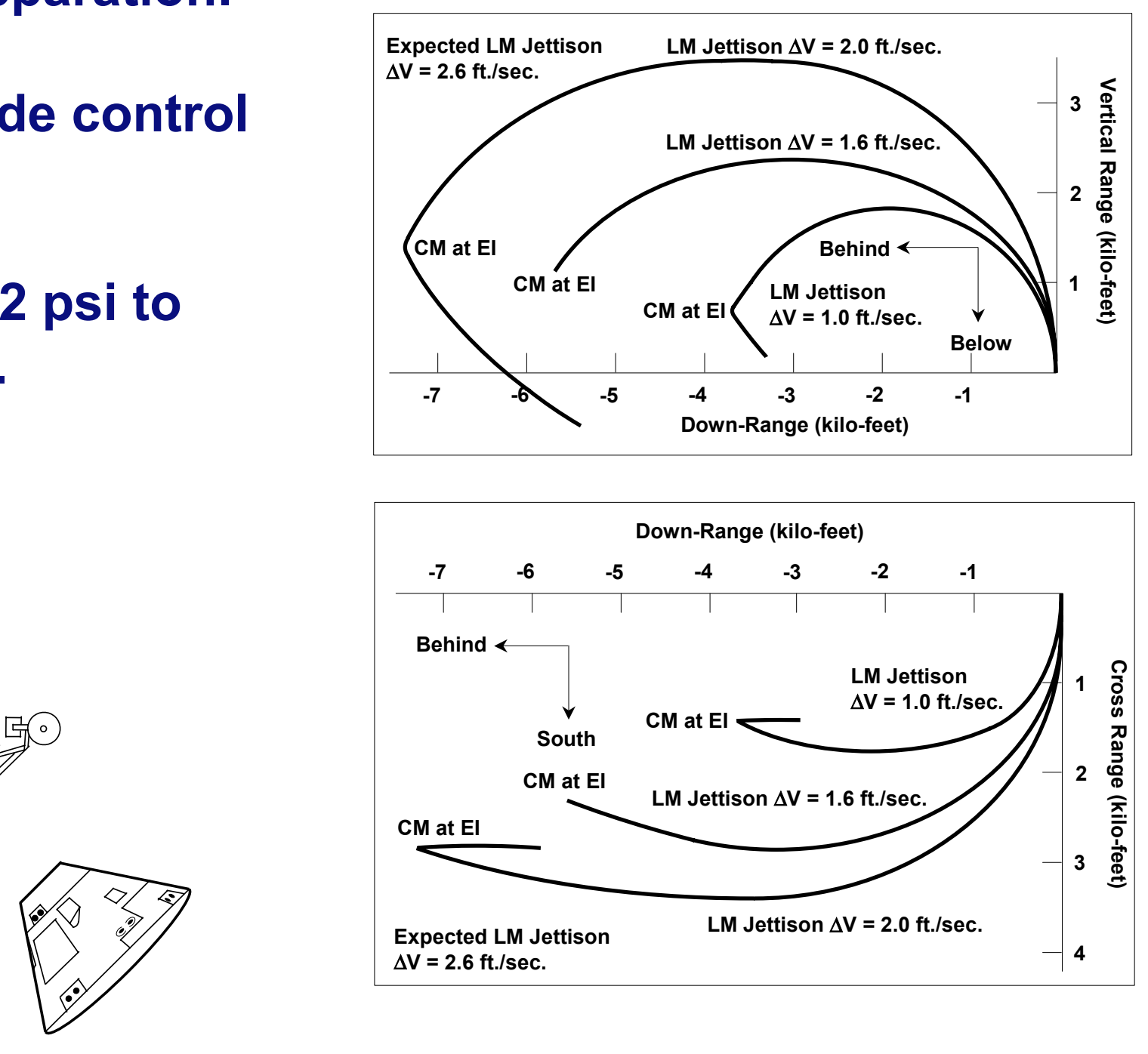


\section{Lunar Module Separation Attitude}

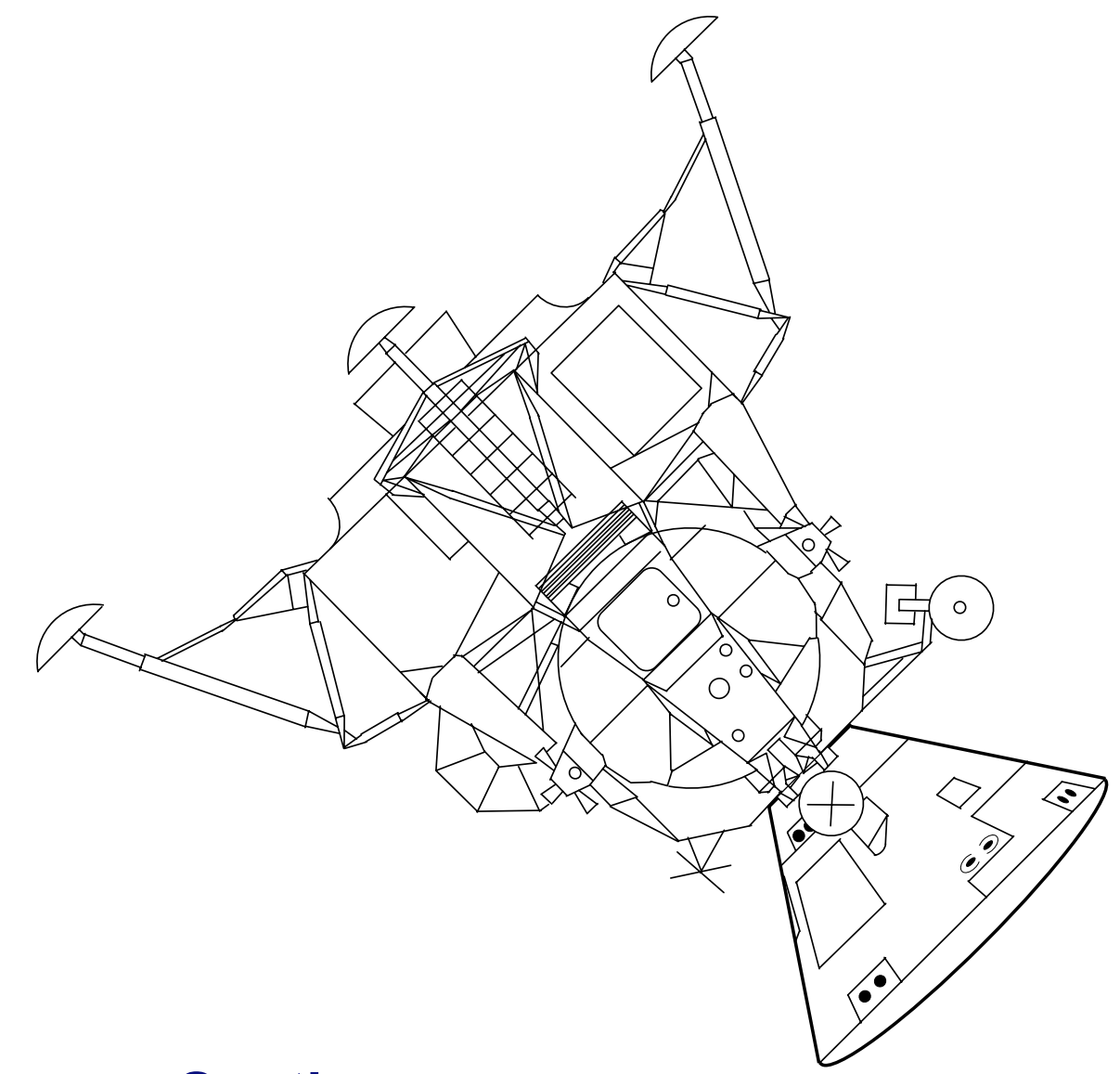

South

$\leftarrow$ Side of Orbit

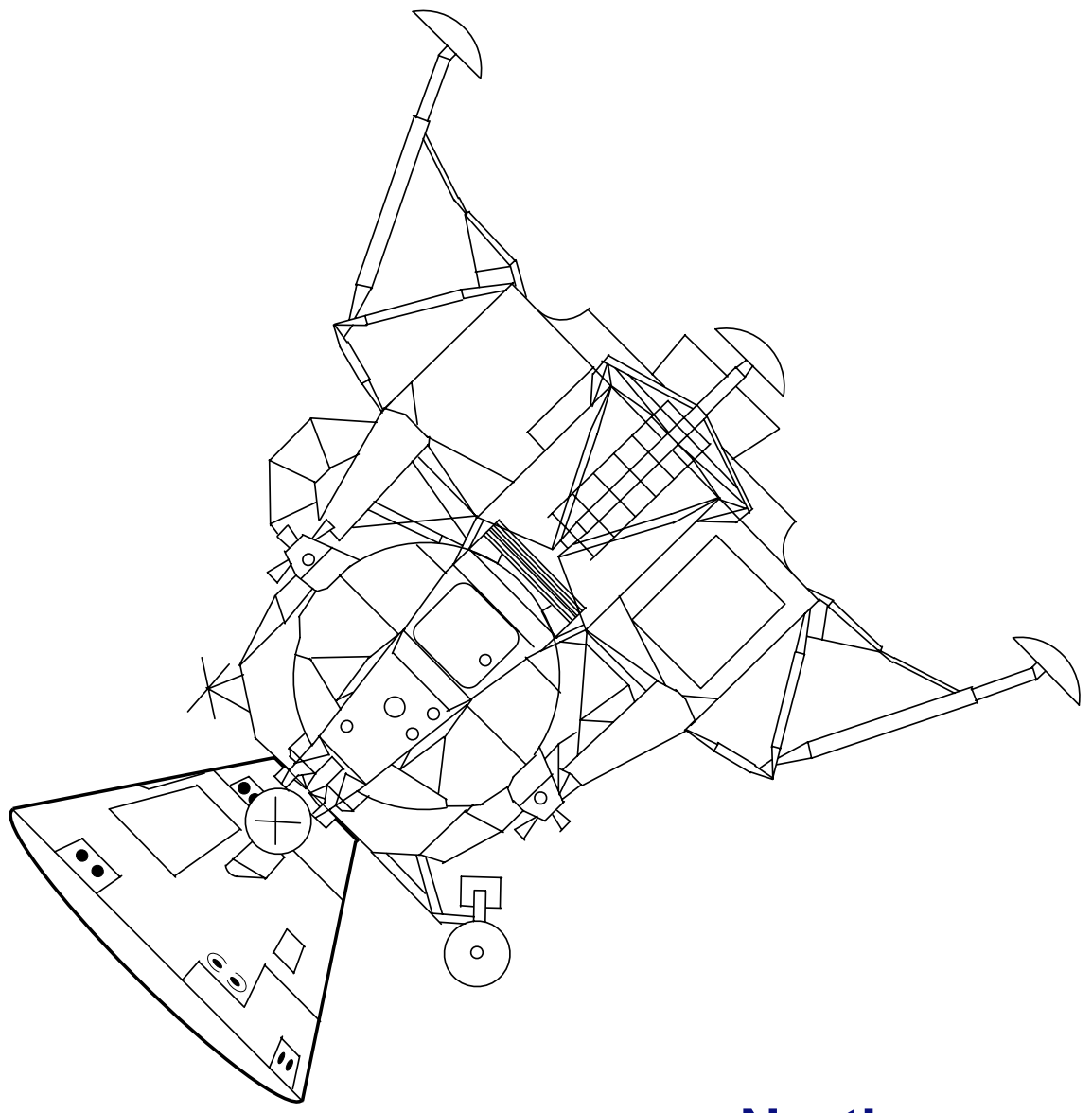

North

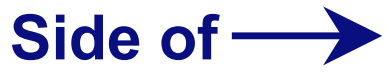
Orbit

Actual Attitude 


\section{Lunar Module Separation}

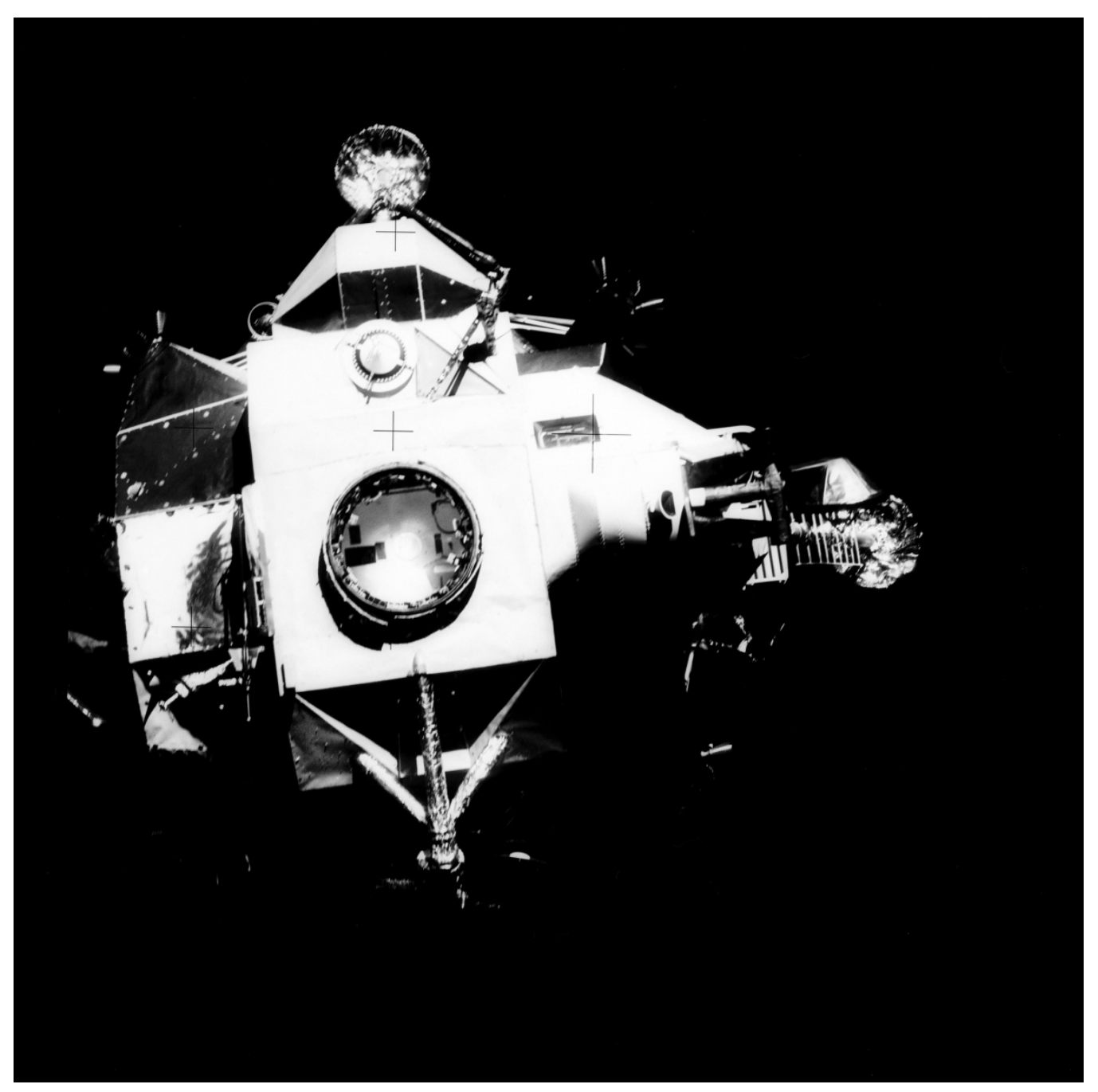




\section{Re-Entry}

Crew entered nominal entry checklist at El-20 minutes.

Pre-El sextant and Moon checks indicated good IMU alignment.

Odyssey splashed down $\sim 1$ $\mathrm{nm}$ from the target point.

Entry GNC performance

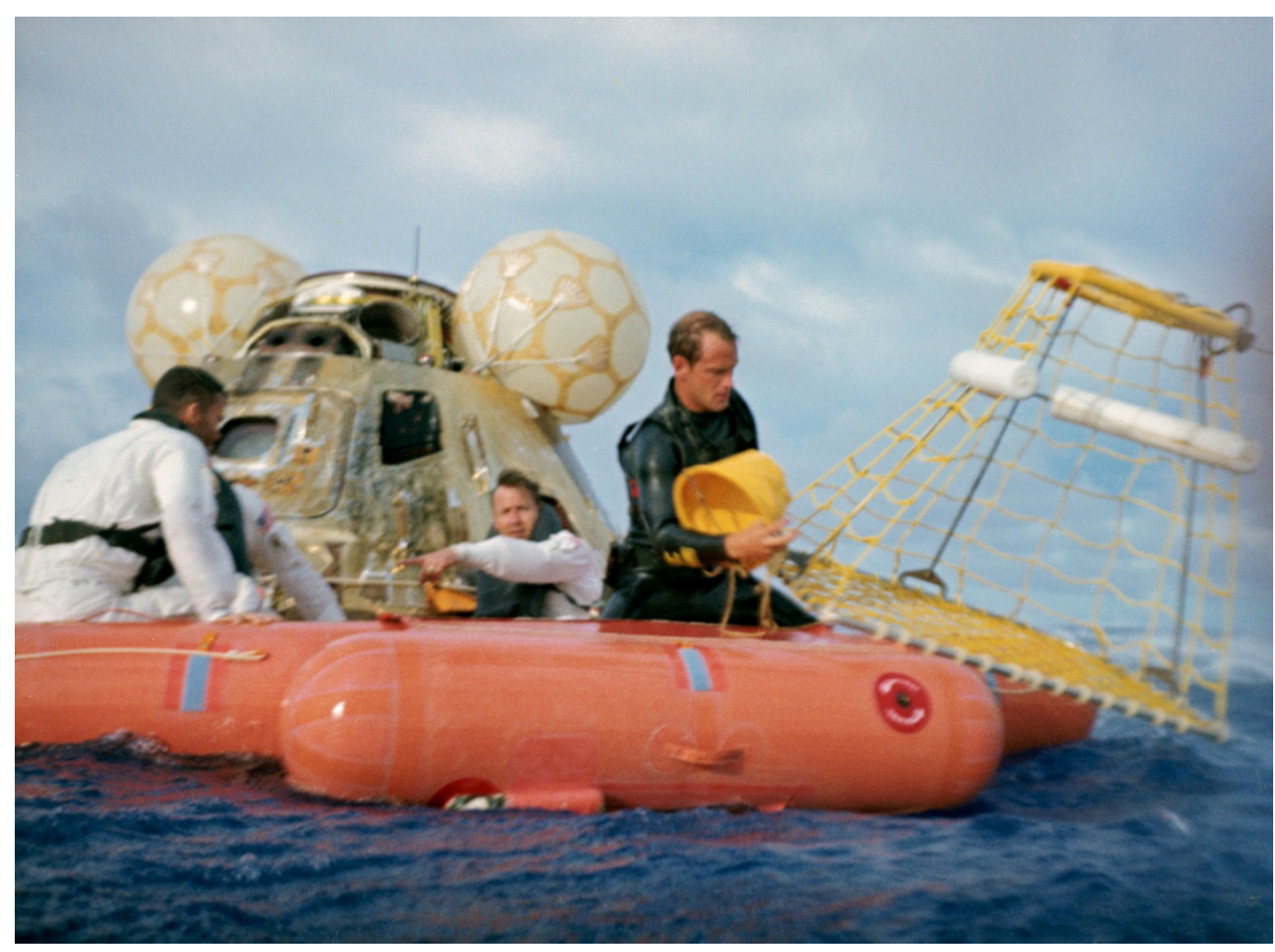
good even though Command Module IMU was unheated for $\sim 80$ hours. 


\section{Challenges That Apollo 13 Did Not Face}

Continuous bad or loss of communications.

Physical damage to GNC hardware.

Software anomalies.

Absence of these problems was a factor in the successful return of the crew. 


\section{Observations on Apollo 13}

Ground support is essential.

Spacecraft recovery with limited systems functionality may be required.

New or modified plans and procedures are required.

Clearly define the problems to be solved.

Procedural errors add risk and should be avoided.

Ensure good air-to-ground communication and manage the crew work load.

Mitigating risk of development does not always mitigate operational risk.

Orbital lighting conditions challenge humans and electro-optical sensors. 


\section{Questions}

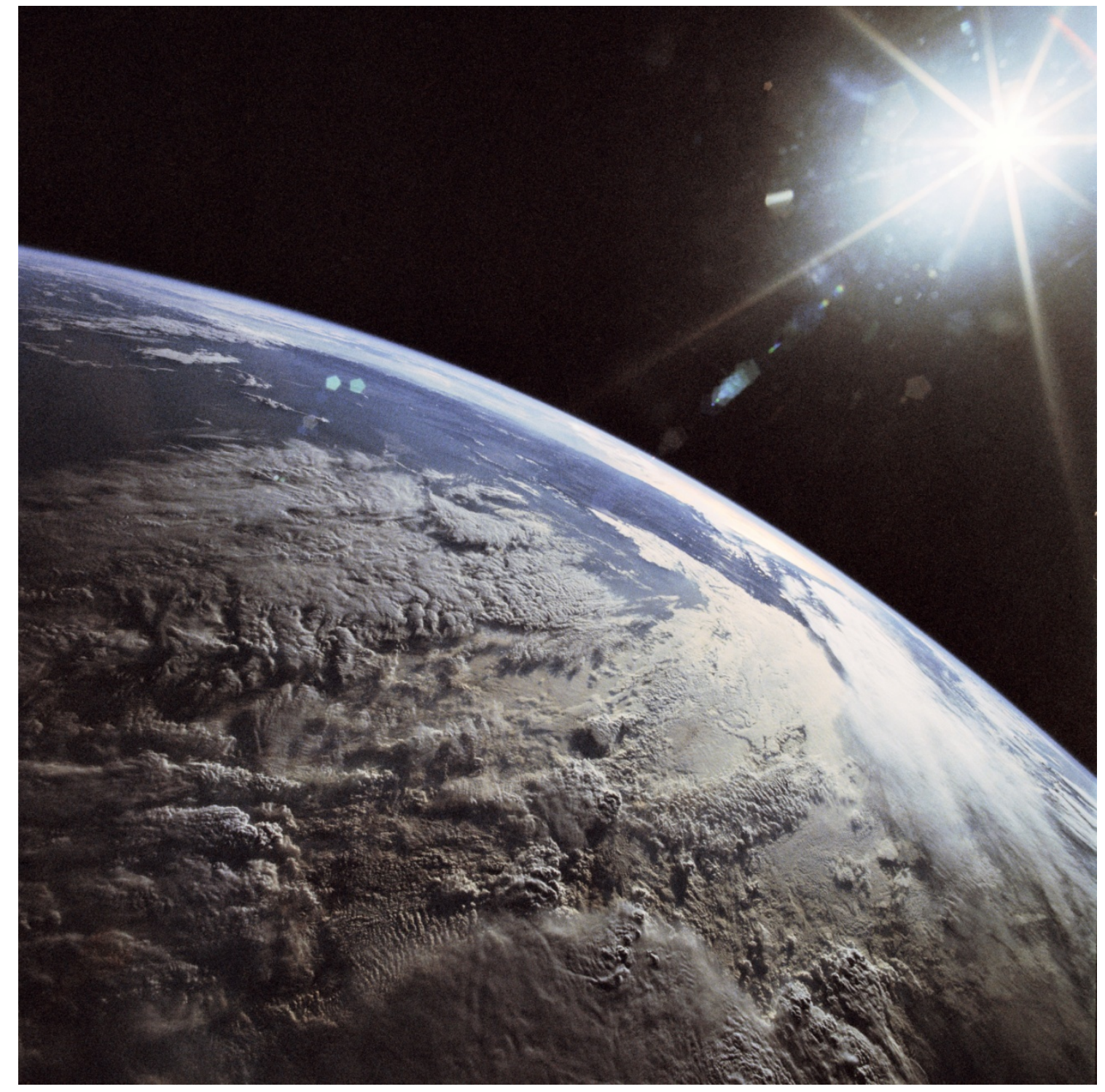

